Military Children with Attention Deficit Hyperactivity Disorder (ADHD): Maximizing Adherence to Clinical Practice Guidelines

\author{
Kelley M. Henson, RN, MSN, CPNP-AC, IBCLC \\ Opelika, Alabama
}

BSN, University of West Georgia, 2003

MSN, Vanderbilt University, 2007

\begin{abstract}
A Scholarly Practice Project presented to the Graduate Faculty of the University of Virginia in Candidacy for the Degree of

Doctor of Nursing Practice
\end{abstract}

\author{
School of Nursing
}

University of Virginia

May, 2017 Degree will be Conferred

(Kathryn B. Reid, PhD, RN, FNP-C)

(Lisa Cantore Letzkus, PhD, RN, CPNP-AC, CCRN)

(Kenneth W Norwood, Jr., MD) 


\begin{abstract}
Introduction: Despite almost two decades of clear clinical practice guidelines (CPG) for the diagnosis and treatment of attention deficit hyperactivity disorder (ADHD), provider adherence to the guidelines continues to vary greatly. While variable adherence to the CPG in non-military settings is widely reported in the literature, adherence in military settings has yet to be established, and recent clinical observations suggest that military children with ADHD may not be receiving evidence based care.

Project Purpose: This project evaluates the current status of provider adherence to the ADHD CPG in a military primary care pediatric clinic 24 months after a targeted educational intervention. In keeping with the quality improvement framework of "Plan-Do-Study-Act" (PDSA) this project additionally incorporates a session for providers to evaluate performance, identify existing barriers that impede guideline adherence, and address areas for improvement through the using evidence-based interventions.
\end{abstract}

Methods: A retrospective chart review was conducted to determine the rates of guideline adherence. Records from a convenience sample of 50 patients during 62 encounters conducted by 4 providers in a military pediatric clinic from January through December, 2016 were reviewed. A goal-oriented meeting was held with the providers, nurses, and clinic staff to disseminate findings and assist in the process of identifying barriers and solutions to guideline adherence using the "Plan-Do-Study-Act" model.

Results: Providers in the selected military clinic adhered to $2 / 6$ of the key guideline components. Of 85 total variables, the providers have an overall mean adherence rate of $28.6 \%(0-100 \%$, SD 33.8\%). During the PDSA session, provides and nurses identified interventions to implement for further improvement. 


\section{Table of Contents}

List of Tables 5

Chapter 1: Introduction to the Scholarly Project 6

$\begin{array}{ll}\text { Background and Significance of the Problem } & 7\end{array}$

ADHD as a Chronic Condition 8

Patient Centered Medical Home 8

Military Considerations $\quad 10$

Overview of the ADHD CPG 12

Summary of ADHD CPG 13

Chapter 2: Review of the Literature 14

Evaluation of Adherence to the AAP CPG 15

ADHD Prevalence Comparison 16

ADHD Treatment in Military Pediatric Clinics 20

Barriers to Guideline Adherence $\quad 21$

Interventions to Improve ADHD CPG Adherence 21

Theoretical Framework 23

Chapter 3: Methods 24

Definitions of Terms 25

Project Design $\quad 30$

Description of the Sample 31

Setting $\quad 33$

Protection of Human Subjects 36

Procedures $\quad 37$ 
Measures $\quad 38$

Data Analysis Plan 40

Chapter 4: Results 41

CPG Adherence $\quad 41$

PDSA Session $\quad 48$

Chapter 5: Discussion 53

Strengths and Limitation of Design 55

Nursing Practice Implications 56

Products of the DNP Project 57

Recommendations for Future Research $\quad 57$

ADHD Research $\quad 57$

The Role of Telehealth in ADHD Care $\quad 58$

Conclusion $\quad 60$

References 61

Tables and Figures $\quad 77$

Appendix A 105

Measures Used to Collect Data for Project 105

Original Chart Abstraction Tool 105

Adapted Initial Chart Abstraction Tool 106

Adapted Follow-up Chart Abstraction Tool 107

Original Provider Survey Tool 108

Adapted Provider Survey Tool 113

Appendix B. Literature Review Table $\quad 118$ 
Appendix C. IRB Forms 135

\section{List of Tables and Figures}

Figure 1. Flow chart demonstrating the literature review process 77

Table 1. Adherence to ADHD guidelines 78

Table 2. Interventions to improve adherence to ADHD guidelines 79

Figure 2. Plan-Do-Study-Act model 81

Table 3. Individual variables used to measure CPG adherence $\quad 82$

Table 4. Sample demographics $\quad 83$

Table 5. Military rank and affiliated service 84

Table 6. Distribution of encounters evaluated per provider by appointment type 85

Figure 3. Adherence percentage $\quad 86$

Figure 4. Strengths 87

Figure 5. Weaknesses 88

Figure 6. Visit comparison 89

Table 7. CPG adherence during all visits 90

Table 8. Comparison of adherence rates $\quad 92$

Table 9. CPG adherence during initial visits $\quad 94$

Table 10. CPG adherence to DSM criteria among initial visits conducted by PCMs

Table 11. CPG adherence during follow-up visits $\quad 97$

Table 12. Documentation of ADHD symptoms 99

Figure 7. Follow-up durations $\quad 100$

Figure 8. Telephone follow-up durations 101

Figure 9. Provider documentation template 102 
Military Children with Attention Deficit Hyperactivity Disorder (ADHD): Maximizing Adherence to Clinical Practice Guidelines

\section{Introduction}

Despite almost 2 decades of clear clinical practice guidelines (CPG) for the diagnosis and treatment of attention deficit hyperactivity disorder (ADHD), provider adherence to the guidelines continues to vary greatly. While variable adherence to the guidelines in non-military settings is widely reported in the literature, published evaluations of adherence in military settings is lacking. The purpose of this project is two-fold: 1) to assess current adherence with the American Academy of Pediatrics (AAP) ADHD CPG among pediatric providers in a military clinic, 2) to empower providers and staff to identify existing barriers that impede guideline adherence and address areas for improvement through the use of an established quality improvement process.

The American Academy of Pediatrics (AAP) published CPG for the care of children and adolescents with ADHD in 2000 and 2001 and subsequently revised the CPG in 2011. Over a decade after the release of the ADHD CPG, studies evaluating community pediatric provider adherence demonstrate ongoing variability among providers, and anecdotal observations suggest this is also true in military pediatric primary care settings. In response, action was taken by an experienced Pediatric Nurse Practitioner (PNP) from 2013-2015 to improve provider adherence to the CPG, including a series of "Lunch and Learn" sessions as well as in-clinic coaching and support. This project, in keeping with the quality improvement framework of "Plan-Do-StudyAct" (PDSA), has the following objectives: 
1. Evaluate the current status of provider adherence to the ADHD CPG in the selected military setting following the targeted educational intervention previously carried out, hereinafter referred to as "CPG evaluation," and

2. Demonstrate Doctorate of Nursing Practice (DNP) level leadership to improve quality care delivery using the PDSA model, hereinafter referred to as "PDSA session." The PDSA session will be conducted to empower providers, nurses, and clinical staff to evaluate performance, identify existing barriers that impede guideline adherence, and address areas for improvement through the use of evidence-based interventions.

\section{Background and Significance of the Problem}

ADHD is a common pediatric neurodevelopmental disorder affecting between 7 and $11 \%$ of children in the United States (Akinbmai, Liu, Pastor, \& Reuben, 2011). The Centers for Disease Control and Prevention (CDC) report a 5\% annual increase in ADHD prevalence over the last decade (Akinbmai, Liu, Pastor, \& Reuben, 2011). The core symptoms of ADHD include hyperactivity, inattention, and/or impulsivity, and cause impairment in multiple settings (e.g. school and home) (American Psychiatric Association [APA], 2013). Youth with ADHD also often have comorbid mental health disorders, substance abuse, learning difficulties, peer relationship difficulties, and difficulty with completion of activities of daily living (Wolraich, Brown, \& Brown, 2011). Advances in neuroimaging and neuropsychological testing in children with ADHD identify difficulties with forward planning, abstract reasoning, mental flexibility, working memory, and response inhibition (Barkley, 1999; Pennington \& Ozonoff, 1996). People with ADHD have a higher incidence of injuries, motor vehicular accidents, drinking and driving, and traffic violations, and the estimated U.S. economic burden of this disorder is between $\$ 36$ and $\$ 52$ billion annually (Akinbmai, Liu, Pastor, \& Reuben, 2011). 
Risk factors related to ADHD are largely unknown, however there is a strong genetic component (CDC, 2017). Other possible risk factors include brain injury, exposure to environmental toxins (e.g., lead) during pregnancy or at a young age, alcohol and tobacco use during pregnancy, premature delivery, and low birth weight (CDC, 2017). Children with a genetic predisposition for developing ADHD may be more vulnerable to exhibiting core symptoms if their psychosocial environment is one with high levels of stress and/or contains parents who are unable or unwilling to model coping techniques and self-regulation (Lange et al., 2005).

ADHD as a Chronic Condition. It has been well established that ADHD is a chronic condition that is often present, and impairing, into adulthood (Friedman, Blaschke, Klam, \& Stein, 2006). Treatment with stimulants and/or behavior therapy has shown to be effective; however, long-term medication compliance is a significant issue for this population (AAP, 2011). Primary care providers are responsible for caring for children with ADHD under the medical home model (World Health Organization [WHO], 2015) and should not routinely refer children to a mental health professional. Standardized psychological tests are costly and time consuming, and are not as reliable as clinical interview in diagnosing ADHD (AAP, 2011). Despite this recommendation, provision of comprehensive care in the primary care setting can be quite challenging, particularly when addressing mental health disorders in children (Foy et al., 2010), and significant disparities among populations persist (Akinbmai, Liu, Pastor, \& Reuben, 2011).

Patient Centered Medical Home. The concept of primary care as the medical home has been recommended for over thirty years, and has been reported to be an effective means to provide patient-centered, preventive care, while improving quality, cost, and integration of 
services (WHO, 2015). The AAP began endorsing the implementation of the medical home concept in 1967 in an effort to centralize medical records for children with special health care needs (CSHCN) (Sia, Tonniges, Osterhus, \& Taba, 2004, p. 1476). The AAP continued to expand upon this concept, and published a policy statement in 1992 defining the medical home as the model to provide care to infants, children, and adolescents that is "accessible, continuous, comprehensive, family-centered, coordinated, and compassionate" (Sia, Tonniges, Osterhus, \& Taba, 2004). In response to this international emerging trend, the medical home model has been adopted by many agencies under the name "Patient-Centered Medical Home," which is regulated by the National Committee for Quality Assurance (NCQA) (Marshall et al., 2011). The PCMH model has been reported to improve access, care coordination, patient satisfaction, and cost of care, and was implemented by U.S. Air Force, Navy, and Army in 2008 (Marshall et al., 2011). Air Force Instruction (AFI) 44-171 states that the purpose of the PCMH model is “To deliver the highest quality, evidence-based, patient-centered care to enrolled patients through team-oriented processes, enhanced access, improved provider continuity, superior communications and coordinated prevention, education, and management of patients. This approach will provide operational health and readiness for all military members and promote optimal clinical currency for the members of the team" (2014, section 1.1.1, p. 5).

The military and civilian models are similar, however continuity of care in the military population presents an additional challenge due to the constant transition of both providers and patients (Marshall et al., 2011). There is limited research related to the impact of the implementation of the PCMH model on military children with ADHD specifically; however, family-centered programs lead to improvement in mental health outcomes of military children 
during times of parental deployment (Lester et al., 2013). Studies show improvement in healthrelated outcomes for CSHCN, as well as a reduction of economic burden among families of children with ADHD who are receiving care under the medical home model (Homer et al., 2008; Ronis, Baldwin, Blumkin, Kuhlthau, \& Szilagyi, 2015).

While barriers to the provision of evidence-based care for children with ADHD are described in the civilian sector, little research has been done to measure adherence to guidelines and perceived barriers within the U.S. military healthcare system. Military and civilian primary care systems both operate under a medical home model, yet continuity of care in the military population presents a unique challenge due to the constant transition of both providers and patients (Marshall et al., 2011). A potential limitation of the medical home model in general is that it requires not only organizational, but also personal change of both the patient and the healthcare team (Gallo, Hill, Hoagwood, \& Olin, 2015); coordination of this personal change can be difficult in the unique setting of the military healthcare system (Marshall et al., 2011).

Military Considerations. When evaluating children and their families for presence of significant stressors as part of the ADHD evaluation, military affiliation and the current status of the service member are important considerations. Approximately 2 million dependent children live in active-duty, reserve, or guard families, and since the attack on 9/11, over 2 million children have had a parent deploy (The National Military Family Association (NMFA), 2017). This population is vulnerable to experiencing significant trauma related to the increased wartime demands over the last decade (Clever \& Segal, 2013), necessitating frequent relocations, geographic separation from family members due to deployment or military training, and the potential for a parent sustaining combat-related injuries or death (Meadows, et al., 2015). The NMFA report that the service member's obligations often take a toll on the family members' 
finances, relationships, and health (2017). While protective factors such as stable income, community support, and consistent accessibility to healthcare are noted among military families, studies also demonstrate an increase in anxiety, drug use, risk taking behaviors, and suicide rates among children and adolescents who undergo frequent relocations (Millegan, McLay, \& Engel, 2014). It is estimated that military children have almost twice as many ADHD-related outpatient visits per year than their civilian counterparts, making up 30\% of all mental health visits (HiselGorman, Eide, Coll, \& Gorman, 2014), yet prevalence and management of the disorder is poorly studied in this population. In relation to poor treatment compliance among civilian patients with $\mathrm{ADHD}$, it can be assumed that there may be an even larger disparity in a population that is frequently relocating to new communities with new medical homes.

Finally, in addition to frequent relocations among the patient population, military providers are typically reassigned to a different military treatment facility (MTF) every 2-4 years. The transient atmosphere in the clinic creates challenges when working to establish professional relationships with the community members who are needed to assist in providing support to children with ADHD. These unique factors may make the military population particularly vulnerable to fragmented care, poor treatment compliance, and loss of follow up. Provision of comprehensive, high quality care to military dependents is essential for maintaining an effective, resilient military force, especially during times when the demands on service members are high.

Air Force medicine. The United States Air Force (USAF) has a mission to "fly, fight, and win in air, space, and cyberspace) (USAF Mission, 2016). The Air Force Medical Service (AFMS) supports this overall mission with an individual mission "to enable medically fit forces, provide expeditionary medics, and improve the health of all we serve to meet our Nation's 
needs" (AFMS, 2015). Strategic goals of the AFMS include readiness, better care, better health, and best value. "Readiness" involves keeping military members healthy so they are able to complete the mission, as well as ensuring that Air Force medics (medical personnel) are properly trained to provide care both in deployed locations and the home station. The goal of better care targets reliable access to safe, quality care. Better health emphasizes creating a health-based culture to improve resiliency and reduce illness and injury. Lastly, the goal of best value addresses appropriate utilization of people and resources. The scope of care provided by the AFMS ranges from primary care in an ambulatory setting to critical care, and battlefield aeromedical evacuation (AMFS, 2015). Rapid global mobility is a key capability unique to the USAF, enabling forces to be deployed, provision of supplies and equipment, and evacuation of personnel anywhere on the planet (Air University, 2016).

The AFMS provides medical services under the policy and fiscal guidance of the Office of the Secretary of Defense for Personnel and Readiness and the Office of the Assistant Secretary of Defense for Health Affairs (Graser, Blum, \& Brancato, 2010). Although each service is designed to provide care to it's own members and dependents, military members can obtain care from any military treatment facility (MTF) (Graser, Blum, \& Brancato, 2010). Each of the military branches often work together at joint bases and when deployed.

The AFMS provides health-care services for active duty members, retirees, dependents, and other categories of eligible beneficiaries. Total AFMS force consists of 57,240 members; medical personnel are a combination of active duty (42,281), reserve/guard $(14,959)$, civilian $(7,413)$, and contractors $(4,171)$ (AFMS, 2015). These medics operate 74 military treatment facilities (MTF) throughout the world and provide health care to about 2.6 million eligible beneficiaries (AFMS, 2015). 
The Nurse Corps is the only Corps that is majority female (70\%); the percentage of male nurses in the Air Force (30\%) is much higher than in the civilian sector (6\%) (Keating, Massey, Mele, \& Mundell, 2010). Females are a minority in the medical corps (20\%) (Keating, Massey, Mele, \& Mundell, 2010). Demographics of the overall active duty include 308,606 members; of which, approximately 60,000 are officers and 250,000 are enlisted (AF Demographics, 2016). The average officer age is 35 years, and the average age for the enlisted member is 29 years (AF Demographics, 2016). Women comprise $19 \%$ of the active duty force. Race distribution among active duty members is $72 \%$ White, $14 \%$ Black or African American, $3.5 \%$ Asian, $0.6 \%$ American Indian/Native Alaskan, 1.1\% Native Hawaiian/Other Pacific Islander, 3.7\% identify as more than one race, and 4.5\% decline to respond (AF Demographics, 2016). The majority of active duty AF members (82.7\%) are not Hispanic or Latino. Approximately half of the force is married; more officers are married than enlisted members ( $71 \%$ of officers, $54 \%$ of enlisted), and active duty personnel support 400,656 family members (AF Demographics, 2016).

Air Force MTFs are required to comply with AF instruction 44-102 regarding clinic flow, services to be offered, and processes, and maintain accreditation through Joint Commission and Accreditation Association for Ambulatory Healthcare. Facilities are required to be handicap accessible and contain assistive devices for those with disabilities (AFI 44-102, 2015). Most medical treatment facilities have a pharmacy, laboratory, and radiology department on site. Treatment facilities are located on Air Force bases; therefore patients must have base access to receive care, and patients must be eligible for Tricare to receive care at an AF MTF (AFI 41-210, 2012). Delays in patient care are common during base exercises and/or during security threats, and access to care can be negatively impacted by provider/staff training requirements and deployments. 
Patient surveys are sent and reported quarterly to obtain feedback related to quality and patient satisfaction. Feedback forms are also available in all clinics, which are reviewed by a patient advocate trained in resolving issues that may arise. Healthcare Effectiveness Data and Information Set (HEDIS) metrics and compliance with PCMH model data are presented to health care teams monthly. Accrediting bodies as aforementioned also review processes and provide feedback.

ADHD prevalence among military children. No large studies have been conducted to report the prevalence rate of ADHD among military children compared with the civilian population. Studies using adult veteran or military samples report ADHD prevalence rates from 7.0\%-61.7\% (Shura, Miskey, Williams, Jadidian, \& Rowland, 2016). Despite the significant variability among prevalence reports between studies, these rates support suggestions that the ADHD prevalence is likely higher among military members than the in the general population (Shura, Miskey, Williams, Jadidian, \& Rowland, 2016). Given the significant role of genetics in ADHD, one may question if a higher prevalence of ADHD among Armed Forces members compared with the general population could lead to a higher ADHD prevalence in children with parental military affiliation. While multiple nationally representative surveys and administrative data sources such as the National Survey of Children's Health and the National Survey of CSHCN have reported data on children with ADHD, these surveys fail to collect data related to parental military affiliation (CDC, 2017). Furthermore, many military members and their dependents are actively excluded from these large surveys in an effort to provide a representation of a civilian, noninstitutionalized population. In order to receive approval and funding to conduct quality longitudinal studies related to experiences and outcomes of children with ADHD who are military dependents, the prevalence and treatment of the disorder must be accurately measured. 


\section{Overview of the ADHD CPG}

In an effort to reduce variability among providers, decrease cost, minimize harm, and produce optimal health outcomes (AAP, 2004), the AAP publishes evidence-based guidelines for the diagnosis and treatment of ADHD (AAP, 2011). Development of the ADHD CPG involves an extensive multilevel, systematic literature review across medical, psychological, and educational fields to establish an evidence base (AAP, 2011). The CPG recommends that ADHD be treated as a chronic condition by the medical home, and have individualized treatment goals with ongoing follow-up care (AAP, 2011). The most recent updated guidelines include an expanded age range, expanded scope, and a process-of-care algorithm for diagnosis and treatment (AAP, 2011). Standardization of care and quality are promoted with the use of validated assessment tools and evidence-based interventions including assessment for comorbid conditions, medication management, behavior therapy, and recommendations for timing and focus of follow-up visits (AAP, 2011).

\section{Summary of ADHD CPG}

Determination of the evidence quality for recommendations include a benefit verses harm assessment, and recommendations are categorized as a strong recommendation, recommendation, or option (AAP, 2011). The guidelines are based on the chronic care and medical home models (AAP, 2011). Key action statements include:

1. The primary care clinician should initiate an evaluation for ADHD in any child ages 4-18 years presenting with academic or behavioral problems and symptoms of inattention, hyperactivity, or impulsivity (strong recommendation) (AAP, 2011).

2. Diagnosis should be made based on DSM criteria, using validated instrument such as the Vanderbilt Scale (strong recommendation) (AAP, 2011). 
3. Identify possible co-morbidities (strong recommendation). Common co-existing disorders include anxiety, depression, oppositional defiant disorder, conduct disorder, learning and language disorders or other neurodevelopmental disorders, and physical conditions such as tics, sleep apnea (AAP, 2011).

4. Treat ADHD as a chronic condition, and follow the chronic care and medical home models (strong recommendation) (AAP, 2011).

5. Treatment recommendations based on age:

a. Treat preschool-aged children with behavior therapy as first-line (strong recommendation); may prescribe methylphenidate if no improvement (recommendation) (AAP, 2011).

b. Elementary school-aged children should be treated with medication and/or behavior therapy (strong recommendation) (AAP, 2011).

c. Adolescents should be treated with medication (strong recommendation) and may receive behavior therapy (recommendation) (AAP, 2011).

6. Medication dosages should be adjusted with a goal of maximum benefit and minimum side effects (strong recommendation) (AAP, 2011).

The AAP's intent is clear throughout the guideline to improve the continuity of care provided to children with ADHD. The chronic care model recommended in the guideline emphasizes that the community and the health organization work together to support an informed, involved patient with targeted goals as well as a prepared, proactive health care team (AAP, 2001). The AAP notes that since long-term treatment compliance is a significant issue in this population, it is essential that the primary care manager (PCM) maintain close communication with the family, school, and mental health team (2011). Ongoing follow up is recommended to assess for 
medication efficacy and potential adverse effects using a validated follow-up tool such as the Vanderbilt ADHD follow-up scale (AAP, 2011). The PCM may consider referral to a specialist (e.g. psychiatrist, developmental-behavioral pediatricians, neurodevelopmentalists, neurology, and/or child/school psychologist) for unclear diagnosis, significant comorbities, or inadequate treatment response (AAP, 2011).

\section{Review of the Literature}

A review of the literature is undertaken to further explore the status of ADHD CPG adherence. One hundred and forty eight articles are reviewed using the key words "attention deficit," "attention deficit hyperactivity disorder," "hyperactivity," "hyperkinesis," and "guideline." The search is limited to human subjects with ADHD under 19 years of age, studies written in the English language, and published after 2000. In line with the purpose of this project, only studies that measure adherence to the guideline are included. Ovid Medline search retrieves 56 studies, and 21 studies excluded based on title review. Upon review of the abstracts, an additional 15 studies are determined not to meet inclusion criteria. A full article review leads to the exclusion of 7 studies due to poor design quality, insufficient sample size, or failure to measure guideline adherence as an outcome variable. Next, a CINAHL (EBSCOhost) search is conducted, and 18 articles are retrieved; 7 articles are excluded based on title review, and another 7 are excluded based on abstract review. One of the remaining studies does not measure adherence to the CPG, but is included as it contains pertinent information related to perceived barriers to ADHD care. Finally, a PubMed search retrieves 62 articles, and 58 are excluded after title review. An additional 3 articles are excluded after the abstract review. All 3 databases are searched again using the key terms "ADHD" or "attention deficit" AND "military"; these searches retrieve 12 studies; 10 articles are excluded based on title review, and 1 study is 
excluded after abstract review. See figure 1 for a summary of the number of articles reviewed and included or excluded.

Literature review results are divided into 4 categories: 1) evaluation of adherence to the AAP CPG; 2) ADHD prevalence and treatment patterns among military treatment facilities; 3) barriers to guideline adherence; and 4) interventions designed to improve adherence to AAP CPG. Adherence and interventional findings are summarized in tables 1 and 2, and a more complete study table is located in Appendix $B$.

\section{Evaluation of adherence to the AAP CPG}

Despite the AAP's attempts to widely disseminate guidelines for diagnosis and treatment of ADHD, studies show that primary care management of ADHD continues to lack standardization (Chan, Hopkins, Perrin, Herrerias, \& Homer, 2005; Dreyer, O’Laughlin, Moore, \& Milam, 2010; Epstein et al., 2014; Gordon et al., 2016; McElligott et al., 2014; Rushton, Rant, \& Clark, 2004; Visser et al., 2014; Visser et al., 2015). Variability among providers' diagnosis and management of ADHD can lead to delayed or incorrect diagnosis, under-identification of comorbid conditions, and subjection of the patient to unnecessary testing procedures (McElligott et al., 2014). A survey of 1,374 pediatricians reveals that $78 \%$ report using ADHD guidelines, $55 \%$ report using DSM criteria, and $80 \%$ report routine collection of parent and teacher rating scales (Rushton, Rant, Clark, 2004); however, additional studies involving multiple chart reviews are inconsistent with pediatricians' self reports, thereby invalidating provider surveys as a tool to measure guideline adherence (Epstein et al., 2014). Chart reviews performed on 311 patients (including 84 pediatricians from 19 different practices) reveal that only $38 \%$ of children have documentation of meeting DSM criteria for a diagnosis of ADHD (Epstein et al., 2008). Follow up rating scales are rarely collected to monitor treatment response after diagnosis (9\%), 
and fewer than half of children have a follow-up visit documented within the first month (Epstein et al., 2008). A condensed summary of these studies is included in table 1.

\section{ADHD Prevalence Comparison}

A review of the literature is also undertaken to further explore the prevalence of ADHD among the general population and in children with parental military affiliation. First, 205 articles are reviewed using the key words "attention deficit hyperactivity disorder" and "prevalence". The search is limited to human subjects under 19 years of age, studies written in the English language, published after 2010, and only studies that measure ADHD prevalence are included. Ovid Medline search retrieves 202 studies, and 192 studies are excluded based on title review. Upon reviewing the abstracts, an additional 5 studies are determined not to meet inclusion criteria. A full article review led to the exclusion of 1 study due to poor design quality. Next, a Psych Info search is conducted, and 3 articles are retrieved; all 3 articles are excluded based on title review. Finally, a Pubmed search retrieves no new articles. All 3 databases are searched again using the key terms "ADHD" and "military;" these searches retrieve 25 studies; 17 articles are excluded based on title review, and 3 studies are excluded after abstract review. Finally, 4 articles are excluded after full review due to lack of appropriate design; however, these articles are retained for use in background section.

Of the studies measuring prevalence rates of ADHD in children, 2 utilize data collected from U.S. national surveys. Both surveys contained large, nationally representative samples, and are obtained by telephone interviews of the child's parent or guardian by interviewers who have completed standardized training sessions. Utilization of these data provides significant strength to the generalizability of findings, reduce sampling bias, and improve feasibility and reproducibility of findings. Limitations of both surveys include the potential for recall bias and 
social desirability bias (i.e. not wanting to report the diagnosis). Additionally, neither survey assesses the military status of family members. Active duty service members are actively excluded, however households containing veterans and/or parental separation are not.

The first study, a data brief, reports prevalence treads from the National Health Interview Survey (NHIS) collected from 1998-2000 (Akinbmai, Liu, Pastor, \& Reuben, 2011). An annual average of $9 \%$ of children ages 5-17 years have ever been diagnosed with ADHD for the 20072009 reporting period; this is an increase from a prevalence of $6.9 \%$ during the $1998-2000$ period (Akinbmai, Liu, Pastor, \& Reuben, 2011). Prevalence increases are seen among all demographic areas with the exception of Mexican children and those with a family income less than $200 \%$ of the poverty level (Akinbmai, Liu, Pastor, \& Reuben, 2011).

Following the data brief, Visser et al. expands upon the previous findings to include data collected from the National Survey of Children's Health (NSCH) across the 2003, 2007, and 2011 collection points (2014). This robust study compares data from the NSCH and the NHIS, and reports that $11 \%$ (6.4 million) children ages 4-17 years have ever received a diagnosis of ADHD with a total increase in ADHD prevalence from 2003-2011 of $42 \%$ (PR=1.42, 95\% $\mathrm{CI}=1.33-1.50$; average annual increase $=5 \%$ ) (Visser et al., 2014). ADHD prevalence is higher in boys than in girls ( $15.1 \%$ vs. $6.7 \%)$ and is higher among black and white children than other races $(p<0.05)$ (Visser et al., 2014). The median age of diagnosis is 6.2 years $(95 \% \mathrm{CI}=6.0-6.4$; mean $=7.0,95 \% \mathrm{CI}=6.9-7.2$ ) (Visser et al., 2014). Study strengths include the utilization of national survey data and identification of prevalence, treatment, and demographic trends. Study limitations include use of parental report rather than assessment of ADHD symptoms, as parental report indicators are not validated (Visser et al., 2014). Additionally, lack of clarity related to 
parental military affiliation limits the use of this sample as a comparison group in future studies related to ADHD among military children.

One large community-based study is identified in the review of literature. The study measures prevalence in ADHD by screening children from 2 different states (ages 5-13 years; $\mathrm{n}=10,427)$, resulting in a prevalence of $8.7 \%$ in $\mathrm{SC}(95 \% \mathrm{CI}=[7.2,10.5])$, and $10.6 \%$ in $\mathrm{OK}$ $(95 \% \mathrm{CI}=[7.5,14.9])($ Wolraich et al., 2014). The study uses a multistage stratified random sampling design (Wolraich et al., 2014). Strengths of the study include large sample size and a combination of parent and teacher behavioral information to improve diagnostic accuracy. Limitations of this study include differences among demographic characteristic between samples from each state, lack of generalizability to children in other geographic areas or outside of the public school system, and nonresponse bias. As with the previous 2 studies, parental military affiliation is not included the demographic report. This study also does not contain data that distinguish incidence verses prevalence.

A population-based study is conducted to estimate the prevalence of ADHD among elementary school-aged children enrolled in public schools within the selected county. A sample of 7,857 children is selected using stratified sampling methods, and the participants are screened both by teachers using DSM IV criteria and parental interview (Rowland et al., 2015). The prevalence of ADHD among children screened is 15.5\% (95\% CI; 14.6\%-16.4\%]) (Rowland et al., 2015). Strengths of the population-based study include screening of almost the entire student body (grades 1-5) and screening information obtained from both parents and teachers to improve diagnostic accuracy. Limitations include lack of generalizability, small sample size, failure to include full age range of children affected by ADHD, nonresponse bias, and failure to include a random sample of non-cases to serve as a control (Rowland et al., 2015). Also of note, the study 
requires patients to have fewer symptoms to meet criteria for diagnosis than the standard criteria (3 at home and 3 at school rather than 6 and 6), and has false positive diagnosis in $9 \%$ of the cases, thereby weakening the validity of the study. No data regarding parental military affiliation is reported.

Only 1 study is retrieved from the review of literature measuring prevalence of ADHD in children with military affiliation. A retrospective cohort study of children with ADHD ( $n=413,665$; ages $4-8$ years) in the military health system is conducted to evaluate medication use during parental military deployment from 2006-2007 (Hisle-Gorman, Eide, Coll, \& Gorman, 2014). A prevalence of $8.3 \%$ is reported and children with ADHD had $13 \%$ increase in mental and behavioral health visits while their parents are deployed (IRR 1.13; 95\% CI; 1.12-1.14; $p<0.00001)(p<0.05$ considered statistically significant) (Hisle-Gorman, Eide, Coll, \& Gorman, 2014). Study strengths include large sample size and database integration allowing researchers to link parental deployment with the child's medical record. Study limitations include failure to include full age range of children with potential diagnosis of ADHD, reliance on provider codes for identification of diagnosis (possibly missing patients that no longer had this diagnosis on the active problem list), and inability to include specific details related to deployment phases, presence of dual-military parents, and number and length of deployments.

\section{ADHD Treatment in Military Pediatric Clinics}

There are no studies evaluating ADHD treatment or CPG adherence in the military sector, and recent clinical observations suggest that military children with ADHD may not be receiving evidence-based care. The previously described retrospective cohort study of 413,665 military children ages 4-8 years evaluate mental health visits and medication changes during parental deployment, and provides limited insight on ADHD treatment (Hisel-Gormon, Eide, 
Coll, \& Gorman, 2014). The study identifies an ADHD prevalence rate of $8 \%$, and $55.9 \%$ of children in the study are prescribed ADHD medications. Children with ADHD and a deployed parent have a $13 \%$ increase in mental health visits and a decrease in medication changes (HiselGormon, Eide, Coll, \& Gorman, 2014). It is unclear why these children are accessing mental health care more frequently yet receiving fewer changes in medication dosages during parental deployment. The percentage of patients receiving a medication for ADHD is also low considering that medication is widely recognized to be the most effective treatment. Of note, these data related to ADHD medications are likely a poor representation of the entire pediatric ADHD population among military children since the study only includes children 4-8 years of age. Further studies are needed to measure guideline adherence in military children with ADHD.

\section{Barriers to Guideline Adherence}

Although the current guidelines have a strong evidence base, many barriers to addressing pediatric mental health concerns remain (AAP, 2011; Foy et al., 2010; Leslie, Weckerly, Plemmons, Landsverk, \& Eastman, 2004). Common barriers that are identified by civilian pediatric providers include lack of time and/or expertise, limited access to pediatric mental health specialists, stigma, and reimbursement for services (AAP, 2011; Foy et al., 2010). A study designed to implement the AAP guidelines in primary care settings conducts focus groups to discuss barriers to guideline adherence (Leslie, Weckerly, Plemmons, Landsverk, \& Eastman, 2004). Providers in the study report having limited knowledge of different ADHD rating scales and management of coexisting conditions and poor access to community resources for patient and family support, therapy, and education (Leslie, Weckerly, Plemmons, Landsverk, \& Eastman, 2004). Lack of time to interview children and families, communicate with the schools, and coordinate referrals, as well as insufficient reimbursement for time and effort, are additional 
barriers mentioned in the focus groups (Leslie, Weckerly, Plemmons, Landsverk, \& Eastman, 2004).

\section{Interventions to Improve ADHD CPG Adherence}

A variety of interventions are effective in improving ADHD guideline adherence including education protocols, decision support tools, web portals, telehealth, and patient registry programs (Baum, Epstein, \& Kelleher, 2013; Geltman et al., 2015; Myers, Vander Stoep, Zhou, McCarty, \& Katon, 2015; Nelson, Duncan, Peacock, \& Bui, 2012; Polaha, Cooper, Meadows, \& Kratochivil, 2005). These interventions are summarized in table 2. One study evaluating a webbased program does not measure provider adherence to guideline directly, however the barrier related findings are pertinent given persistently poor access to teacher rating scales by the primary care team. (Bhatara Vogt, Patrick, Doniparthi, \& Ellis, 2006). Smart phone applications and online behavior therapy programs have also been developed for patients with ADHD; however, no evidence base to support these technologies exists (Baum, Epstein, \& Kelleher, 2013).

The most promising of the existing interventions for improving provider ADHD CPG adherence is a quality improvement program implemented by Epstein, Langberg, Lichtenstein, Kolb, \& Stark (2010). The program consists of didactic training sessions focusing on evidencebased guidelines, as well as office-based process-improvement interventions that empower the staff to efficiently incorporate guideline-based care into their daily operations through use of the PDSA model. Immediate improvements in guideline adherence with this quality improvement model are noted and are sustained 2 years after training (Epstein, Langberg, Lichtenstein, Kolb, \& Stark, 2010). Regardless of the modality chosen, the interventional key components should target systems that improve early identification of ADHD, ongoing follow-up to monitor 
symptoms, patient registries to monitor outcomes, and communication between patients, providers, schools, and communities (Baum, Epstein, \& Kelleher, 2013).

While a number of interventions designed to improve ADHD guideline adherence are successful in non-military settings, it is unclear whether these findings can be generalized and applied to the unique dynamics of the military health system. Furthermore, it cannot be assumed that the rate of CPG adherence among civilian providers parallels that of military providers. ADHD guideline adherence is well documented in the literature; however, military providers and/or identification of the subjects' parental military status are not included in any of these studies. The purpose of this project is to assess current adherence to the AAP ADHD CPG among pediatric providers in a military clinic, to identify existing barriers to guideline adherence, and to empower providers and staff to address areas for improvement with evidencebased interventions using the PDSA method.

\section{Theoretical Framework}

Although substantial evidence supports the implementation of the AAP CPG, efforts are not sufficient to consistently adopt into practice (Epstein et al., 2014). The current quality improvement project will utilize theories included in the PDSA model, organizational change theory, and chronic care model to maximize provider adherence to the ADHD CPG within the selected military clinic.

The primary theoretical framework chosen for this project is the PDSA model. Plan-dostudy-act is a 4-step cyclical process that is ideal for testing change in a busy practice setting (Holly, 2014). Step 1 (Plan) involves identifying the problem and formulating a solution with stated objectives. The implementation phase (Do), step 2, activates the plan while collecting data for later evaluation. The third step (Study) analyzes data that have been collected, and compares 
outcomes with the stated objective. Finally, step 4 (Act) identifies successes and failures and refines the plan as needed for further improvement and/or sustainability of the changed process (Holly, 2014). This framework will be used to guide a session designed to empower providers, nurses, and clinical staff to evaluate performance, identify existing barriers that impede guideline adherence, and address areas for improvement through the using evidence-based interventions (see figure 2).

Another theoretical framework used to guide this project is the organizational change theory. Lewin developed the model of organizational change in 1952, and it has been shown to be effective in changing group behavior (Bareil et al., 2015). The organizational change theory supports process improvement through strengthening corroboration among the health care team, fostering shared goals, identifying barriers to change, and involving the organization in the implementation of the change (Edberg, 2015, p. 51-54). Aspects of this theory are applied to the dissemination of chart review findings and outcomes of the PDSA session.

Lastly, the chronic care model (CCM) is heavily relied upon in this quality improvement project, as it is one of the key components of the ADHD CPG. The CCM was created by Edward H. Wagner, and effectively reduces costs and utilization of health care among adult patients with diabetes, congestive heart failure, and asthma. The six essential elements of this model include organization, clinical information systems, delivery system design, decision support, selfmanagement support, and community resources (Bodenheimer et al., 2002). The CCM is not thoroughly studied in the pediatric population with ADHD, however there are improvements noted in quality outcomes, cost reduction, and decreased health care utilization among depressed adults (Foy et al., 2010).

\section{Methodology}


From 2013-2015, a master's prepared PNP exerted clinical leadership to facilitate implementation of the AAP ADHD CPG in an Air Force pediatric clinic. Prior to implementation of the guidelines, all patients presenting to the pediatric clinic with academic or behavioral problems and symptoms of inattention, hyperactivity, or impulsivity were referred to an off-base, community psychologist for a full psychoeducational evaluation. These evaluations required approximately 3 days of testing billed at $\$ 1,000-\$ 5,000$ per child (AAP, 2011), and the average wait for an appointment was 3-6 months (S. Szari, personal communication, December 15, 2016). After completion of the off-base evaluation, an appointment was scheduled with the PCM to review the results and prescribe ADHD medications if recommended by the psychologist.

During implementation of the CPG in 2013, providers and staff were educated on the clinical practice guidelines, and a standardized clinic process was developed for initial assessment and follow-up of patients with ADHD. Providers received real-time clinical training with patients during both initial assessments and ADHD follow up visits, and were able to receive ongoing support from the experienced PNP as needed. A chart review of 1-2 encounters related to ADHD per provider was peer-reviewed (including documentation of assessment for side effects and medication response to stimulant therapy) on a monthly basis and feedback was provided. A more thorough evaluation of current adherence to the ADHD CPG among the military pediatric providers is now needed to ensure that military dependents with ADHD are receiving quality, evidence-based care within the medical home. As previously stated, this project, in keeping with the quality improvement framework of "Plan-Do-Study-Act" has the following objectives: 
1. Evaluate the current status of provider adherence to the ADHD CPG in the specific military setting following the targeted educational intervention previously carried out, and

2. Demonstrate DNP level leadership to improve quality care delivery using the PDSA model. The PDSA session will be conducted to empower providers, nurses, and clinical staff to evaluate performance, identify existing barriers that impede guideline adherence, and address areas for improvement through the using evidence-based interventions.

\section{Definition of Terms}

Study key variables. The primary variable of the study is ADHD guideline adherence. Adherence is evaluated based each of the 6 components of the AAP ADHD CPG (2011). Variables measured for each key component include:

1. The primary care clinician initiates an evaluation for ADHD in any child ages 4-18 years presenting with academic or behavioral problems and symptoms of inattention, hyperactivity, or impulsivity (see table 3 for complete list of variables).

a. Were the initial visits conducted by the PCM or a psychologist in the community?

b. Recommended visit components for initial evaluation

i. History of symptoms, past medical history, family history, psychosocial history

ii. Physical exam including neurological examination and cardiovascular status

iii. Baseline height, weight, blood pressure, and pulse

iv. Cardiac history assessment

v. Hearing screening 
vi. Vision screening

2. Diagnosis is made based on DSM criteria, using validated instrument such as the Vanderbilt Scale.

a. Symptoms present prior to 12 years of age

b. Symptoms have been present for longer than 6 months

c. Evidence of impairment in 2 or more major settings for longer than 6 months

d. Parent instrument

e. Teacher instrument

3. Identify possible co-morbidities
a. Psychoeducational evaluation
b. Developmental delay or intellectual disability
c. Conduct disorder or oppositional defiant disorder
d. Depression or anxiety
e. Sleep disorder
f. Tics

4. Treat ADHD as a chronic condition, and follow the chronic care and medical home models; documentation of recent or pending relocation, parental deployment, and assessment of EFMP status were also evaluated under this component, as these variables pertinent to the military child.

a. Establish a management team with a coordination plan and collaboration with family, child, school, and mental health professionals to identify target goals

b. Target goals documented

c. Relationships 

d. Disruptive behavior
e. Academic performance
f. Independence
g. Self-esteem
h. Safety
i. Relocation
j. Deployment
k. EFMP

5. Treatment recommendations based on age:

a. Treat preschool-aged children with behavior therapy as first-line; may prescribe methylphenidate if no improvement

i. Behavior therapy recommendations

ii. Stimulant therapy initiated

b. Treat elementary school-aged children with medication and/or behavior therapy.

i. Stimulant therapy initiated

ii. Behavior therapy recommendations

c. Treat adolescents with medication and they may receive behavior therapy.

i. Stimulant therapy initiated

ii. Behavior therapy recommendations

6. Adjust medication dosages with a goal of maximum benefit and minimum side effects.

a. Systematic reassessment of core symptoms and function using a validated, symptom-based follow-up scale such as the Vanderbilt ADHD follow-up scale (parent and teacher forms) 
b. Regular assessment of target goals

c. Anticipatory guidance and education related to treatment

d. Care coordination

e. Adherence to medication

f. Side effects

g. Weight

h. Frequency of telephone follow-up recommendations and actual telephone encounters

i. Frequency of face-to-face follow-up visits and actual follow-up visits

j. Amount of time since last visit

Other important terms. Definitions for other important terms are described in this section.

Exceptional Family Member Program (EFMP). Program implemented to ensure that family members and dependents of active duty Air Force members receive relocation assignments to geographic locations with needed medical and/or educational resources (AFI 40701, 2014).

Military child. Any person under 19 years of age with a parent or guardian who is currently serving, or has ever served in the U.S. Armed Forces. This includes active duty, reserves, guard, and retirees. There is no minimum duration for service, but the service must have occurred during the child's lifespan.

Deployment. A period of time of at least 6 months when the military service member is required to travel away from the family and assigned installation for official duty. 
Relocation. Permanent change of duty location from one military installation to another in which the service member can be accompanied by dependents.

Primary care manager (PCM). Physician, nurse practitioner, or physician assistant to which the patient is assigned or empaneled.

Medical Technician. Member of the health care team with specific medical training to support the assigned clinic; usually consists of Active Duty service members or licensed practical nurses.

PCMH team. Health care team to which the patient is assigned; usually consists of the PCM, a registered nurse, and 1-2 medical technicians.

Initial visit. A medical encounter in which the patient is being evaluated for ADHD by the PCM for the first time.

Follow-up visit. A medical encounter in which the patient is seeing the PCM for ongoing management of an established diagnosis of ADHD.

Telephone encounter. Any medically related correspondence between the PCMH team and the patient, guardian, school, or other health care provider.

AHLTA. The electronic health record system used by the USAF.

Rank with corresponding pay-grade. Each military rank has a corresponding pay-grade to denote enlisted or officer status and level of leadership. Rank titles vary among services, but pay-grade is consistent throughout the DoD. For example, a pay-grade of E-5 is assigned to a Staff Sergeant (SSgt) in the Air Force and a Petty Officer $2^{\text {nd }}$ Class (PO2) in the Navy.

Off-base provider. Any healthcare professional practicing in the local community, but not affiliated with the military treatment facility.

\section{Description of the Sample}


CPG evaluation. A convenience sample ( $\mathrm{n}=50,62$ total encounters) is selected from a medium-sized Air Force military treatment facility (MTF) pediatric clinic in the Southeastern United States. The pediatric clinic empanels approximately 3,500 patients from birth to 18 years of age, and approximately $10 \%$ of the population has a diagnosis of ADHD (A. Davis, personal communication, October 21, 2014). Patients are dependents of military members or retirees, and are covered by TRICARE. Patients attend local civilian schools based on zoning and/or parental choice, and live both on and off of the military installation.

Inclusion criteria for sample. Initially, plans for the sample population identification include using a random selection of the records provided by a data analyst from the Defense Health Agency using the following inclusion criteria: ages 0-18 years, any ICD-9 code beginning with 314 or ICD-10 codes: F63.9, F81.89, F81.9, F90.0, F90.1, F90.2, F90.8, F90.9, F91.3, F91.8, F91.9, F93.8, F93.9, F94.8, F98.8, F98.9, R41.840, patient is assigned to one of the pediatric providers in the clinic at Tyndall AFB, and ADHD is managed by the PCM; include patients with comorbid disorders as long as the PCM is providing prescriptions for ADHD medications. Due to unforeseen delays in the process of obtaining research approval for the project, this randomized patient list was not available during the data collection period. As an alternative, a convenience sampling approach was utilized by scanning the reason for appointment noted on the providers' daily schedules. Encounters with appointment labels containing the terms "ADHD", "school concerns", "learning problems", "behavior concerns", "behavior problems", "hyperactivity", "inattention", "impulsivity", "problems focusing", or "medication follow-up" were evaluated using the above inclusion criteria.

Exclusion criteria for sample. Patients $>18$ years of age, PCM assignment in the family health clinic or to an off-base provider, or ADHD is managed by specialist off base. 
PDSA Session. Meeting participants for the PDSA session are affiliated with the same clinic as described above. The clinic employs 2 active duty pediatricians and 1 active duty pediatric nurse practitioner (PNP). One pediatrician is assigned to the clinic from January to June 2016, then separates from the military and is replaced by another active duty pediatrician. Board certification is not a practice requirement for active duty providers, however all of the providers evaluated in this study are board certified. All 4 providers are female and Caucasian. All 3 pediatricians are graduates of a military residency. The current clinic is the first duty assignment after residency completion for 2 of the pediatricians, and the second duty station after residency for the third pediatrician. The PNP evaluated in this study is a master's prepared advanced practice nurse, and holds a certification in pediatric primary care with more than 5 years of clinical experience.

\section{Setting}

The selected Air Force MTF provides care for over 36,000 beneficiaries in an outpatient setting. Family health, women's health, pediatrics, flight medicine, immunizations, physical therapy, optometry, dental, pharmacy, laboratory, and radiology services are all offered in the facility, which is located on the Air Force Base. Patients must have access to the military instillation, and be covered by TRICARE to receive care at the facility. Inpatient services are not offered, therefore urgent, emergent, and after-hour needs are routed to the local community hospital. Providers are available during off-duty hours for phone consultation if needed, and patients have access to a nurse advice line 24 hours per day, 7 days per week.

The pediatric clinic empanels approximately 3,500 patients from birth to 18 years of age with a broad range of pediatric conditions. Patients can be dependents of service members from any branch, however, since this is not a joint base, most patients are Air Force affiliated. Services 
offered by the pediatric clinic include well child visits, sick and acute care, and primary care management of other pediatric conditions, including chronic care. The local community hospital offers basic emergency and inpatient care for pediatric patients, however patients with more complex conditions or surgical needs must travel approximately 80 miles to reach a children's hospital for inpatient or outpatient pediatric subspecialty care.

\section{Protection of Human Subjects}

Study IRB provided by: University of Virginia Institutional Review Board for Health Sciences Research HIPAA Privacy Board, IRB-HSR \# 19169 (Margaret W. Ball, Member; Institutional Review Board for Health Sciences Research PO Box 800483, University of Virginia; Charlottesville, VA 22908; 434-924-9634). Approval also received from Air Force Human Research Protection Program Review (HRPO), \# FSG20160050H (Imelda M. Catalasan, Lt Col, USAF, Director, AF Research Oversight and Compliance Division; 7700 Arlington Blvd. Ste. 5151; Falls Church, VA 22042-5151). Lastly, the Data Sharing Agreement for Protected Health Information, DSA \# 16-1622, approved by the Defense Health Agency (Linda S. Thomas, Chief, DHA Privacy and Civil Liberties Office; 7700 Arlington Blvd, Suite 5101; Falls Church, VA 22042-5101; 703-681-7500). See Appendix $C$ for IRB approval forms.

Verbal consent for PDSA session participation has been obtained (Chief Nurse Karyn L. Revelle, Lt. Col, USAF, NC, Chief Nurse, $325^{\text {th }}$ Medical Group, 340 Magnolia Circle; Tyndall Air Force Base, Florida, 32403, 850-283-7446). Meeting agenda emailed to all participants prior to the session with the following statements: Participation is voluntary and this project is not affiliated with the DoD or any military branch. No personal identifiable information collected during the meeting and all responses kept anonymous. No compensation will be offered, and 
participants may choose to not answer questions and/or participate during any portion of the meeting.

\section{Project Design}

CPG adherence. Evaluation of guideline adherence was conducted using a quantitative, retrospective, chart review of a convenience sample $(n=50)$ of patients empaneled to the selected military pediatric clinic from January through December 2016. Among the 50 patients included in the sample, 62 encounters were reviewed to include initial visits (19/62), follow-up visits (43/62), and telephone encounters (5/62) that addressed the patients ADHD. Records were reviewed using an adapted, validated abstraction tool based on the 6 key guideline components (Vreeman, Madsen, Vreeman, Carroll, \& Downs, 2006). The tool was adapted to be consistent with the most recent 2011 guideline and DSM-V criteria, and to assess initial and follow-up visits separately (see Appendix $A 1, A 2$, and $A 3$ ).

PDSA session. After completion of guideline adherence, a face-to-face meeting was held with the providers, nurses, and lead medical technician of the pediatric clinic to review guidelines, discuss chart review findings, and collect feedback regarding barriers to guideline adherence, as well as areas where guideline implementation has been successful. The PDSA model was used to guide discussion related to ongoing quality improvement and additional evidence based interventions that have been successful in improving adherence.

\section{Data Collection Procedures}

CPG adherence. As previously described, a list of patient records meeting inclusion criteria was to be provided by the DHA clinical informatics department, but it was not received in time to allow for project completion. Additionally, approval was not granted by the MTF to conduct the chart review remotely as originally planned; therefore, the researcher was required to 
travel to the MTF during the data collection phase. After receipt of commander approval, access to the MTF was granted upon arrival by facilities management, and AHLTA access provided by information systems management. As an alternative to utilization of a randomized list of subjects for review, provider schedules were examined from January through December 2016, and encounters with the "reason for appointment" labeled "ADHD follow-up," "ADHD initial visit," "behavior problems/concerns," "school problems," or "medication check" were reviewed for inclusion in the sample. The first 50 patient charts to meet inclusion criteria were included in the study, with an extra 12 encounters on the selected patients included to assess continuity of care. Efforts were made to balance the encounter types among the 4 providers and records were selected starting from January moving forward, then from December moving backwards to accommodate for the mid-year provider turnover. Patients were assigned a participant identification number, and no personally identifiable information was retained after the completion of data collection. The chart review was conducted by the author, and took approximately 72 total hours to complete over the course of 5 days.

PDSA session. A single, 2 hour PDSA session was held in-person in the conference room of the pediatric clinic, and the date and time were selected based on provider availability as well as chief nurse, flight commander, and medical group commander approval. Meeting coordination was conducted via email. Meeting and data collection were completed 4 months after planned due to unforeseen delays in obtaining military approval for the project. Questions based on the key guideline components were used to guide discussion regarding perceived barriers to adherence, and were adapted (with permission by Epstein, personal communication, July 9, 2016) from a survey tool used in a study by Epstein et al. (2008). The survey tool was not used as originally intended, as provider report has been shown to be an invalid measure for guideline 
adherence. Survey questions were adapted to inquire about barriers rather than adherence, and were not individually distributed or collected; the researcher presented the questions as topics to facilitate an organized, goal-oriented discussion rather than as an information-gathering tool. See Appendix $A 4$ and $A 5$ for original and adapted versions. The meeting was structured as follows: review of AAP CGP, review of chart review findings, discussion of identified barriers to guideline adherence using the questionnaire as a guide, and discussion of PDSA model and evidence based-interventions to improve adherence to ADHD guidelines. Session notes were typed and emailed to attendees for approval, which was granted.

\section{Variables and Measures}

CPG adherence. An adapted 1-page chart abstraction tool was used to systematically perform chart reviews. The tool was shown to have strong inter-rater reliability when used to evaluate compliance with ADHD guidelines (Vreeman, Madsen, Vreeman, Carroll, \& Downs, 2006). Permission has been granted from the author of a validated chart abstraction tool for replication and adaptation as needed (R.C. Vreeman, personal communication, July 6, 2016). The tool is based on the key components of the AAP CPG from 2001; therefore it was adapted to include the additional updated components of the 2011 guidelines and DSM-V criteria (see Appendix $A 1, A 2$, and $A 3$ for original and adapted versions). The tool was originally designed to evaluate initial ADHD evaluations, so additional adaptions were made to enable measurement of adherence during follow-up visits and telephone encounters (TCON) as well. These additional components include the expanded age range, age-based recommendations for stimulant and behavior therapy, and specific recommendations for follow up (AAP, 2011). Follow-up visit evaluation tools excluded information related to the initial diagnosis process. Military specific information that was added to the tool included parental service and rank, as well as if EFMP 
status, parental deployment status, and upcoming or recent relocations. Charts reviewed included at least 1 record from each provider, as well as encounters from both initial ADHD evaluations and ADHD follow-up visits. Variable data from the chart abstraction tool were entered into excel and coded as not addressed $=0$, addressed $=1$, unknown $=7$, or N/A $=3$; frequencies and percentages were analyzed using SPSS v24.

PDSA session. A survey based on the key components of the ADHD guideline was designed for use in a study published by Epstein et al. (2008). More recent literature indicates that provider report is an invalid measure of guideline adherence; therefore, questions were adapted to inquire about barriers rather than adherence. For example, a survey question asks: "How helpful do you think it is to collect behavior ratings using standardized rating scales from teachers when evaluating a child for ADHD?" The adapted version reads: "How difficult do you think it is to collect behavior ratings using standardized rating scales from teachers when evaluating a child for ADHD?" Guideline questions are rated on a 1-5 Likert scale, and each question prompt for a narrative response that reads, "Please explain." The adapted survey tool's organization of these components is a strength, and adds to the utility. The questionnaire was not formally collected for the quality improvement project, but used to guide discussion. See appendix A for original and revised copies.

\section{Data Analysis Plan}

CPG adherence. Each subject was assigned a participant ID, and no PII was recorded on the chart abstraction tool. Assignment of the participant ID occurred on paper, and was stored in a secured location until data collection was complete, then it was destroyed. Medical records were examined using AHLTA electronic health record on an encrypted, secure, DOD computer, with access granted from the MTF. De-identified data from chart review was recorded on the 
chart abstraction tool, then transferred into an excel spreadsheet. Demographic data were recorded and reported as descriptive statistics to characterize the sample. Each variable received an entry for "addressed" $=1$, "not addressed" $=0$, or "N/A" = 3. The completed excel spreadsheet was imported into SPSS v24 for analysis to be reported as frequency distributions and percentages of adherence to the specific guideline key components. Additional anecdotal notes were recorded to explain any deviation from the guideline so this could be accounted for in the final analysis. De-identified data in excel and SPSS have been password protected and stored on a personal laptop computer. A back up copy of the data were stored on a password protected flash drive stored in a secure location.

PDSA session. After using the questionnaire to guide discussion related to current performance and barriers, the PDSA model was reviewed, and the providers were encouraged to discuss ways the method could be applied to improving guideline adherence. Ideas were recorded in a list format with each of the 4 steps defined. Examples of identified evidence-based interventions to improve adherence were hypothetically taken through the cyclical process to encourage the providers to begin planning and implementing additional process improvements related to the care of military children with ADHD. Careful notes were taken on a laptop in a word document during the session, and were emailed to the participants for approval.

\section{Results}

\section{Sample Demographics}

Demographic information obtained from the electronic health record is presented in table 4. Patients included in the sample are between the ages of 5-18 years (mean 12 years, SD 3). Mean age at diagnosis is 8 years (range 4-13 years, SD 2.4). Females represent $38 \%(n=19)$ of the sample, males $62 \%(n=31)$. Race is largely undocumented in the demographics portion of the 
record, and is either left blank, marked "unknown," or marked as "other" in the charts of 32/50 participants (64\%). Of the encounters with race documented, 17/18 participants are white (94.4\%), and 1/18 is black (5.6\%). Air Force, Army, Navy, and Coast Guard are represented in the sample, with the most frequent ranks being Staff Sergeant (SSgt, E-5) ( $n=13,26 \%)$, Technical Sergeant (TSgt, E-6) $(n=11,22 \%)$, and Master Sergeant (MSgt, E-7) (n=8, 16\%). Air Force dependents comprise $88 \%$ of the sample (see table 5).

\section{CPG Adherence}

Compliance with the AAP CPG is determined by calculating the number of variables in each encounter that address each of the 6 key components. Variables are determent to have "met" the standard if they are addressed in $>/=80 \%$ of the encounters. The variable is determined to have "not met" the standard if addressed in less than $80 \%$ of the encounters. The number of "met" variables under each component is divided by the total number of variables under that component to calculate overall adherence to the specific component.. Evaluation of overall provider adherence to the AAP CPG for ADHD in a military pediatric clinic reveals that 2/6 key components are consistently "met” (see figure 3). Of the 62 encounters reviewed, zero met all 6 key components of the guideline; 3 encounters address at least one variable from each key component to include: PCM initiates the evaluation, use of DSM criteria, assessment for comorbid conditions, assessment of EFMP status, assessment for history of counseling and stimulant therapy, and assessment of side effects and therapeutic response to stimulant therapy (see table 6). Of 85 total variables, the providers have an overall mean adherence rate of $28.6 \%$ (0-100\%, SD 33.8\%). The clinic currently has access to an ADHD specific documentation template that includes some of the variables measured in this study. Rates of adherence among the variables that are included in the documentation template are much higher than those not 
included. Of the 32 variables included on the ADHD template, the mean adherence rate is $63.5 \%$ $(0-100 \%$, SD $31.5 \%)$. Of the 55 variables not included on the template, the mean adherence rate is $7.2 \%(0-27 \%, \mathrm{SD} 7 \%)$.

The CPG is designed to address the full spectrum of care provided to children with ADHD by the medical home, therefore each individual key guideline component does not apply to every type of ADHD visit. Since key recommendations 1 and 2 of the guideline address initial evaluations, adherence rates are calculated from only the encounters that were initial visits $(n=19)$. Key components 3-6 can be applied to all visits or to follow-up visits specifically, depending on the variable being measured. Adherence to each individual variable is evaluated by calculating rates based on the appropriate corresponding appointment type. Of 62 total encounters, 19 are initial visits, 38 are follow-up visits, and 5 are telephone encounters. Since much of the medication management is handled over the phone, the telephone encounters are grouped in with the follow-up visits for most of the data reporting $(n=43)$. The following section describes chart review findings based on the key guideline components for initial and follow up visits.

Initial visits. While all 6 key components apply to clinic visits schedule for initial ADHD evaluations, components 1 and 2 are specifically intended to inform practice related to common presenting complaints, diagnostic criteria, and elements of the patient and family history and physical examination. A summary of the variable measurements for initial visits can be found in table 7 .

Key component 1. To measure adherence to the first key component, the 19 initial ADHD evaluations are included. The PCM initiates the evaluation for ADHD in 4 of the 19 encounters (21.1\%). Most patients at the selected clinic receive the initial evaluation from a 
psychologist in the community $(14 / 19,73.3 \%)$, and 1 of the $19(5.3 \%)$ is conducted by the child's school psychologist. Children who are not evaluated for ADHD within the medical home, schedule appointments with the PCM to receive a medical diagnosis and discuss treatment options. During the initial evaluations, providers routinely document patient history (19/19, 100\%), physical exam (18/19, 94.7\%), and cardiac history assessment (17/19, 89.5\%).

Recommended portions of the visit that are addressed less consistently include neurological examination $(12 / 19,63.2 \%)$, weight $(9 / 19,47.4 \%)$, hearing screening $(1 / 19,5.3 . \%)$, and vision screening $(5 / 19,26.3)$. Providers conducted 4/19 initial without the patient present, between the parents and the provider.

Key component 2. This section of the guideline states that diagnosis is made based on DSM criteria, using validated instrument such as the Vanderbilt Scale. Of the 4 evaluations conducted by the PCM, all 4 report using DSM criteria; however specific documentation related to how the patient met the criteria is less consistent. For example, all four providers document presence of symptoms before age 12, and evidence of impairment in multiple settings, while only 3/4 (75\%) document use of a validated instrument (Vanderbilt parent/teacher rating scales) and1/4 (25\%) note that symptoms have been present for longer than 6 months (see table 8$)$. Of the initial evaluations not initiated by the PCM, providers consistently document use of a validated parent and teacher instruments $(16 / 19,84.2 \%)$ and presence of symptoms prior to 12 years of age $(7 / 19,89.5 \%)$. DSM criteria related to presence of symptoms for longer than 6 months $(9 / 19,47.4 \%)$ and documentation of evidence of impairment in more than one setting $(10 / 19,52.6 \%)$ are noted in fewer encounters.

Key component 3. Adherence to assessment and screening for co-morbidities commonly occurring alongside ADHD is evaluated in both initial visits, and in follow-up and telephone 
encounters as part of ongoing management. The providers that utilize the Vanderbilt scale during initial evaluations $(3 / 4,75 \%)$ address comorbidities as part of the tool. Of the initial evaluations conducted outside of the medical home, none of the variables associated with this component are documented consistently enough to meet the standard including: psychoeducational evaluation to rule out learning disorders $(13 / 19,68.4 \%)$, developmental delay or intellectual disability $(9 / 19$, $47.4 \%)$, conduct disorder or oppositional defiant disorder $(3 / 19,15.8 \%)$, depression or anxiety $(7 / 19,36.9 \%)$, sleep disorders $(12 / 19,63.6 \%)$, and tics $(8 / 19,42.1 \%)$.

Key component 4. This action statement reinforces that ADHD should be treated as a chronic condition, with recommendations to follow the chronic care and medical home models. Provider strengths in addressing this component include documentation of school performance $(17 / 19,89.5 \%)$, enrollment in the exceptional family member program (EFMP) $(19 / 19,100 \%)$, and history of counseling $(15 / 19,80 \%)$. None of the encounters document a team coordination plan or evidence of collaboration with the school. No target goals are documented, although impact on peer and family relationships $(8 / 19,42.1 \%)$, and disruptive behavior $(9 / 19,47.4 \%)$ are addressed in the review of symptoms using the existing ADHD documentation template. Impact on functioning is addressed less consistently related to areas of independence $(3 / 19,15.8 \%)$, selfesteem $(2 / 19,10.5 \%)$, and safety $(3 / 19,15.8 \%)$. Additional factors pertinent to chronic care management that are unique to the military population include assessment of recent or pending relocation $(2 / 19,10.5 \% \%)$ and parental deployment status $(0 / 62,0 \%)$.

Key component \# 5. This component provides treatment guidelines based on age. The two treatment modalities include stimulant therapy and behavior therapy. Stimulant therapy is initiated in $17 / 19(89.5 \%)$ of newly diagnosed patients. Starting medication doses include Adderall XR 5mg (8/19, 42.1\%), Concerta 18mg (5/19, 26.3\%), and Ritalin 5mg (4/19, 21.1\%). 
Both the medication formulation and dose are consistent with the recommendations for stimulant initiation $(17 / 19,89.5 \%)$. The records do not include documentation related to behavior therapy education or parent training provided by PCM; however, assessment for history of counseling is conducted in most encounters $(15 / 19,80 \%)$. Documentation of discussion related to compliance with ongoing behavior therapy is noted in 1 encounter $(5.3 \%)$. Referrals to a mental health professional or developmental pediatrician $(1 / 19,5.3 \%)$ and school counselor $(1 / 19,5.3 \%)$ are also noted in patients with poor treatment response.

Key component 6. The final component provides guidance for titration of stimulant medications and intervals for ongoing follow-up visits. The AAP recommends that patients that have been started on a stimulant medication receive titration recommendations and side effect assessment via phone every 1-2 weeks, follow up face to face within 1 month, then every 3 months until the optimal dose has been established (2011). Patients should then follow up at least every 6 months for maintenance on the optimal dose. Of the initial visits, $16 / 19(84.2 \%)$ receive recommendations to follow-up via phone within 2 weeks; however only 6/19 (31.2\%) actually have a documented telephone encounter during that period of time. Most patients have followed up with a phone call after 4 weeks $(85.7 \%)$, and all (100\%) have followed up at 12 weeks after stimulant initiation. Face-to-face follow up visits are recommended at 4 weeks $(6 / 19,31.6 \%), 12$ weeks $(12 / 19,63.2 \%)$, and 52 weeks $(1 / 19,5,3 \%)$. Patients actually follow up 4 weeks $(2 / 19$, 10.5\%), 12 weeks $(9 / 19,47.4 \%), 52$ weeks $(14 / 19,73.7 \%)$, and 5/19 (26.3\%) have no documented follow up.

Follow-up visits. Provider adherence to the guidelines during ADHD follow-up visits is measured using variables from key components 4, 5, and 6. Key components 1-3 are not applicable to routine follow-up visits. 
Key component 4. Strengths during follow-up visits related to the management of ADHD under the chronic care model include documentation of school performance $(42 / 43,97.7 \%)$, EFMP status $(39 / 43,90.7 \%)$, and history of counseling $(35 / 43,81.3 \%)$ (see figure 4$)$.

Weaknesses in adherence to this component include documentation of a team coordination plan $(0 / 43,0 \%)$, evidence of collaboration with the school $(0 / 43,0 \%)$, and establishment and evaluation of target goals $(0 / 43,0 \%)$ (see figure 5$)$. The following areas are assessed as part of the $\operatorname{ROS}(0 / 43,0 \%)$, relationships $(34 / 43,79.1 \%)$, disruptive behavior $(34 / 43,79.1 \%)$, independence $(9 / 43,20.9 \%)$, self-esteem $(0 / 43,0 \%)$, and safety $(7 / 43,16.3 \%)$. Military specific variables include, deployment $(0 / 43,0 \%)$, and relocation $(6 / 43,14 \%)$.

Key component 5. Adherence to treatment recommendations based on age for follow-up visits is reported in this section. Of the 50 patients included in the chart review, one child ( $2 \%$ of the sample) was in the preschool age range. Behavior therapy is not mentioned specifically, however the provider documents that the patient has a history of receiving counseling. The patient is not prescribed a stimulant by the PCM due to multiple complex co-morbidities, and the provider recommends that a community psychiatrist evaluate and manage medications. Children in the elementary school-age range made up 17/50 (34\%) of the sample. Within this age range, 16/17 (94.1\%) patients are prescribed a stimulant medication. None of the encounters with patients in this age range mention behavior therapy, but $76 \%$ are asked if they had ever seen a counselor, and $40 \%$ answer yes to ever seeing a counselor. Lastly, subjects in the adolescent range make up $34 \%$ of the sample (17/50), and $17 / 17(100 \%)$ are prescribed a stimulant medication. No behavior therapy is mentioned in the documentation, but 17/17 (100\%) patients have been assessed for history of receiving counseling, and 10/17 (58.8\%) report seeing a counselor in the past. 
Key component 6. Adherence to most variables related to this key component is high among providers during follow-up visits. Titration based on effect (93\%), while monitoring side effects $(90.7 \%)$, is consistent among providers. Medication management overall is a strength, and is consistent with the guideline; however, validated follow-up scales are not utilized in any encounters $(0 / 42,0 \%)$ to assess the effectiveness of treatment or medication side effects (see table 9). Re-evaluation of at least one core ADHD symptom or mention of ADHD symptoms in general is documented in 41/43 (95.4\%) follow-up encounters. The most common symptoms documented are hyperactivity, impulsivity, inattention, and decreased concentration, although the setting of symptoms (home verses school) is not consistently noted (see table 10). The patient's weight is recorded in the majority of the encounters $33 / 38(86.8 \%)$. See figure 6 for a visit comparison.

Recommendations for ongoing follow-up are as follows: 24/38 (63.2\%) encounters have recommendations to follow up by phone. Of the 24 with phone follow-up recommendations, $4 / 24(10 \%)$ are told to call in 2 weeks and the remaining 20 are told to call in 12 weeks $(52.6 \%)$. Follow-up encounters with no callback recommendations consist of 14/38 (36.8\%) of the sample. Of the patients that have a follow-up telephone encounter documented $(11 / 38,28.9 \%), 4 / 11$ (36.4\%) patients have called by week $2,9 / 11(82 \%)$ by week 12 , and $11 / 11(100 \%)$ by week 28 (see figure 8). Recommended face-to-face follow up visits are documented in 36/38 patient encounters. Intervals of 4 weeks $(2 / 36,5.3 \%), 12$ weeks $(9 / 36,23.7 \%), 24$ weeks $(23 / 36,60.5 \%)$, and 52 weeks $(1 / 36,2.8 \%)$ are recommended. Actual face-to-face follow-ups visits are documented in 29/38 (76.3\%) encounters; $1 / 29(3.4 \%)$ by 4 weeks, 10/29 (34.5\%) by 12 weeks, 21/29 (72.4\%) patients have followed up by 24 weeks, and 29/29 (100\%) patients have followed up by 40 weeks (see figure 7). The amount of time since the last ADHD-related visit is 
calculated in follow-up encounters as well, and 35/38 (92.1\%) encounters have a previous visit documented. Among patients with established ADHD, 1/35 (2.9\%) have been seen in the last 4 weeks. $8 / 35(22.9 \%)$ have been seen in the last 12 weeks, $21 / 35$ have been seen in the last 6 months $(60 \%), 88 \%$ have been seen by month 8 , and $100 \%$ have been seen by 56 weeks.

\section{PDSA Session}

A quality improvement session held with the providers and clinic nurse is conducted after completion of the chart review. After reviewing the CPG and discussing chart review findings, providers are prompted to discuss perceived strengths as well as barriers to guideline adherence with the selected population. Providers note that military children have many protective factors enabling them to receive comprehensive care. Free access to mental and behavioral health as well as free medical visits and prescription medications make recommended treatments for ADHD accessible and could increase compliance. One provider states that "Free mental health counseling is a huge benefit for our population; utilization could be higher because we are able to access affordable care." Additionally, providers note that most children have at least one parent with a stable income and overall emphasis on health. Children with military parents are able to access a Military Family Life Consultant at school, a licensed psychologist to help with transitions, navigation of the education system, etc. EFMP school liaisons are also available through the military installation to aid identifying local resources for children with special healthcare needs. Common barriers to guideline adherence identified by the clinic staff include timely receipt of completed assessment forms, self-referrals for testing by a psychologist without the PCM's knowledge, limited access in the pediatric clinic, and insufficient time during the appointments. 
Identified barriers and plans for improvement. The 6 key guideline components are used to outline findings from the PDSA session.

Key component 1. Providers report that patients frequently come to the appointment already having received a psychoeducational evaluation by a community psychologist, often without their knowledge. While self-referrals for mental heath counseling are covered by TRICARE, the intent is that extensive educational testing requires a referral by the PCM. The culture at the selected MTF is one in which families ask other families for local resources rather than consulting the PCM. In this particular community, a local psychologist has established a rapport with the parents, and performs testing without seeking prior TRICARE approval. Since there is no referral by the PCM, visit notes and testing results do not get sent to the clinic, unless delivered by the parent. Providers explain that parents often communicate through a Facebook page dedicated to spouses of the installation that is not formally associated with the military. A parent will post a question on the page such as "where do I have my child evaluated for ADHD?" and other parents will respond with the name and contact information for the community psychologist. Further questioning also reveals that clinic nurses are recommending that parents call a psychologist for testing prior to scheduling an initial evaluation with the PCM due to perceived access limitations. Clinic staff explain that that it often takes 2-3 weeks for patients to get an appointment with their PCM, leading to patient complaints. If the parents do not have the evaluation forms completed for the appointment, they are required to reschedule the appointment. Providers report that by they time the parents get the paperwork completed by the school, and are able to schedule another appointment, a couple of months have elapsed. Access limitations are exacerbated by the additional demands of the military and providers are able to offer fewer appointments due to military requirements (training day 1 day per month, meeting 
day, fitness requirements, and any additional wing and/or squadron requirements). Clinic operations are also often negatively impacted by deployments, installation exercises, and transitioning service members. Recommendations for improvement identified by the providers during the PDSA session include talking with the referral specialist about requiring a PCM referral for psychoeducational testing, providing education to the schools regarding the preferred process for ADHD evaluations, and re-educating clinic staff regarding the importance of conducting ADHD evaluations in the medical home rather than by a specialist in the community.

Key component 2. The current process for obtaining evaluation forms from 2 major settings prior to or during the scheduled appointment is reported to be a barrier to guideline adherence. Providers explain that parents often come to the appointment without completed rating scales or copies of testing that has been done by the school or by another provider; this process can be exceptionally difficult when parents are also stressed by a deployment or relocation. One provider suggests that a system be put in place where teachers and parents can access the forms online, and can either print them out for completion, or complete electronically and email them to the healthcare team. Suggestions for putting the links to the forms on the medical group official Facebook page are discussed, however the clinic staff explain that the process for obtaining approval to add to the site is laborious, and the page is not perceived to be a resource that families utilize as routinely as they do the spouse support page. Another provider explains, "The DSM criteria is not worded in patient friendly manner. The questions are too technical, with cumbersome wording, and examples are tailored to older kids. I would suggest tailoring the criteria to each age group and simplifying the terminology. It would also be helpful for the guideline to provide age appropriate examples for the presentation of core symptoms." Finally, 
adding the DSM criteria to the existing ADHD documentation template is suggested as a way to improve adherence (see figure 9 for new proposed provider template).

Key component 3. During the discussion related to comorbid disorder assessment, the providers feel that they are screening for these disorders routinely, however it is not being captured in their documentation. They agree that adding a statement regarding assessment for comorbidities will improve adherence to this key component. Providers report that while they do have access to the community psychologist for psychoeducational evaluations, they have an overall lack of quality resources and mental health professionals that accept TRICARE in the area to consult for more complex cases. They lack confidence in the local non-pediatric psychiatrists' ability to manage children, and often do not agree with how their patients have been managed in the past by community mental health providers.

Key component 4. Military relocation and deployment requirements are identified as barriers to provision of care under the CCM. Providers feel that they do not have the time or clinical support staff to dedicate to facilitating ongoing communication with the school systems. The providers explain that finding time during the workday when members of the child's team are available is difficult, as teachers are often in the classroom during clinic hours. Another barrier identified to management of chronic conditions is the pharmacy's formulary restrictions. Providers explain that if a child comes to them with prescriptions that are not on the formulary, it can be difficult to obtain these medications. Lastly, the current electronic health record is not web-based, therefore it does not integrate with facilities outside of the military health system. There is a web-based data repository that is used to store medical records from specialty providers, but it the connection is not always reliable, thereby limiting the ability to provide 
coordinated care. Plans for a military-wide transition to a new web-based EHR have been discussed.

Key component 5. The providers all feel confident and competent in prescribing stimulant medications to this population, and do not perceive compliance to be a significant issue. All of the providers are familiar with the existing Vanderbilt follow-up scale, but report not realizing that use for assessment of response and side effects is recommended in the guideline. During the PDSA session, providers conclude that implementation of the Vanderbilt follow-up scales is identified as an acceptable practice change to improve adherence to this guideline. Providers do express concerns related to potential difficulties getting the completed forms back from the school and the parents having enough time to complete the forms during the encounter. Providers also discuss revising the existing nurse telephone questionnaire for ADHD to address the key components.

Key component 6. Related to timing of follow-up appointments and telephone encounters: “parent's just don't call back if things are going well; if they need us, they call sooner." Another provider agrees: “The responsibility is on the parent to call and follow-up because we don't know when they actually start the medication. Some parents wait a week or so before beginning treatment." When asked if there are any perceived barriers to phone follow-ups, the team reports "There could be some difficulty getting a hold of the nurses, but it's the exception, not the rule. $80 \%$ of the time they get through to someone the same day." Providers discuss adding 1-month follow-up visit after stimulant initiation to comply with guideline recommendations and consider creating a protocol for a nurse-led visit if the face-to-face appointments are not feasible due to clinic access limitations. 
The PDSA session provides valuable information related to the clinic staff's perceived strengths and barriers. The group is receptive to utilizing the PDSA model to guide ongoing quality improvements, and agree that the process is logical, efficient, and user-friendly. Interventions that are identified by the team to address areas for improvement included revision of the provider ADHD documentation template to include each of the 6 components, a standardized format for documenting the interview, exam findings, and assessment and plan, and utilizing the Vanderbilt follow-up ADHD scales to assess treatment response and presence of side effects. Finally, providers plan to educate clinic nurses, referral specialists, and patients to visit the PCM first for concerns related to core ADHD symptoms to improve the initial visit rate.

\section{Discussion}

This project, including the process and findings, addresses a critical gap in the diagnosis and treatment of military children with ADHD. This pediatric population is particularly vulnerable due to transiency of care associated with frequent family relocations and parental deployments. Facilitating adherence to CPG will foster improved behavioral, academic, and physiological outcomes for these children and their families. Finally, this project highlights the important role of the DNP-prepared APRN in fostering evidence-based practice and outcome improvement.

Findings from the retrospective chart review indicate that efforts to implement the CPG in the selected military pediatric clinic have not been fully sustained 24 months post-intervention. The providers' prescribing practices are consistent with the guideline, starting with the lowest dose, and titrating up for maximum effect with the least side effects. Providers also typically start younger children with short acting stimulant formulations, and older children with extended release preparations as recommended by the AAP (2011). Treatment of comorbid sleep disorders by the PCM is also evident in multiple encounters, and providers commonly recommend sleep 
hygiene, melatonin, and/or clonidine. Low rates of adherence to screening for comorbidities are identified by the chart review, despite providers' report that this screening is routine when they are treating ADHD. Furthermore, documentation of behavior therapy recommendations is rare, although patients are being assessed for a history of counseling. Providers report that they do often recommend behavior therapy, but fail to document these recommendations. Additionally, TRICARE does not require a referral from the PCM for mental or behavioral health counseling, so providers are not required to enter the recommendation into the system for the patient to access care coverage. When behavior concerns are mentioned, providers report frequently distributing a list of local mental health professionals for parents to contact. It is possible that children within the military clinic are receiving higher levels of CPG based care that is not reflected in the medical record. Revision of the ADHD documentation template is identified by the clinic staff as an intervention to improve documentation of the key guideline components. In response to this suggestion, an updated template was created and disseminated to the providers after their input, review, and approval.

While providers' prescribing practices are consistent with the guideline, they are conducting very few initial evaluations within the medical home. Efforts made to change this practice by providing education providers and clinic staff are not sustained 24 months post intervention. None of the providers currently assigned to the selected clinic were present for the initial implementation of the CPG 2 years ago, suggesting that the practice change may not have been passed along during provider turnover. Interestingly, the local culture of the patients and families maintains (or reverts back to) the practice of self-referring to the off-base psychologist. As advice, resources, support, and social connections are handed down to families as the relocate in and out of the selected community via social media, patients could be receiving misinformation, 
and there appears to be a disconnect between the patient and the medical home. Strict military regulations related to the use of social media on behalf of the USAF could be creating a barrier to disseminating health related information to the local patient population. The clinic staff suggests providing updated resources, clinic policies, etc. on the existing Facebook page for the medical group, but perceive this page to receive less exposure than the non-affiliated spouse's support page.

Sustaining change in clinical practice requires ongoing goal setting and performance evaluation with associated revision of the implementation plan if needed. The clinic staff are currently required to have a peer review process in place, which could be used to support adherence improved to CPGs. The key is to view the current process in a meaningful way rather than as just another required duty. The cyclical PDSA process supports this proactive approach to quality improvement by ensuring that goals have been established, data are being collected during the implementation phase, and the process is re-evaluated and adapted based on outcomes.

\section{Strengths and Limitations of the Design}

This project has several strengths, and is the first to evaluating provider adherence to the ADHD CPG within the military health system. The adapted provider questionnaire facilitates focused discussion related to current performance and perceived barriers to guideline adherence. The tool also provides an opportunity for staff to highlight areas of strengths/successes. Evaluation of current performance and discussion of perceived barriers will facilitate development of a plan to standardize and improve ADHD care among all DoD pediatric clinics. This study is limited by a small sample size, within one pediatric clinic, in a military treatment facility; therefore findings cannot be generalized to other settings. Another limitation of the current project is the small number of initial visits evaluated that were conducted by the PCM 
within the medical home. While the convenience sampling design could have omitted a number of initial evaluations conducted by the PCM, providers anecdotally agree that the sampled distribution of visit types is an accurate representation. Additionally, of the initial visits conducted by off-base psychologists, PCM validation of the findings is not evident in the initial visit encounter. Since records from the psychologists and/or schools are not available to the researcher, only the PCM's documentation of his/her interpretation can be used to measure adherence. The PCM's documentation does not consistently report the use of DSM criteria and/or validated parent and teacher rating scales when summarizing the interpretation of these findings; therefore this variable is unable to be accurately assessed related to initial visits.

The difficulty in obtaining approval for the project by the military also presents significant limitations, requiring a change in the sampling design from randomized to convenience sampling. Convenience sampling methods have the potential for bias, therefore care was taken to select subjects systematically. Barriers such as the length of time required to obtain approval and the complexity of the application process have potential to discourage researchers from choosing this population to study, and may contribute to the current scarcity of published work. Lastly, turnover of the clinical staff since the initial guideline implementation could be considered a limitation; alternatively, being that frequent relocation is one of the factors unique to this population, the potential for practice variation is illustrated, demonstrating the importance of implementing an established quality improvement process.

\section{Nursing Practice Implications}

The AAP has published evidence-based guidelines for youth with ADHD, placing an emphasis on chronic care (2011); however these guidelines have not been consistently adopted among pediatric primary care practices (Visser, 2015). Findings from a recent retrospective chart 
review designed to evaluate provider adherence to the CPG in a military pediatric clinic support previous findings of variable adherence in the civilian sector. DNP prepared APRNs are in an ideal position to guide evidence-based practice, improve chronic disease management (Fiandt, 2006), and to improve overall provider adherence to guidelines. DNPs have the unique ability to create clinical processes that utilize the full scope of both providers and nurses. Process improvement methodology such as the PDSA model provides an effective framework by which DNPs can utilize, thereby empowering staff to continue evaluating, improving, and sustaining quality care at the organizational level.

\section{Products of the DNP Project}

The current project is designed to evaluate provider adherence to the AAP CPG within the selected clinic 24 months after implementation of the guideline. Data gleaned from the chart review and provider/staff meeting are utilized to provide an opportunity for the clinic team to examine current practice and reflect on any issues that may be impeding guideline adherence. The PDSA model is used to aid in eliciting the providers' collective recommendations for future quality improvement efforts. Lessons learned from this project are being disseminated in an effort to raise awareness to the vulnerability of this population, and to facilitate further research and quality improvement among military children with ADHD. Current dissemination efforts include a recent poster presentation of the project at the National Association for Pediatric Nurse Practitioner's conference in Denver, CO (March, 2017), plans for additional submissions for poster and/or podium presentations at pediatric and military conferences, and journal publication. Contacts made at the national conference identify additional resources for dissemination such as the Triservice nursing research program. Approval will be requested from the Air Force 
Medicine Operations Agency for replication of this project in other Air Force pediatric clinics, followed by the Department of Defense level to reach all service branches.

\section{Recommendations for Future Research}

ADHD research. Large, national survey data is generalizable, feasible, and accessible to the public, but may fail to include the variable of interest. Additionally, the presence of unknown confounding factors not included in these datasets (such as parental military affiliation) are not able to be controlled for or evaluated for measures of association. The addition of demographic questions assessing family members' past and current military status to existing national surveys that evaluate children with ADHD is essential to enable further examination of this relationship. Since the numbers of questions on these surveys are limited, smaller studies may be needed to demonstrate the association between ADHD and parental military affiliation. If an association is found between the risk factor (parental military affiliation) and the outcome (ADHD), researchers can better advocate for including assessment of familial military status as part of routine demographic information.

While current research on ADHD in military children is scarce, studies by the RAND Corporation are being conducted to evaluate the impact of parental deployment on ADHD. The effects of deployment on military children certainly need to be understood to improve the quality of care to the population; however, the effects of frequent relocations have yet to be studied. Many of these children will experience a parent deploy in their lifetime, but most, if not all children with military parents will be forced to undergo relocations. The extent of the ramifications that frequent relocations place on the child, the family unit, and the military healthcare system must be identified to guide quality improvement measures and provision of 
care. Additionally, it is critical to create awareness of the vulnerability of the military child to pave the way for future research that has the potential to strengthen our military force.

The role of telemedicine in $A D H D$ care. This study demonstrates that quality improvement interventions are not easily sustained in the setting of military health care. Providers identify barriers such as limited access in the pediatric clinic and lack of quality pediatric mental health professionals. Telehealth has been utilized improve health care access and delivery, provide specialty consultations to patients in remote locations, and provide continuing education (AAP Committee on Pediatric Workforce, 2015; Dixon, Hook, \& McGowan, 2008; Myers, Vander Stoep, Zhou, McCarty, \& Katon, 2015). The AAP Committee on Pediatric Workforce advocates for the use of telehealth technologies in the medical home setting, and report that utilization of telemedicine can improve communication among clinicians and lead to efficient, cost effective, high quality care (2015). Broadening the scope of the pediatric primary care provider in the medical home reduces the burden of travel for patients and families, as well as the time spent by staff coordinating referrals, scheduling appointments, and tracking down records from outside providers (AAP Committee on Pediatric Workforce, 2015).

Although studies related to treatment of ADHD specifically via telehealth are limited, it has been shown to be effective in improving outcomes for children with other mental health conditions (Myers, Vander Stoep, Zhou, McCarty, \& Katon, 2015). Several studies have shown that the use of telemedicine in pediatrics is feasible, acceptable to primary care providers, parents, and youth, and is reliable in establishing diagnoses (Myers, Vander Stoep, Zhou, McCarty, \& Katon, 2015). One community-based randomized controlled trial evaluated effectiveness of a telehealth service delivery model for 233 children with ADHD, and revealed 
significant improvement in adherence to guideline-based care (Myers, Vander Stoep, Zhou, McCarty, \& Katon, 2015).

The military has been utilizing telemedicine for the last 20 years, and finds it to be cost effective and beneficial in treating traumatic brain injury, medical readiness, humanitarian missions, dermatology, and behavioral health conditions (Doarn \& Merrell, 2014). Interviews conducted with six USAF medical leaders confirm that telemedicine is not currently being widely used to treat pediatric mental health disorders such as ADHD in Air Force medical treatment facilities (MTF) (Y. Sculley, J. Bratz, J. Weatherwax, B. Brandlun, D. Frazine, A. Billups, personal communication, October, 2015). B. Brandlun \& A. Billups reveal that while most mental health clinics are equipped with telehealth capabilities, the technology is not consistently used for clinical patient care (personal communication, October, 2015). Utilization of telemedicine within the military medical home has potential to significantly improve guideline adherence, access to care, and to promote efforts that add to the current body of literature surrounding military children with ADHD.

\section{Conclusion}

A retrospective chart review evaluating military provider adherence to the ADHD CPG is consistent with findings of poor adherence in the civilian sector. A PDSA session conducted with clinic providers effectively identifies barriers to guideline adherence and interventions to improve the quality of care. Since previous quality improvement efforts to implement the CPG in the selected clinic are not sustainable throughout periods of provider turnover, the PDSA model's cyclical process is used to design evaluation methods alongside intervention development. Development of a standardized documentation template to address each of the guideline components is a product of this project in response to chart review findings and 
provider preferences. The validated chart abstraction tool adapted for this study is an efficient method to conduct future follow-up evaluations to CPG adherence, and is also available to the participating providers. Further studies are needed to compare findings from the selected clinic with other military medical homes providing care to children with ADHD. 


\section{References}

Air Force Medical Service. (2015, October). Retrieved from http://www.airforcemedicine.af.mil/About-Us on June 02, 2016.

Air Force Personnel Center - Air Force Personnel Demographics. (2016, March 31). Retrieved from http://www.afpc.af.mil/library/airforcepersonneldemographics.asp on June 02, 2016.

American Academy of Pediatrics. ADHD: Clinical practice guideline for the diagnosis, evaluation, and treatment of attention-deficit/ hyperactivity disorder in children and adolescents.(2011). Pediatrics, 128(5), 1007-1022. doi:10.1542/peds.2011.2654

American Academy of Pediatrics. Committee on Quality Improvement Subcommittee on Attention Deficit/Hyperactivity Disorder. (2000). Clinical practice guideline: Diagnosis and evaluation of the child with attention-Deficit/Hyperactivity disorder. Pediatrics, 105(5), 1158-1170. Retrieved on 10/10/2015 from http://ovidsp.ovid.com/ovidweb.cgi?T=JS\&CSC $=$ Y\&NEWS=N\&PAGE $=$ fulltext\&D $=$ yrovft $\underline{\mathrm{d} \& \mathrm{AN}=00006455-200005000-00050}$

American Academy of Pediatrics. Policy statement. Classifying Recommendations for Clinical Practice Guidelines. (2004). Pediatrics, 114(3), 874-877 4p. Retrieved on 10/10/2015 from https://search.ebscohost.com/login.aspx?direct=true\&AuthType=ip\&db=c8h\&AN=1066324 94\&site=ehost-live

American Academy of Pediatrics. Subcommittee on Attention-Deficit/Hyperactivity Disorder and Committee on Quality Improvement. (2001). Clinical practice guideline: Treatment of the school-aged child with attention-deficit/hyperactivity disorder. Pediatrics, 108(4), 10331044. Retrieved on 10/10/2015 from 
http://ovidsp.ovid.com/ovidweb.cgi?T $=\mathrm{JS} \& \mathrm{CSC}=\mathrm{Y} \& \mathrm{NEWS}=\mathrm{N} \& \mathrm{PAGE}=$ fulltext\&D=med4 $\underline{\mathrm{AN}}=11581465$

Akinbami, L. J., Liu, X., Pastor, P. N., \& Reuben, C. A. (2011). Attention deficit hyperactivity disorder among children aged 5-17 years in the united states, 1998-2009. NCHS Data Brief, (70)(70), 1-8.

American Psychiatric Association. (2013). Diagnostic and statistical manual of mental disorders:: DSM-5 ManMag.

Bareil, C., Duhamel, F., Lalonde, L., Goudreau, J., Hudon, É., Lussier, M., et al. (2015). Facilitating implementation of interprofessional collaborative practices into primary care: A trilogy of driving forces. Journal of Healthcare Management, 60(4), 287-300 14p. Retrieved from

https://search.ebscohost.com/login.aspx?direct=true\&AuthType=ip\&db=c8h\&AN=1098203 64\&site $=$ ehost-live

Barkley, R. A. (1999). In Quay HC H. A. (Ed.), Theories of attention-deficit/hyperactivity disorder. handbook of disruptive behavior disorders. . New York: Kluwer Academic/Plenum.

Baum RA, Epstein JN, \& Kelleher K. (2013). Healthcare reform, quality, and technology: ADHD as a case study. Current Psychiatry Reports, 15(7), 369. doi:http://dx.doi.org/10.1007/s11920-013-0369-0

Bhatara, V. S., Vogt, H. B., Patrick, S., Doniparthi, L., \& Ellis, R. (2006). Acceptability of a web-based attention-deficit/hyperactivity disorder scale (T-SKAMP) by teachers: A pilot study. Journal of the American Board of Family Medicine: JABFM, 19(2), 195-200.

Retrieved from 
http://ovidsp.ovid.com/ovidweb.cgi?T=JS\&CSC=Y\&NEWS=N\&PAGE $=$ fulltext\&D $=$ med5 $\underline{\& \mathrm{AN}}=16513909$

Bodenheimer, T., Wagner, E. H., \& Grumbach, K. (2002). Improving primary care for patients with chronic illness: The chronic care model, part 2. Jama, 288(15), 1909-1914.

CDC finds best practices guidelines used for most children assessed for ADHD...U.S. centers for disease control and Prevention's national center for health statistics. diagnostic experiences of children with attention-Deficit/Hyperactivity disorder. September 3, 2015, number 81.(2015). Mental Health Weekly, 25(35), 1-3 3p. doi:10.1002/mhw

Centers for Disease Control. Facts about ADHD (2017). Retrieved from https://www.cdc.gov/ncbddd/adhd/facts.html on March 9, 2017.

Chan, E., Hopkins, M. R., Perrin, J. M., Herrerias, C., \& Homer, C. J. (2005). Diagnostic practices for attention deficit hyperactivity disorder: A national survey of primary care physicians. Ambulatory Pediatrics, 5(4), 201-208. Retrieved from http://ovidsp.ovid.com/ovidweb.cgi? $=\mathrm{JS} \& \mathrm{CSC}=\mathrm{Y} \& \mathrm{NEWS}=\mathrm{N} \& \mathrm{PAGE}=$ fulltext\&D $=\mathrm{med} 5$ $\& \mathrm{AN}=16026184$

Chandra, A., \& London, A. S. (2013). Unlocking insights about military children and families. The Future of Children, 23(2), 187-198.

Clever, M., \& Segal, D. R. (2013). The demographics of military children and families. Future of Children, 23(2), 13-39. Retrieved from http://ovidsp.ovid.com/ovidweb.cgi? $\mathrm{T}=\mathrm{JS} \& \mathrm{CSC}=\mathrm{Y} \& \mathrm{NEWS}=\mathrm{N} \& \mathrm{PAGE}=$ fulltext $\& \mathrm{D}=$ medl $\underline{\mathrm{AN}}=25518690$ 
Dreyer, A. S., O'Laughlin, L., Moore, J., \& Milam, Z. (2010). Parental adherence to clinical recommendations in an ADHD evaluation clinic. Journal of Clinical Psychology, 66(10), 1101-1120. doi:http://dx.doi.org/10.1002/jclp.20718

Edberg, M. (2007). Essentials of health behavior: Social and behavioral theory in public health (p. 51-54). Sadbury, MA: Jones and Bartlett,

Epstein, J. N., Kelleher, K. J., Baum, R., Brinkman, W. B., Peugh, J., Gardner, W., et al. (2014). Variability in ADHD care in community-based pediatrics. Pediatrics, 134(6), 1136-1143. doi:10.1542/peds.2014-1500 [doi]

Epstein, J. N., Langberg, J. M., Lichtenstein, P. K., Kolb, R. C., \& Stark, L. J. (2010). Sustained improvement in pediatricians' ADHD practice behaviors in the context of a communitybased quality improvement initiative. Children's Health Care, 39(4), 296-311 16 p. doi:10.1080/02739615.2010.515931

Epstein, J. N., Langberg, J. M., Lichtenstein, P. K., Mainwaring, B. A., Luzader, C. P., \& Stark, L. J. (2008). Community-wide intervention to improve the attention-deficit/hyperactivity disorder assessment and treatment practices of community physicians. Pediatrics, 122(1), 19-27 9p. Retrieved from http://search.ebscohost.com/login.aspx?direct=true\&AuthType=ip\&db=c8h\&AN=10578661 $\underline{4 \& \text { site }}=$ ehost-live

Epstein, J. N., Langberg, J. M., Lichtenstein, P. K., Kolb, R., Altaye, M., \& Simon, J. O. (2011). Use of an internet portal to improve community-based pediatric ADHD care: A cluster randomized trial. Pediatrics, 128(5), e1201-8. doi:http://dx.doi.org/10.1542/peds.2011-0872

Foy JM, Kelleher KJ, Laraque D, \& American Academy of Pediatrics Task Force on Mental Health. (2010). Enhancing pediatric mental health care: Strategies for preparing a primary 
care practice. Pediatrics, 125(Suppl 3), S87-108. doi:http://dx.doi.org/10.1542/peds.2010$\underline{0788 \mathrm{E}}$

Friedman LS, Blaschke GS, Klam WP, \& Stein MT. (2006). ADHD, medication, and the military service: A pediatrician's dilemma. Journal of Developmental \& Behavioral Pediatrics, 27(2), 141-144. Retrieved from http://ovidsp.ovid.com/ovidweb.cgi?T $=\mathrm{JS} \& \mathrm{CSC}=\mathrm{Y} \& \mathrm{NEWS}=\mathrm{N} \& \mathrm{PAGE}=$ fulltext $\& \mathrm{D}=\mathrm{med} 5$ $\underline{\mathrm{AN}}=16682880$

Gallo, K. P., Hill, L. C., Hoagwood, K. E., \& Olin, S. S. (2015). A narrative synthesis of the components of and evidence for patient- and family-centered care. Clinical Pediatrics, doi:0009922815591883 [pii]

Gallus, J. A., Gouge, M. C., Antolic, E., Fosher, K., Jasparro, V., Coleman, S., ... \& Klafehn, J. L. (2014). Cross-Cultural Competence in the Department of Defense: An Annotated Bibliography (No. SR-71). ARMY RESEARCH INST FOR THE BEHAVIORAL AND SOCIAL SCIENCES FORT BELVOIR VA.

Geltman, P. L., Fried, L. E., Arsenault, L. N., Knowles, A. M., Link, D. A., Goldstein, J. N., et al. (2015). A planned care approach and patient registry to Improve adherence to clinical guidelines for the diagnosis and management of attention-Deficit/Hyperactivity disorder. Academic Pediatrics, 15(3), 289-296. doi:http://dx.doi.org.proxy.its.virginia.edu/10.1016/j.acap.2014.12.002

Gordon, M. K., Baum, R. A., Gardner, W., Kelleher, K. J., Langberg, J. M., Brinkman, W. B., et al. (2016). Comparison of performance on ADHD quality of care indicators: Practitioner self-report versus chart review. Journal of Attention Disorders, doi:1087054715624227 [pii] 
Gorman, G. H., Eide, M., \& Hisle-Gorman, E. (2010). Wartime military deployment and increased pediatric mental and behavioral health complaints. Pediatrics, 126(6), 1058-1066. doi:10.1542/peds.2009-2856 [doi]

Graser, J. C., Blum, D., \& Brancato, K. (2010). The Economics of Air Force Medical Service Readiness. Rand Corporation. Retrieved from http://www.rand.org/content/dam/rand/pubs/technical_reports/2010/RAND_TR859.pdf on June 02, 2016.

Hisle-Gorman, E., Eide, M., Coll, E. J., \& Gorman, G. H. (2014). Attention deficit hyperactivity disorder and medication use by children during parental military deployments. Military Medicine, 179(5), 573-578. doi:10.7205/MILMED-D-13-00334

Holly, C. (2014). In Zuccarini M. (Ed.), Scholarly inquiry and the DNP capstone. New York, NY: Springer Publishing Company.

Homer, C. J., Klatka, K., Romm, D., Kuhlthau, K., Bloom, S., Newacheck, P., et al. (2008). A review of the evidence for the medical home for children with special health care needs. Pediatrics, 122(4), e922-37. doi:10.1542/peds.2007-3762 [doi]

Institute for healthcare improvement. (2016). Retrieved 07/10, 2016, from http://www.ihi.org/resources/Pages/HowtoImprove/ScienceofImprovementSpreadingChang es.aspx

Jensen PS, Hinshaw SP, Swanson JM, Greenhill LL, Conners CK, Arnold LE, et al. (2001). Findings from the NIMH multimodal treatment study of ADHD (MTA): Implications and applications for primary care providers. Journal of Developmental \& Behavioral Pediatrics, 22(1), 60-73. Retrieved from 
http://ovidsp.ovid.com/ovidweb.cgi? $=\mathrm{JS} \& \mathrm{CSC}=\mathrm{Y} \& N E W S=\mathrm{N} \& \mathrm{PAGE}=$ fulltext $\& \mathrm{D}=\mathrm{med} 4$ $\underline{\mathrm{AN}}=11265923$

Keating, E. G., Massey, H. G., Mele, J. D., \& Mundell, B. F. (2010). An Analysis of the Populations of the Air Force's Medical and Professional Officer Corps. RAND PROJECT AIR FORCE SANTA MONICA CA. Retrieved from http://www.rand.org/content/dam/rand/pubs/technical_reports/2010/RAND_TR782.pdf on 02 June, 2016. Klein, R. G., Abikoff, H., Hechtman, L., \& Weiss, G. (2004). Design and rationale of controlled study of long-term methylphenidate and multimodal psychosocial treatment in children with ADHD. Journal of the American Academy of Child \& Adolescent Psychiatry, 43(7), 792-801. Retrieved from http://ovidsp.ovid.com/ovidweb.cgi? $=\mathrm{JS} \& \mathrm{CSC}=\mathrm{Y} \& \mathrm{NEWS}=\mathrm{N} \& \mathrm{PAGE}=$ fulltext $\& \mathrm{D}=\mathrm{med} 5$ $\underline{\mathrm{AN}}=15213580$

Langberg, J. M., Vaughn, A. J., Brinkman, W. B., Froehlich, T., \& Epstein, J. N. (2010). Clinical utility of the Vanderbilt ADHD rating scale for ruling out comorbid learning disorders. Pediatrics, 126(5), e1033-8. doi:10.1542/peds.2010-1267 [doi]

Lange, G., Sheerin, D., Carr, A., Dooley, B., Barton, V., Marshall, D., et al. (2005). Family factors associated with attention deficit hyperactivity disorder and emotional disorders in children. Journal of Family Therapy, 27(1), 76-96. doi:10.1111/j.1467-6427.2005.00300.x

Leslie, L. K., Weckerly, J., Plemmons, D., Landsverk, J., \& Eastman, S. (2004). Implementing the american academy of pediatrics attention-deficit/hyperactivity disorder diagnostic guidelines in primary care settings. Pediatrics, 114(1), 129-140. Retrieved from http://ovidsp.ovid.com/ovidweb.cgi?T=JS\&CSC=Y\&NEWS=N\&PAGE=fulltext\&D=med5 $\underline{\mathrm{AN}}=15231919$ 
Lester, P., \& Bursch, B. (2011). The long war comes home: Mitigating risk and promoting resilience in military children and families. Psychiatric Times, 28(7), 26-29. Retrieved from http://search.ebscohost.com/login.aspx?direct=true\&AuthType=ip\&db=c8h\&AN=10824436 $\underline{2 \& \text { site }}=$ ehost-live

Lester, P., Stein, J. A., Saltzman, W., Woodward, K., MacDermid, S. W., Milburn, N., et al. (2013). Psychological health of military children: Longitudinal evaluation of a familycentered prevention program to enhance family resilience. Military Medicine, $178(8), 838$ 845. doi:10.7205/MILMED-D-12-00502

Malouin, R. A., \& Turner, J. (2009). A review of the evidence for the medical home for children with special health care needs...pediatrics. 2008;122(4). available at:

Www.pediatrics.org/cgi/content/full/122/4/e922. Pediatrics, 123(2), e369-e369 1p. doi:10.1542/peds.2008-3250

Mansfield, A. J., Kaufman, J. S., Engel, C. C., \& Gaynes, B. N. (2011). Deployment and mental health diagnoses among children of US army personnel. Archives of Pediatrics \& Adolescent Medicine, 165(11), 999-1005. doi:10.1001/archpediatrics.2011.123 [doi]

Marshall, R. C., Doperak, M., Milner, M., Motsinger, C., Newton, T., Padden, M., et al. (2011). Patient-centered medical home: An emerging primary care model and the military health system. Military Medicine, 176(11), 1253-1259. Retrieved from http://search.ebscohost.com/login.aspx?direct=true $\& \mathrm{db}=\mathrm{mth} \& \mathrm{AN}=67216278 \&$ site= $=$ ehost$\underline{\text { live } \& \text { scope }}=$ site

McElligott, J. T., Lemay, J. R., O'Brien, E. S., Roland, V. A., Basco, W. T.,Jr, \& Roberts, J. R. (2014). Practice patterns and guideline adherence in the management of attention 
deficit/hyperactivity disorder. Clinical Pediatrics, 53(10), 960-966.

doi:10.1177/0009922814540985 [doi]

Meadows, S. O., Beckett, M. K., Bowling, K., Golinelli, D., Fisher, M. P., Martin, L. T., et al. (2015). Family resilience in the military: Definitions, models, and policies. Santa Monica, CA: RAND Corporation.

Metzger, R., \& Rivers, C. (2014). Advanced practice nursing organizational leadership model. The Journal for Nurse Practitioners, 10(5), 337-343.

doi:http://dx.doi.org.proxy.its.virginia.edu/10.1016/j.nurpra.2014.02.015

Milburn, N. G., \& Lightfoot, M. (2013). Adolescents in wartime US military families: A developmental perspective on challenges and resources. Clinical Child and Family Psychology Review, 16(3), 266-277. doi:10.1007/s10567-013-0144-0 [doi]

Millegan, J., McLay, R., \& Engel, C. (2014). The effect of geographic moves on mental healthcare utilization in children. Journal of Adolescent Health, 55(2), 276-280. doi:http://dx.doi.org/10.1016/j.jadohealth.2014.01.009

Moscicki, E. K., Clarke, D. E., Kuramoto, S. J., Kraemer, H. C., Narrow, W. E., Kupfer, D. J., et al. (2013). Testing DSM-5 in routine clinical practice settings: Feasibility and clinical utility. Psychiatric Services (Washington, D.C.), 64(10), 952-960. doi:10.1176/appi.ps.201300098 [doi]

MTA Cooperative, G. (2004). National institute of mental health multimodal treatment study of ADHD follow-up: 24-month outcomes of treatment strategies for attentiondeficit/hyperactivity disorder. Pediatrics, 113(4), 754-761. Retrieved from http://ovidsp.ovid.com/ovidweb.cgi?T=JS\&CSC=Y\&NEWS=N\&PAGE=fulltext\&D=med5 $\underline{\mathrm{AN}}=15060224$ 
Myers K, Vander Stoep A, Zhou C, McCarty CA, \& Katon W. (2015). Effectiveness of a telehealth service delivery model for treating attention-deficit/hyperactivity disorder: A community-based randomized controlled trial. Journal of the American Academy of Child \& Adolescent Psychiatry, 54(4), 263-274. doi:http://dx.doi.org/10.1016/j.jaac.2015.01.009

National Center for Health Statistics (2011). National Survey of Children's Health. Retrieved from https://www.cdc.gov/nchs/slaits/nsch.htm on March 5, 2017.

National Center for Health Statistics (2010). National Survey of Children with Special Healthcare Needs. Retrieved from https://www.cdc.gov/nchs/slaits/cshcn.htm on March 5, 2017.

National institute of mental health multimodal treatment study of ADHD follow-up: 24-month outcomes of treatment strategies for attention-deficit/hyperactivity disorder.(2004). Pediatrics, 113(4), 754-761 8p. Retrieved from http://www.proxy.its.virginia.edu/login?url=http://search.ebscohost.com/login.aspx?direct=t $\underline{\text { rue } \& \mathrm{db}=\mathrm{c} 8 \mathrm{~h} \& \mathrm{AN}=106635597 \& \text { site }=\text { ehost-live } \& \text { scope }=\text { site }}$

National Military Family Association (2017). Mission. Retrieved from http://www.militaryfamily.org/about-us/mission.html on March 5, 2017.

Nelson EL, Duncan AB, Peacock G, \& Bui T. (2012). Telemedicine and adherence to national guidelines for ADHD evaluation: A case study. Psychological Services, 9(3), 293-297. doi:http://dx.doi.org/10.1037/a0026824

Office of Disease Prevention and Health Promotion. (2015). Healthy people 2020: Mental health and mental disorders.. Retrieved 10/30, 2015, from http://www.healthypeople.gov/2020/leading-health-indicators/2020-lhi-topics/Mental$\underline{\text { Health }}$ 
Olson, B. G., Rosenbaum, P. F., Dosa, N. P., \& Roizen, N. J. (2005). Improving guideline adherence for the diagnosis of ADHD in an ambulatory pediatric setting. Ambulatory Pediatrics, 5(3), 138-142. Retrieved from http://ovidsp.ovid.com/ovidweb.cgi? $=\mathrm{JS} \& \mathrm{CSC}=\mathrm{Y} \& N E W S=\mathrm{N} \& \mathrm{PAGE}=$ fulltext $\& \mathrm{D}=\mathrm{med} 5$ $\underline{\mathrm{AN}}=15913406$

Park, N. (2011). Military children and families: Strengths and challenges during peace and war. American Psychologist, 66(1), 65-72. doi:10.1037/a0021249

Pennington, B. F., \& Ozonoff, S. (1996). Executive functions and developmental psychopathology. Child Psychology \& Psychiatry \& Allied Disciplines, 37(1), 51-87. doi:10.1111/j.1469-7610.1996.tb01380.x

Perou, R., Bitsko, R. H., Blumberg, S. J., Pastor, P., Ghandour, R. M., Gfroerer, J. C., et al. (2013). Mental health surveillance among children--united states, 2005-2011. MMWR Supplements, 62(2), 1-35. doi:su6202a1 [pii]

Polaha, J., Cooper, S. L., Meadows, T., \& Kratochvil, C. J. (2005). The assessment of attentiondeficit/hyperactivity disorder in rural primary care: The portability of the american academy of pediatrics guidelines to the "real world". Pediatrics, 115(2), e120-6. Retrieved from http://ovidsp.ovid.com/ovidweb.cgi?T $=\mathrm{JS} \& \mathrm{CSC}=\mathrm{Y} \& \mathrm{NEWS}=\mathrm{N} \& \mathrm{PAGE}=$ fulltext $\& \mathrm{D}=\mathrm{med} 5$ \&AN=15687419 on June 5, 2016.

Polanczyk, G., \& Jensen, P. (2008). Epidemiologic considerations in attention deficit hyperactivity disorder: A review and update. Child and Adolescent Psychiatric Clinics of North America, 17(2), 245-60, vii. doi:10.1016/j.chc.2007.11.006 [doi] 
Polanczyk, G., de Lima, M. S., Horta, B. L., Biederman, J., \& Rohde, L. A. (2007). The worldwide prevalence of ADHD: A systematic review and metaregression analysis. Ajp, 164(6), 942-948. doi:10.1176/ajp.2007.164.6.942

Reeves, W. C., Strine, T. W., Pratt, L. A., Thompson, W., Ahluwalia, I., Dhingra, S. S., et al. (2011). Mental illness surveillance among adults in the united states. MMWR Surveill Summ, 60(Suppl 3), 1-29.

Ronis, S. D., Baldwin, C. D., Blumkin, A., Kuhlthau, K., \& Szilagyi, P. G. (2015). Patientcentered medical home and family burden in attention-deficit hyperactivity disorder. Journal of Developmental \& Behavioral Pediatrics, 36(6), 417-425. doi:10.1097/DBP.0000000000000161

Rowland, A. S., Skipper, B. J., Umbach, D. M., Rabiner, D. L., Campbell, R. A., Naftel, A. J., et al. (2015). The prevalence of ADHD in a population-based sample. Journal of Attention Disorders, 19(9), 741-754. doi:10.1177/1087054713513799

Rushton, J. L., Fant, K. E., \& Clark, S. J. (2004). Use of practice guidelines in the primary care of children with attention-deficit/hyperactivity disorder. Pediatrics, 114(1), e23-8. Retrieved from

http://ovidsp.ovid.com/ovidweb.cgi?T=JS\&CSC $=$ Y\&NEWS $=$ N\&PAGE $=$ fulltext\&D $=$ med5 $\underline{\mathrm{AN}}=15231969$

Schreiber, J. E., Possin, K. L., Girard, J. M., \& Rey-Casserly, C. (2014). Executive function in children with attention deficit/hyperactivity disorder: The NIH EXAMINER battery. Journal of the International Neuropsychological Society, 20(1), 41-51. doi:10.1017/S1355617713001100 
Shura, R. D., Miskey, H. M., Williams, V. G., Jadidian, A., \& Rowland, J. A. (2016). Informing evidence-based assessment of ADHD in veterans and service members. Military Psychology, , No Pagination Specified. doi:10.1037/mil0000138

Sia C, Tonniges TF, Osterhus E, \& Taba S. (2004). History of the medical home concept. Pediatrics, 113(5 Suppl), 1473-1478. Retrieved from http://ovidsp.ovid.com/ovidweb.cgi?T=JS\&CSC=Y\&NEWS=N\&PAGE=fulltext\&D=med5 $\underline{\mathrm{AN}}=15121914$

Siegel, B. S., Davis, B. E., \& Committee on Psychosocial Aspects of Child and Family Health and Section on Uniformed Services. (2013). Health and mental health needs of children in US military families. Pediatrics, 131(6), e2002-15. doi:10.1542/peds.2013-0940 [doi]

Thapar, A., Holmes, J., Poulton, K., \& Harrington, R. (1999). Genetic basis of attention deficit and hyperactivity. The British Journal of Psychiatry : The Journal of Mental Science, 174, $105-111$

Thomas, R., Sanders, S., Doust, J., Beller, E., \& Glasziou, P. (2015). Prevalence of attentiondeficit/hyperactivity disorder: A systematic review and meta-analysis. Pediatrics, 135(4), e994-1001. doi:10.1542/peds.2014-3482 [doi]

Trautmann, J., Alhusen, J., \& Gross, D. (2015). Impact of deployment on military families with young children: A systematic review. Nursing Outlook, 63(6), 656-679. doi:http://dx.doi.org/10.1016/j.outlook.2015.06.002

United States Department of the Air Force Air University. (2016). Global Engagement: A Vision for the 21st Century Air Force. Retrieved from http://www.airuniversity.af.mil on March 5, 2017. 
United States Department of the Air Force (2016). Mission, Retrieved from https://www.airforce.com/mission June 02, 2016.

United States Department of the Air Force. (2015). Medical Care Management (AFI 44-102).

Retrieved from http://static.e-publishing.af.mil/production/1/af sg/publication/afi44102/afi44-102.pdf on 02 June, 2016.

United States Department of the Air Force (2014). Medical Support to Family Member Relocation and Exceptional Family Member Program (AFI 40-701). Retrieved from http://static.e-publishing.af.mil/production/1/af_sg/publication/afi40-701/afi40-701.pdf on March 5, 2017.

United States Department of the Air Force. (2014, November). Patient Centered Medical Home Operations (AFI 44-171). Retrieved from http://static.epublishing.af.mil/production/1/af_sg/publication/afi44-171/afi44-171.pdf on 10 March, 2017.

United States Department of the Air Force. (2012, June). Tricare Operations and Patient Administration Functions (AFI 41-210). Retrieved from http://static.epublishing.af.mil/production/1/af_sg/publication/afi41-210/afi41-210.pdf on 02 June, 2016. United States Food and Drug Administration. (2013). Retrieved 01/09, 2017, from http://www.fda.gov/Drugs/DrugSafety/PostmarketDrugSafetyInformationforPatientsandPro viders/ucm107918.htm

Van Cleave J, \& Leslie LK. (2008). Approaching ADHD as a chronic condition: Implications for long-term adherence. Journal of Psychosocial Nursing \& Mental Health Services, 46(8), 2837. Retrieved from 
http://ovidsp.ovid.com/ovidweb.cgi?T $=\mathrm{JS} \& \mathrm{CSC}=\mathrm{Y} \& \mathrm{NEWS}=\mathrm{N} \& \mathrm{PAGE}=$ fulltext\&D=med5 $\underline{\& \mathrm{AN}}=18777966$

Visser SN, Bitsko RH, Danielson ML, Ghandour RM, Blumberg SJ, Schieve LA, et al. (September, 2015). Treatment of attention Deficit/Hyperactivity disorder among children with special health care needs. Journal of Pediatrics, 166(6), 1423-30.e1-2. doi:http://dx.doi.org/10.1016/j.jpeds.2015.02.018

Visser, S. N., Visser, S. N., Zablotsky, B., Holbrook, J. R., Danielson, M. L., \& Bitsko, R. H. (February, 2015). Diagnostic experiences of children with attention-Deficit/Hyperactivity disorder. National Health Statistics Reports, (81)(81), 1-8.

Visser, S. N., Danielson, M. L., Bitsko, R. H., Holbrook, J. R., Kogan, M. D., Ghandour, R. M., et al. (2014). Trends in the parent-report of health care provider-diagnosed and medicated attention-deficit/hyperactivity disorder: United states, 2003-2011. Journal of the American Academy of Child \& Adolescent Psychiatry, 53(1), 34-46. doi:10.1016/j.jaac.2013.09.001

Vreeman, R. C., Madsen, K. A., Vreeman, D. J., Carroll, A. E., \& Downs, S. M. (2006). Compliance with guidelines for ADHD: A pilot study of an evaluation tool. The Journal of Pediatrics, 149(4), 568-571.e1. doi:http://dx.doi.org.proxy.its.virginia.edu/10.1016/j.jpeds.2006.07.024

Wagner, E. H. (1998). Chronic disease management: What will it take to improve care for chronic illness? Effective Clinical Practice : ECP, 1(1), 2-4.

World Health Organization. (2015). Service delivery and Safety. Retrieved from http://www.who.int/servicedeliverysafety/about/en/ on October 10, 2015. 
Wolraich, M., Brown, L., \& Brown, R. (2011). Implementing the key action statements: An algorithm and explanation for process of care for the evaluation, diagnosis, treatment, and monitoring of ADHD in children and adolescents. Pediatrics, 128(5)

Wolraich, M. L., Wibbelsman, C. J., Brown, T. E., Evans, S. W., Gotlieb, E. M., Knight, J. R., et al. (2005). Attention-deficit/hyperactivity disorder among adolescents: A review of the diagnosis, treatment, and clinical implications. Pediatrics, 115(6), 1734-1746 13p. Retrieved from https://search.ebscohost.com/login.aspx?direct=true\&AuthType=ip\&db=c8h\&AN=1065222 21\&site $=$ ehost-live

Wolraich, M. L., McKeown, R. E., Visser, S. N., Bard, D., Cuffe, S., Neas, B., et al. (2014). The prevalence of ADHD: Its diagnosis and treatment in four school districts across two states. Journal of Attention Disorders, 18(7), 563-575. doi:10.1177/1087054712453169 
Potentially relevant studies in the initial searching $(n=378)$

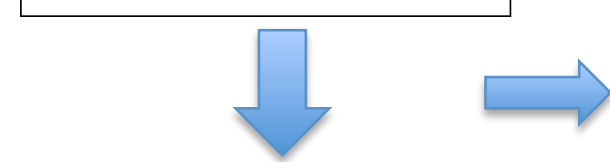

Studies after reviewing the titles $(n=70)$
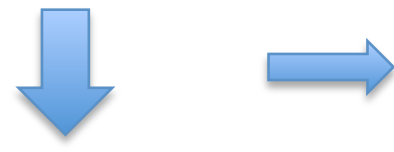
34 did not meet inclusion criteria according to abstract

Studies reviewed for more detailed evaluation $(n=36)$
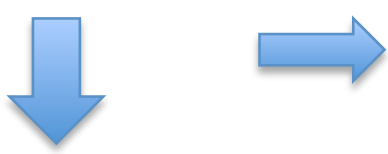

12 articles excluded (poor design, insufficient sample size, or outcome measures not based on CPG)

Studies met inclusion criteria $(n=24)$
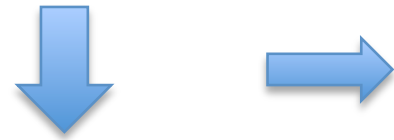

0 articles added by inspecting reference lists

Studies included in final review $(n=24)$

Figure 1. Flow chart demonstrating the literature review process. 
Table 1

Adherence to ADHD Guidelines

\begin{tabular}{|c|c|c|}
\hline & Author & Sample and Findings \\
\hline Provider & Chan, Hopkins, Perrin, & National survey pediatric PCPs $(n=2000)(1999)$ \\
\hline \multirow[t]{10}{*}{ Report } & Herrerias, \& Homer, & $-28 \%$ use of DSM criteria \\
\hline & 2005 & $-83 \%$ use school information \\
\hline & & $-70 \%$ use ADHD-specific rating scales \\
\hline & & $-25 \%$ obtain screening labs \\
\hline & & $-74 \%-91 \%$ assess for comorbid conditions \\
\hline & McElligott et al., (2014) & $\begin{array}{l}\text { Provider survey }(\mathrm{n}=42) \text { - significant variation in } \\
\text { recommended follow-up intervals }\end{array}$ \\
\hline & & $\begin{array}{l}\text {-differences in practice patterns exist by } \\
\text { practitioner experience, location, and practice type. }\end{array}$ \\
\hline & Rushton, Fant, \& Clark, & Survey primary care physicians $(n=1,374)(2002)$ \\
\hline & $(2004)$ & $-61 \%$ report following guidelines \\
\hline & & $\begin{array}{l}-53 \% \text { recommended routine medication follow-up } \\
\text { visits; } 53 \% \text { recommended behavior therapy }\end{array}$ \\
\hline Parental & Dreyer, O’Laughlin, & Survey of caregivers $(n=80)$ \\
\hline \multirow[t]{9}{*}{ Report } & Moore, \& Milam, (2010) & $\begin{array}{l}-80 \% \text { adherence to recommendations for ADHD } \\
\text {-medication and self-help recommendations, had } \\
\text { higher parental compliance than referrals to } \\
\text { psychological services }\end{array}$ \\
\hline & Visser et al., (Feb, 2015) & $\begin{array}{l}\text { The National Survey }(n=9,459) \text { parents }(2009 \text { - } \\
\text { 2010) }\end{array}$ \\
\hline & & $-74 \%$ had received medication treatment \\
\hline & & $-44 \%$ had received behavior therapy \\
\hline & & $-50 \%$ of preschoolers received behavioral therapy \\
\hline & Visser et al., (Sept, & The National Survey (2014) \\
\hline & 2015) & $-53 \%$ diagnosed by their primary care physicians \\
\hline & & $-89.9 \%$ diagnosed with behavior rating scale \\
\hline & & $-81.9 \%$ had school information obtained \\
\hline \multirow[t]{6}{*}{ Chart Review } & Epstein et al., (2014) & Random sample $(\mathrm{n}=1594), 188$ PCPs \\
\hline & & $-70.4 \%$ DSM \\
\hline & & $-93 \%$ receiving medication \\
\hline & & $-13 \%$ receiving psychosocial treatment \\
\hline & & $-10 \% / 7 \%$ parent/teacher rating scales \\
\hline & & $-47 \%$ follow up within 1 month of starting meds \\
\hline \multirow{3}{*}{$\begin{array}{l}\text { Survey and } \\
\text { Chart Review }\end{array}$} & Gordon et al., (2016) & Providers $(n=188)$ charts $(n=1,599)$ \\
\hline & & -adherence over-reported \\
\hline & & -self-report not valid adherence measure \\
\hline
\end{tabular}

Note. This table presents condensed findings from the review of literature. See appendix A for a comprehensive study table. 
Table 2

Interventions to Improve Adherence to ADHD Guidelines

\begin{tabular}{|c|c|c|c|}
\hline & Author & Sample and Study Design & Findings \\
\hline \multirow[t]{2}{*}{$\begin{array}{l}\text { Education } \\
\text { Protocols }\end{array}$} & $\begin{array}{l}\text { Epstein et al., } \\
2008 \text { and } 2010\end{array}$ & $\begin{array}{l}\mathrm{N}=84 \mathrm{PCP}, \mathrm{n}=19 \text { practices } \\
\text { Provider education } \\
\text { PDSA model for staff } \\
\text { Followed study done to show } \\
\text { sustainability }\end{array}$ & $\begin{array}{l}\text { Parent/teacher rating } \\
\text { scales } 52 \% \text { to } 100 \% \\
\text { follow up visits with } \\
\text { rating scales to assess } \\
\text { response to medications } \\
9 \% \text { to } 40 \% \\
\text { Improvements sustained } \\
\text { at } 2 \text { yr evaluation } \\
\text { (Epstein et al., 2010). }\end{array}$ \\
\hline & $\begin{array}{l}\text { Polaha, } \\
\text { Cooper, } \\
\text { Meadows, \& } \\
\text { Kratochvil, } \\
2005\end{array}$ & $\begin{array}{l}\text { Education protocol for } 2 \text { rural } \\
\text { practices }\end{array}$ & $\begin{array}{l}\text { Parent and/or teacher } \\
\text { rating scales } 21 \% \text { to } 88 \% \\
\text {-improvements } \\
\text { maintained } 2-3 \text { yrs after } \\
\text { training }\end{array}$ \\
\hline \multirow[t]{2}{*}{$\begin{array}{l}\text { Decision } \\
\text { Support } \\
\text { Tool }\end{array}$} & $\begin{array}{l}\text { Carroll et al., } \\
2013\end{array}$ & $\begin{array}{l}\mathrm{N}=84 \text { patients, } 4 \text { practices } \\
\text {-computer program with guideline- } \\
\text { based prompts } \\
\text {-pre-screening questionnaire } \\
\text {-provider worksheet } \\
\text {-rating forms scored by computer } \\
\text { system and a summary sheet is } \\
\text { generated }\end{array}$ & $\begin{array}{l}\text { DSM criteria increased } \\
\text { from } 60 \% \text { to } 81 \%\end{array}$ \\
\hline & $\begin{array}{l}\text { Olson, } \\
\text { Rosenbaum, } \\
\text { Dosa, \& } \\
\text { Roizen, } 2005\end{array}$ & $\begin{array}{l}\mathrm{N}=31 \text { pcp, } \mathrm{n}=63 \text { patients diagnostic } \\
\text { protocol and toolkit for diagnosing } \\
\text { ADHD } \\
\text {-Provider education } \\
\text {-An evaluation packet- home/ } \\
\text { school rating scales provided; } \\
\text { forms returned prior to scheduling } \\
\text {-semi-structured interview with } \\
\text { DSM criteria and assessment for } \\
\text { comorbidities }\end{array}$ & $\begin{array}{l}\text {-Improvement in } \\
\text { guideline adherence } \\
\text { across all measured } \\
\text { components } \\
\text {-provider adherence rates } \\
4 \% \text { to } 82 \%\end{array}$ \\
\hline Web Portal & $\begin{array}{l}\text { Bhatara, Vogt, } \\
\text { Patrick, } \\
\text { Doniparthi, \& } \\
\text { Ellis, } 2004\end{array}$ & $\begin{array}{l}\text { Teachers completed web-based } \\
\text { scales to monitor treatment } \\
\text { response; } n=17\end{array}$ & $\begin{array}{l}89.5 \% \text { - rated program } \\
\text { easier, shorter, simpler, } \\
\text { and more informative } \\
\text { than paper-based scales }\end{array}$ \\
\hline
\end{tabular}




\begin{tabular}{|c|c|c|c|}
\hline & $\begin{array}{l}\text { Epstein et al., } \\
2011\end{array}$ & $\begin{array}{l}\text { cluster-randomized trial }(\mathrm{n}=49) \\
\text { pcps at } 8 \text { practices } \\
\text { Internet portal intervention } \\
4 \text { training sessions via } \\
\text { videoconferencing } \\
\text {-Internet portal allowed for input } \\
\text { from parents, teachers, and PCP } \\
\text {-computerized algorithms scored } \\
\text { and interpreted data, then created a } \\
\text { report } \\
\text {-medication monitoring and } \\
\text { titration tools } \\
\text {-online report card to identify areas } \\
\text { for improvement in guideline } \\
\text { adherence } \\
\text { PDSA cycles taught for continued } \\
\text { improvement }\end{array}$ & $\begin{array}{l}\text { improved adherence in } \\
\text { utilization of ADHD } \\
\text { rating scales (parent- } \\
\text { Cohen's } d=0.69 \text {; teacher- } \\
d=0.68) \\
\text {-DSM criteria }(d=0.85) \\
\text {-treatment response } \\
(d=1.01) \\
\text {-decreased reliance on } \\
\text { mental health referrals for } \\
\text { diagnosis } \\
\text {-Pediatricians reported } \\
\text { high levels of satisfaction } \\
\text { with program }\end{array}$ \\
\hline \multirow[t]{2}{*}{ Telehealth } & $\begin{array}{l}\text { Myers, Stoep, } \\
\text { Zhou, } \\
\text { McCarty, \& } \\
\text { Katon, } 2015\end{array}$ & $\begin{array}{l}\text { Randomized controlled trial } \\
\text { ( } \mathrm{n}=233 \text { ) patients } \\
\text { Telehealth service delivery model } \\
\text { provided direct patient care by a } \\
\text { child psychiatrist, training of local } \\
\text { community therapists to provide } \\
\text { behavior therapy, and allowed for } \\
\text { collaboration between the PCP and } \\
\text { specialist }\end{array}$ & $\begin{array}{l}\text { High adherence to } \\
\text { guideline-based care } \\
\text { (telepsychiatrists } 91.6 \% \\
+/-9.5 \% \text { reliability; } \\
\text { therapists } 94.2 \%+/-9.7 \% \\
\text { reliability). }\end{array}$ \\
\hline & $\begin{array}{l}\text { Nelson } \\
\text { Duncan, } \\
\text { Peacock, \& } \\
\text { Bui, 2012 }\end{array}$ & $\begin{array}{l}\text { Case study- school-based } \\
\text { telemedicine setting }(\mathrm{n}=22) \text { patients } \\
\text { Real-time videoconferencing was } \\
\text { used to promote communication } \\
\text { among patients, families, and the } \\
\text { specialty mental health team }\end{array}$ & $\begin{array}{l}\text { High rates of adherence to } \\
\text { the guidelines were } \\
\text { demonstrated among all } \\
\text { areas. }\end{array}$ \\
\hline $\begin{array}{l}\text { Patient } \\
\text { Registry }\end{array}$ & $\begin{array}{l}\text { Geltman et al., } \\
2015\end{array}$ & $\begin{array}{l}\text { Electronic patient registry } \\
\text { to coordinate and track care and } \\
\text { ensure use of validated rating scales } \\
\text {-adapt clinical work flows to } \\
\text { incorporate guideline based care } \\
\text {-track compliance over time }\end{array}$ & $\begin{array}{l}\text { increased follow-up visits } \\
\text {-more Vanderbilt scales } \\
\text { than control sites }(48.5 \% \\
\text { vs } 23.1 \%, p=.024) \\
\text {-modest improvement in } \\
\text { diagnostic and treatment } \\
\text { process }\end{array}$ \\
\hline
\end{tabular}

Note. This table presents condensed findings from the review of literature. See Appendix B for a comprehensive study table. 


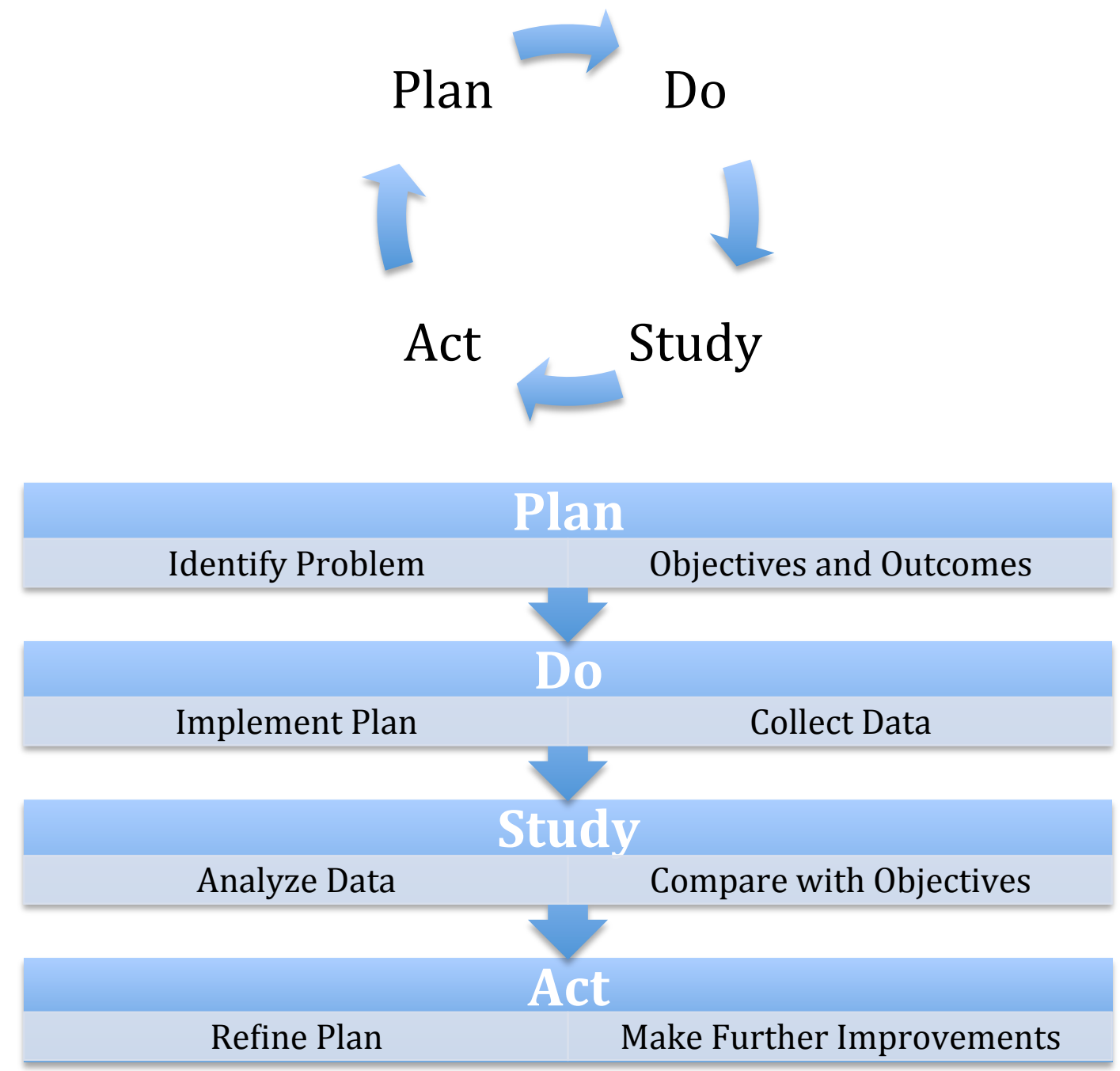

Figure 2. Plan-Do-Study-Act Model is a quality improvement method used to implement ongoing process improvements by clinical staff working in a busy environment. The model emphasizes continuous data collection and revision of the plan to promote ongoing improvement efforts and/or sustainability efforts. The cycle was originally developed by Walter A. Shewhart, and referred to as the "Plan-Do-Check-Act". The model was later revised by W. Edwards Deming, who replaced the "Check" step with "Study"(Institute for Healthcare Improvement (IHI), 2016). 
Table 3

Individual Variables Used to Measure CPG Adherence

\begin{tabular}{|c|c|c|c|}
\hline In Template & Rate & Not in Template & Rate \\
\hline History & 1 & Hearing screen & 0.053 \\
\hline Physical exam & 0.947 & Vision Screening & 0.263 \\
\hline Neurological exam & 0.632 & Relocation & 0.129 \\
\hline $\begin{array}{l}\text { Validated Parent } \\
\text { Instrument }\end{array}$ & 0.75 & Deployment & 0 \\
\hline $\begin{array}{l}\text { Validated Teacher } \\
\text { Instrument }\end{array}$ & 0.75 & Independence & 0.194 \\
\hline $\begin{array}{l}\text { Re-evaluation of } \\
\text { symptoms }\end{array}$ & 0.93 & Self esteem & 0.032 \\
\hline School performance & 0.952 & Safety & 0.161 \\
\hline Depression/Anxiety & 0.339 & $\begin{array}{l}\text { Behavior Therapy (BHT) } \\
\text { Education provided }\end{array}$ & 0 \\
\hline $\begin{array}{l}\text { Family History for related } \\
\text { symptoms }\end{array}$ & 0.947 & $\begin{array}{l}\text { Behavior Therapy parent training } \\
\text { provided }\end{array}$ & 0 \\
\hline Sleep disorder & 0.871 & Mental Health referral & 0.113 \\
\hline Tics & 0.565 & School counseling referral & 0.016 \\
\hline $\begin{array}{l}\text { History of cardiac } \\
\text { symptoms }\end{array}$ & 0.895 & $\begin{array}{l}\text { Assess response to Behavior } \\
\text { Therapy }\end{array}$ & 0 \\
\hline Relationships & 0.677 & Discuss compliance to BHT & 0.16 \\
\hline Disruptive behavior & 0.694 & Psychoeducational evaluation & 0.21 \\
\hline Academic performance & 0.855 & $\mathrm{DD} / \mathrm{ID}$ & 0.274 \\
\hline Start Stimulant & 0.895 & $\mathrm{CD} / \mathrm{ODD}$ & 0.048 \\
\hline $\begin{array}{l}\text { Assess side effects of } \\
\text { medication }\end{array}$ & 0.907 & $\begin{array}{l}\text { Team coordination plan } \\
\text { documented }\end{array}$ & 0 \\
\hline $\begin{array}{l}\text { Assess response to } \\
\text { medication }\end{array}$ & 0.93 & Sxbeforeage12 & 0.1 \\
\hline $\begin{array}{l}\text { Discuss compliance with } \\
\text { medication }\end{array}$ & 0.884 & Symptoms for $>6$ months & 0.25 \\
\hline Classroom intervention & 0.419 & Evidence of Impairment & 0.1 \\
\hline $\begin{array}{l}\text { Asked if patient has ever } \\
\text { seen a counselor }\end{array}$ & 0.806 & $\begin{array}{l}\text { Evidence of collaboration with } \\
\text { school }\end{array}$ & 0 \\
\hline Asked about EFMP status & 0.907 & & \\
\hline $\begin{array}{l}\text { F/U Validated Parent } \\
\text { Instrument }\end{array}$ & 0 & & \\
\hline $\begin{array}{l}\mathrm{F} / \mathrm{U} \text { Validated teacher } \\
\text { Instrument }\end{array}$ & 0 & & \\
\hline
\end{tabular}

Note. This table presents adherence rates for individual variables included in the existing documentation template compared with variables not included in the template. 
Table 4

Sample Demographics

\begin{tabular}{lll}
\hline & Range & Mean (SD) \\
\hline Age (yrs) & $5-18$ & $12.76(3.01)$ \\
Age (yrs) at Diagnosis & $4-13$ & $7.98(2.40)$ \\
Weight (lbs) & $35.2-206.4$ & $81.09(33.33)$ \\
Height (inches) & $44.3-61.3$ & $52.26(5.29)$ \\
\hline
\end{tabular}


Table 5

Military Rank and Affiliated Service

\begin{tabular}{ll}
\hline $\begin{array}{l}\text { Military Status } \\
\text { n=50 }\end{array}$ & n (\%) \\
\hline Rank \\
Officer & $4(8 \%)$ \\
Enlisted & $37(74 \%)$ \\
Retired & $9(18 \%)$ \\
& \\
Service & \\
Army & $4(8 \%)$ \\
Navy & $1(2 \%)$ \\
Air Force & $44(88 \%)$ \\
Coast Guard & $1(2 \%)$ \\
Marines & 0 \\
\hline
\end{tabular}


Table 6

Distribution of Encounters Evaluated per Provider by Appointment Type

\begin{tabular}{llrr}
\hline Appt Type (Initial, F/U, TCON) & \\
\hline \multirow{2}{*}{ Provider 1 } & Follow-up & Frequency & Percent \\
& Initial & 6 & 25 \\
& TCON & 3 & 50 \\
& Total & 12 & 25 \\
Provider 2 & Follow-up & 12 & 66.7 \\
& Initial & 5 & 27.8 \\
& TCON & 1 & 5.6 \\
& Total & 18 & 100 \\
Provider 3 & Follow-up & 11 & 64.7 \\
& Initial & 5 & 29.4 \\
& TCON & 1 & 5.9 \\
& Total & 17 & 100 \\
Provider 4 4 & Follow-up & 12 & 80 \\
& Initial & 3 & 20 \\
& Total & 15 & 100 \\
\hline
\end{tabular}

Note. Provider 1 left the clinic mid-year, and was replaced by provider 2 . 


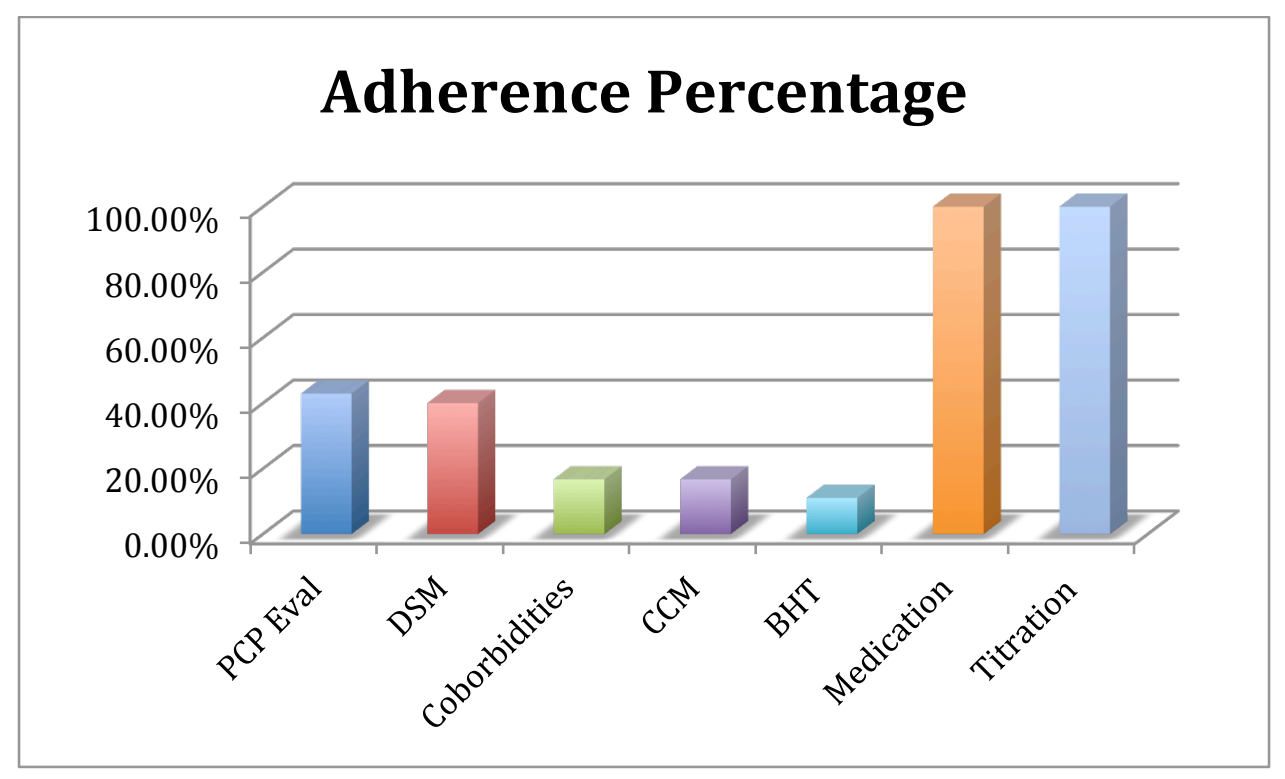

Figure 3. Overall provider adherence to each of the 6 key components of the guideline. Variables addressed in $>/=80 \%$ of encounters are determent to have "Met" the standard and variables addressed in $<80 \%$ of the encounters have "Not Met" the standard. 


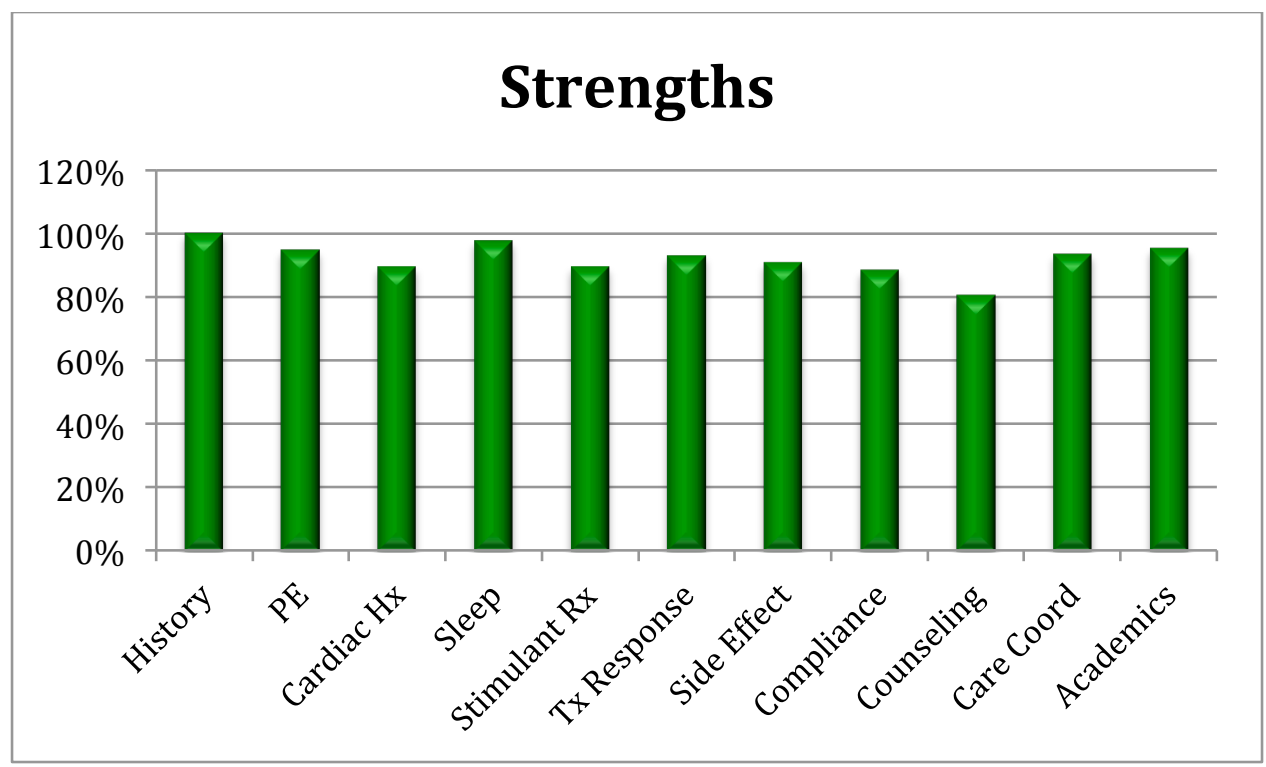

Figure 4. Variables with $>/=80 \%$ compliance. 


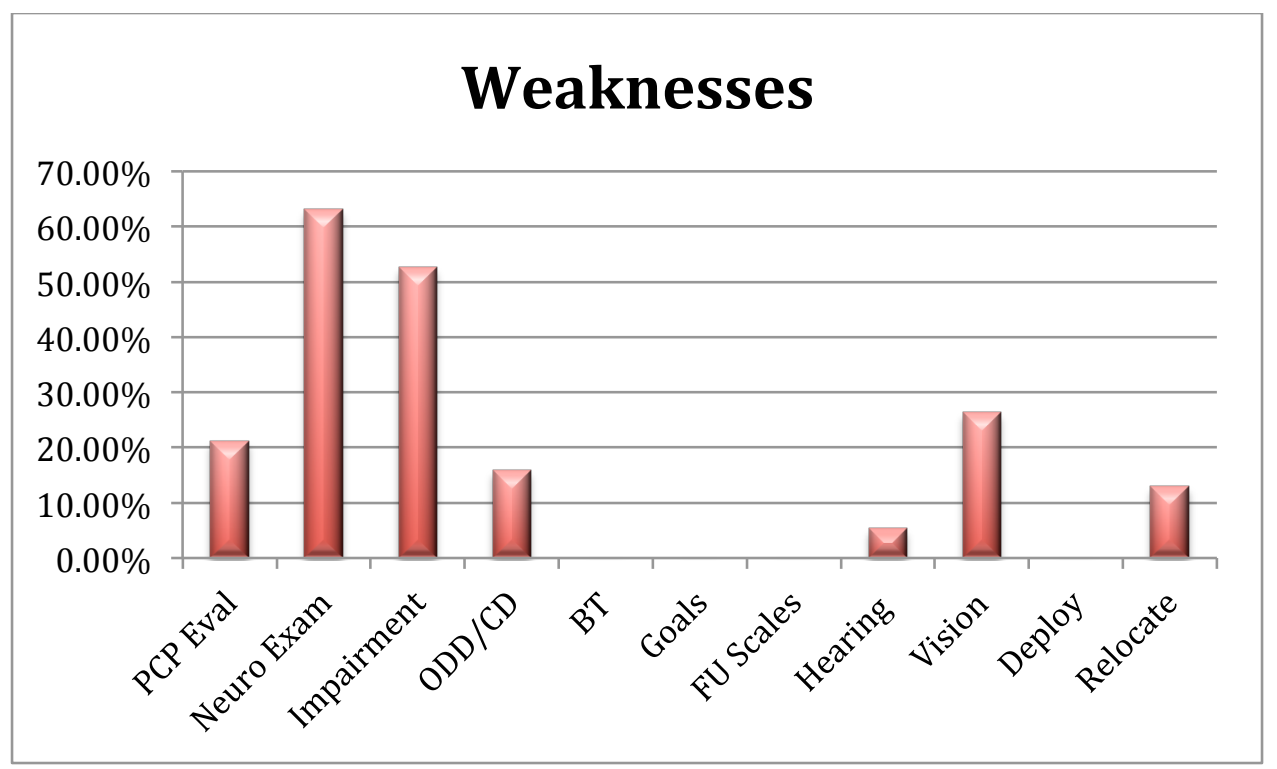

Figure 5. Variables with $<80 \%$ compliance. BT $=$ behavior therapy, $\mathrm{FU}=$ follow-up. 


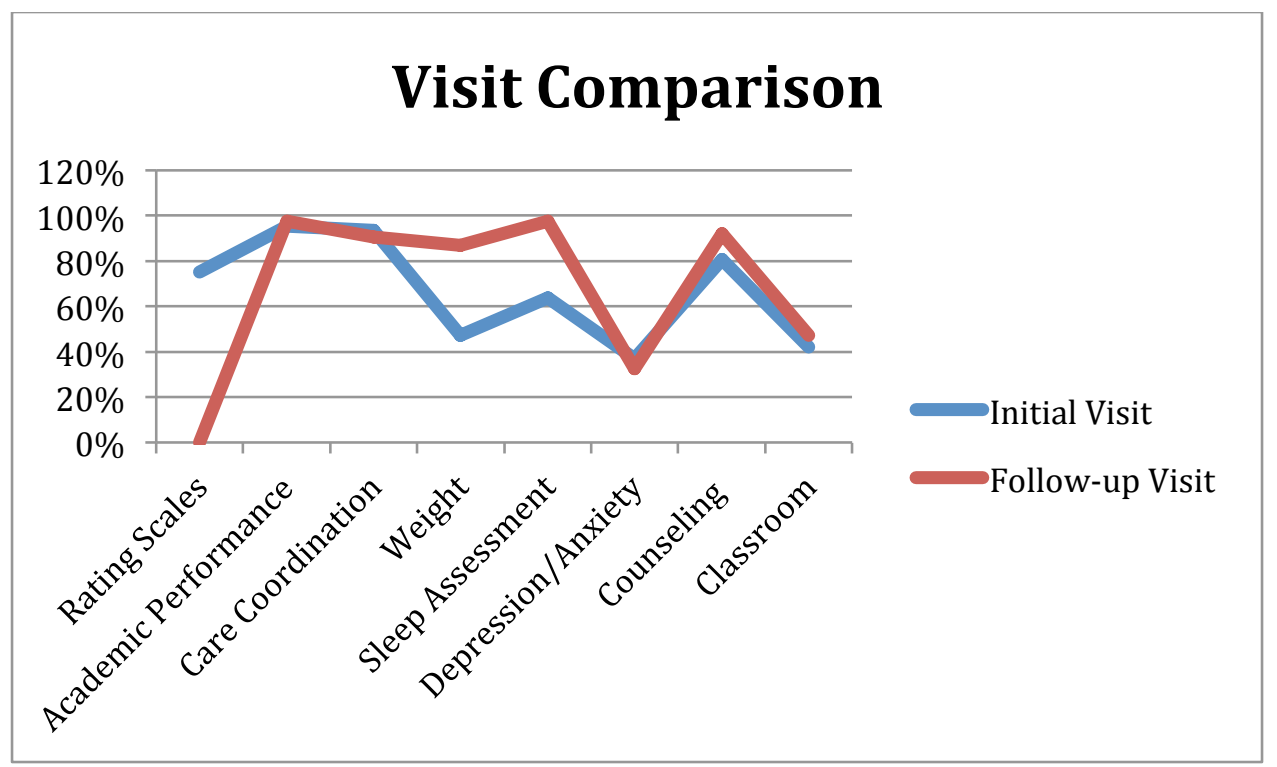

Figure 6. Comparison of variables that apply to all visit types. 
Table 7

CPG Adherence During All Visits

$\begin{array}{ll}\text { Number }(\%) \text { of Total } & \text { Met/Did Not } \\ \text { Encounters with Variable } & \text { Meet Standard } \\ \text { Addressed }(n=62) & \end{array}$

Key Component \#1 (N/A)

Key Component \#2 (N/A)

Key Component \#3 Comorbidity

Assessment

$13(21 \%) \quad$ Not Met

Psychoeducational evaluation

$\mathrm{DD} / \mathrm{ID}$

$17(27.4 \%)$

Not Met

$\mathrm{CD} / \mathrm{ODD}$

$3(4.8 \%)$

Not Met

Depression/anxiety

$21(33.9 \%)$

Sleep disorder

$54(87.1 \%)$

Not Met

Tics

$35(56.5 \%)$

Met

Not Met

Key Component \# 4 (CCM)

School performance documented

$59(95.2 \%)$

Met

Team coordination plan documented or

Evidence of collaboration with the

$0(0 \%)$

$0(0 \%)$

Not Met

school.

Asked about EFMP status

$58(93.5 \%)$

Not Met

Enrolled or referred for enrollment in

EFMP

Target Goals Documented

$6(9.7 \%)$

Met

Relationships

$0(0 \%)$

N/A

Disruptive behavior

$42(67.7 \%)$

Not Met

$43(69.4 \%)$

Not Met

Academic performance

$53(85.5 \%)$

Not Met

Independence

$12(19.4 \%)$

Met

Self-esteem

$2(3.2 \%)$

Not Met

Safety

$10(16.1 \%)$

Not Met

Deployment

$0(0 \%)$

Relocation

$8(12.9 \%)$

Not Met

Not Met

Not Met

\section{Key Component \#5 Treatment}

Recommendations (Behavior

Therapy)

Behavior Therapy Education

$0(0 \%)$

Not Met

Parent training

$0(0 \%)$

Not Met

Classroom interventions discussed

$26(41.9 \%)$

Not Met

Mental Health or Developmental Peds

$7(11.3 \%)$

N/A

Referral 


\begin{tabular}{lll}
\hline School Counseling Referral & $1(1.6 \%)$ & N/A \\
Assess Response to therapy & $0(0 \%)$ & Not Met \\
$\begin{array}{l}\text { Discussion of Compliance with } \\
\text { Treatment }\end{array}$ & $1(1.6 \%)$ & Not Met \\
$\begin{array}{l}\text { Asked if patient has ever seen a } \\
\text { counselor }\end{array}$ & $50(80.6 \%)$ & Met \\
$\begin{array}{l}\text { Patients that answered yes to ever } \\
\text { having seen a counselor }\end{array}$ & $21(33.9 \%)$ & N/A \\
& & \\
Key Component \#5 (Stimulant & & \\
Therapy) & & \\
Simulant Initiation & $19(30.6 \%)$ & N/A \\
$\begin{array}{l}\text { Discussion of compliance with } \\
\text { treatment }\end{array}$ & $54(87.1 \%)$ & Met \\
Key Component \#6 & & \\
Change Drug & & N/A \\
Change Dose & & N/A \\
Stop Drug & $4(6.5 \%)$ & N/A \\
Assess side effects & $5(8.1 \%)$ & Not Met \\
Assess response & $1(1.6 \%)$ & Not Met \\
\hline
\end{tabular}

Note. Variables addressed in $>/=80 \%$ of encounters are determent to have "Met" the standard and variables addressed in $<80 \%$ of the encounters have "Not Met" the standard. 
Table 8

Comparison of Adherence Rates

\begin{tabular}{|c|c|c|c|}
\hline & $\begin{array}{l}\text { Initial Visits } \\
\mathrm{n}=19\end{array}$ & $\begin{array}{l}\text { Follow Up Visits } \\
n=43\end{array}$ & $\begin{array}{l}\text { All Visits } \\
\mathrm{n}=62\end{array}$ \\
\hline \multicolumn{4}{|l|}{ In Template } \\
\hline & $\begin{array}{l}1 \\
0.947 \\
0.632 \\
0.75 \\
0.75 \\
0.947 \\
0.895 \\
0.895\end{array}$ & $\begin{array}{l}0.93 \\
0.907 \\
0.93 \\
0.884 \\
0.419 \\
0 \\
0\end{array}$ & $\begin{array}{l}0.952 \\
0.339 \\
0.871 \\
0.565 \\
0.677 \\
0.694 \\
0.855 \\
0.806 \\
0.907 \\
0.403 \\
0.226 \\
0.645 \\
0.274 \\
0.677 \\
0.097 \\
0.371\end{array}$ \\
\hline \multicolumn{4}{|l|}{$\begin{array}{l}\text { Not In } \\
\text { Template }\end{array}$} \\
\hline & $\begin{array}{l}0.053 \\
0.263 \\
0.1 \\
0.25 \\
0.1\end{array}$ & $\begin{array}{l}0 \\
0.16\end{array}$ & $\begin{array}{l}0.129 \\
0 \\
0.194 \\
0.032 \\
0.161 \\
0 \\
0 \\
0.21 \\
0.274 \\
0.048 \\
0 \\
0 \\
0.065 \\
0.065 \\
0.226 \\
0.145 \\
0.032\end{array}$ \\
\hline
\end{tabular}




\begin{tabular}{ll}
\hline & 0.032 \\
0.048 \\
0.032 \\
0.032 \\
0.065 \\
0.065 \\
0.048 \\
0.065 \\
0.065 \\
0.032 \\
0.032 \\
0.081 \\
0.065 \\
0.032 \\
0.032 \\
0.032 \\
0.032 \\
0.032 \\
0.032 \\
0.032 \\
0.032 \\
0.081 \\
0.097 \\
0.032 \\
0.048 \\
0.032 \\
0.032 \\
0.032 \\
0.032 \\
\hline
\end{tabular}

Note. Overall mean adherence rate among 85 variables of $28.6 \%$ (0-100\%, SD 33.8\%). Mean adherence rate among variables included in the documentation template (32) is $63.5 \%(0-100 \%$, SD $31.5 \%$ ). Of the 55 variables not included on the template, the mean adherence rate is $7.2 \%$ $(0-27 \%$, SD 7\%). 
Table 9

CPG Adherence During Initial Visits

\begin{tabular}{|c|c|c|}
\hline & $\begin{array}{l}\text { Number }(\%) \text { of Encounters with } \\
\text { Variable Addressed During Initial } \\
\text { Evaluation }(n=19)\end{array}$ & $\begin{array}{l}\text { Met/Did Not } \\
\text { Meet Standard }\end{array}$ \\
\hline \multicolumn{3}{|l|}{ Key Component \#1 } \\
\hline PCP initiates evaluation & $4(21 \%)$ & Did not meet \\
\hline History & $19(100 \%)$ & Met \\
\hline Physical exam & $18(94.7 \%)$ & Met \\
\hline Neuro exam & $12(63.2 \%)$ & Did not meet \\
\hline Cardiac history assessment & $17(89.5 \%)$ & Met \\
\hline Hearing screening & $1(5.3 . \%)$ & Did not meet \\
\hline Vision screening & $5(26.3)$ & Did not meet \\
\hline \multicolumn{3}{|l|}{ Key Component \#2 } \\
\hline DSM Criteria and Validated Tool & Unknown & $\mathrm{N} / \mathrm{A}$ \\
\hline Symptoms since before age 12 & $12(63.2 \%)$ & Did not meet \\
\hline Symptoms for $>6$ months & $9(47.4 \%)$ & Did not meet \\
\hline Evidence of Impairment & $10(52.6 \%)$ & Did not meet \\
\hline Parent instrument & $16(84.2 \%)$ & Met \\
\hline Teacher instrument & $16(84.2 \%)$ & Met \\
\hline \multicolumn{3}{|l|}{ Key Component \#3 } \\
\hline \multicolumn{3}{|l|}{ Comorbidity Assessment } \\
\hline Psychoeducational evaluation & $13(68.4 \%)$ & Did not meet \\
\hline DD/ID & $9(47.4 \%)$ & Did not meet \\
\hline $\mathrm{CD} / \mathrm{ODD}$ & $3(15.8 \%)$ & Did not meet \\
\hline Depression/anxiety & $7(36.9 \%)$ & Did not meet \\
\hline Sleep disorder & $12(63.6 \%)$ & Did not meet \\
\hline Tics & $8(42.1 \%)$ & Did not meet \\
\hline \multicolumn{3}{|l|}{ Key Component \# 4} \\
\hline School performance documented & $17(89.5 \%)$ & Met \\
\hline $\begin{array}{l}\text { Team coordination plan } \\
\text { documented or }\end{array}$ & $0(0 \%)$ & Not Met \\
\hline $\begin{array}{l}\text { Evidence of collaboration with } \\
\text { the school. }\end{array}$ & $0(0 \%)$ & Not Met \\
\hline Asked about EFMP status & $19(100 \%)$ & Met \\
\hline Referred for enrollment in EFMP & $0(0 \%)$ & $\mathrm{N} / \mathrm{A}$ \\
\hline Target Goals Documented & $0(0 \%)$ & Not Met \\
\hline Relationships & $8(42.1 \%)$ & Not Met \\
\hline Disruptive behavior & $9(47.4 \%)$ & Not Met \\
\hline Academic performance & $16(84.2 \%)$ & Met \\
\hline Independence & $3(15.8 \%)$ & Not Met \\
\hline
\end{tabular}




\begin{tabular}{|c|c|c|}
\hline Self-esteem & $2(10.5 \%)$ & Not Met \\
\hline Safety & $3(15.8 \%)$ & Not Met \\
\hline Deployment & $0(0 \%)$ & Not Met \\
\hline Relocation & $2(10.5 \%)$ & Not Met \\
\hline \multicolumn{3}{|l|}{$\begin{array}{l}\text { Key Component \#5 (Stimulant } \\
\text { Therapy) }\end{array}$} \\
\hline $\begin{array}{l}\text { Stimulant Initiation (Initial } \\
\text { Visits) }\end{array}$ & $17(89.5 \%)$ & Met \\
\hline $\begin{array}{l}\text { Discussion of Compliance with } \\
\text { Treatment }\end{array}$ & $16(84.2 \%)$ & Met \\
\hline Adderall XR 5mg & $8(42.1 \%)$ & N/A \\
\hline Concerta $18 \mathrm{mg}$ & $5(26.3 \%)$ & N/A \\
\hline Ritalin 5mg & $4(21.1 \%)$ & N/A \\
\hline \multicolumn{3}{|l|}{$\begin{array}{l}\text { Key Component \#5 (Behavior } \\
\text { Therapy) }\end{array}$} \\
\hline Behavior Therapy Education & $0(0 \%)$ & Not Met \\
\hline Parent training & $0(0 \%)$ & Not Met \\
\hline $\begin{array}{l}\text { Classroom interventions } \\
\text { discussed }\end{array}$ & $8(42.1 \%)$ & Not Met \\
\hline $\begin{array}{l}\text { Mental Health or Developmental } \\
\text { Peds Referral }\end{array}$ & $1(5.3 \%)$ & N/A \\
\hline School Counseling Referral & $1(5.3 \%)$ & N/A \\
\hline $\begin{array}{l}\text { Assess Response to Behavior } \\
\text { Therapy }\end{array}$ & $0(0 \%)$ & Not Met \\
\hline $\begin{array}{l}\text { Discussion of Compliance with } \\
\text { BHT }\end{array}$ & $1(5.3 \%)$ & Not Met \\
\hline $\begin{array}{l}\text { Asked if patient has ever seen a } \\
\text { counselor }\end{array}$ & $15(78.9 \%)$ & Met \\
\hline $\begin{array}{l}\text { Patients that answered yes to ever } \\
\text { having seen a counselor }\end{array}$ & $2(10.5 \%)$ & N/A \\
\hline
\end{tabular}

Note. Variables addressed in $>/=80 \%$ of encounters are determent to have "Met" the standard and variables addressed in $<80 \%$ of the encounters have "Not Met" the standard. 
Table 10

CPG Adherence to DSM Criteria among Initial Visits Conducted by PCMs

\begin{tabular}{lll}
\hline Key Component \#2 & $\begin{array}{l}\text { Number (\%) of Encounters with Variable } \\
\text { Addressed during PCM Initial Evaluations } \\
(\mathbf{n}=4)\end{array}$ & $\begin{array}{l}\text { Met/Did Not } \\
\text { Meet Standard }\end{array}$ \\
\hline $\begin{array}{l}\text { DSM Criteria and } \\
\text { Validated Tool }\end{array}$ & $3(75 \%)$ & Not Met \\
$\begin{array}{l}\text { Symptoms since } \\
\text { before age 12 }\end{array}$ & $4(100 \%)$ & Met \\
$\begin{array}{l}\text { Symptoms for }>\mathbf{6} \\
\text { months }\end{array}$ & $1(25 \%)$ & Not Met \\
$\begin{array}{l}\text { Evidence of } \\
\text { Impairment }\end{array}$ & $4(100 \%)$ & Met \\
Parent instrument & $3(75 \%)$ & Not Met \\
Teacher instrument & $3(75 \%)$ & Not Met \\
\hline
\end{tabular}

Note. This table evaluates the 4 encounters identified in which the initial ADHD evaluation was conducted by the primary care provider. Variables addressed in $>/=80 \%$ of encounters are determent to have "Met" the standard and variables addressed in $<80 \%$ of the encounters have "Not Met" the standard. 
Table 11

CPG Adherence During Follow-up Visits

\begin{tabular}{|c|c|c|}
\hline & $\begin{array}{l}\text { Number }(\%) \text { of Follow-up } \\
\text { Encounters with Variable } \\
\text { Addressed }(n=43)\end{array}$ & $\begin{array}{l}\text { Met/Did Not } \\
\text { Meet Standard }\end{array}$ \\
\hline Key Component \#1 & $\mathrm{N} / \mathrm{A}$ & $\mathrm{N} / \mathrm{A}$ \\
\hline Key Component \#2 & N/A & $\mathrm{N} / \mathrm{A}$ \\
\hline \multicolumn{3}{|l|}{$\begin{array}{l}\text { Key Component \#3 Comorbidity } \\
\text { Assessment }\end{array}$} \\
\hline Psychoeducational evaluation & $0(0 \%)$ & Not Met \\
\hline $\mathrm{DD} / \mathrm{ID}$ & $8(18.6 \%)$ & Not Met \\
\hline $\mathrm{CD} / \mathrm{ODD}$ & $0(0 \%)$ & Not Met \\
\hline Depression/anxiety & $14(32.6 \%)$ & Not Met \\
\hline Sleep disorder & $42(97.7 \%)$ & Met \\
\hline Tics & $27(62.8 \%)$ & Not Met \\
\hline \multicolumn{3}{|l|}{ Key Component \# 4 (CCM) } \\
\hline School performance documented & $42(97.7 \%)$ & Met \\
\hline $\begin{array}{l}\text { Team coordination plan } \\
\text { documented }\end{array}$ & $0(0 \%)$ & Not Met \\
\hline $\begin{array}{l}\text { Evidence of collaboration with the } \\
\text { school. }\end{array}$ & $0(0 \%)$ & Not Met \\
\hline Asked about EFMP status & $39(90.7 \%)$ & Met \\
\hline Referred for enrollment in EFMP & $6(14 \%)$ & Not Met \\
\hline Target Goals Documented & $0(0 \%)$ & Not Met \\
\hline Relationships & $34(79.1 \%)$ & Not Met \\
\hline Disruptive behavior & $34(79.1 \%)$ & Not Met \\
\hline Academic performance & $37(86 \%)$ & Met \\
\hline Independence & $9(20.9 \%)$ & Not Met \\
\hline Self-esteem & $0(0 \%)$ & Not Met \\
\hline Safety & $7(16.3 \%)$ & Not Met \\
\hline Deployment & $0(0 \%)$ & Not Met \\
\hline Relocation & $6(14 \%)$ & Not Met \\
\hline \multicolumn{3}{|l|}{$\begin{array}{l}\text { Key Component \#5 (Stimulant } \\
\text { Therapy) }\end{array}$} \\
\hline Stimulant Initiation (Initial Visits) & $2(4.7 \%)$ & $\mathrm{N} / \mathrm{A}$ \\
\hline $\begin{array}{l}\text { Discussion of Compliance with } \\
\text { Treatment }\end{array}$ & $38(88.4 \%)$ & Met \\
\hline $\begin{array}{l}\text { Key Component \#5 (Behavior } \\
\text { Therapy) }\end{array}$ & & \\
\hline
\end{tabular}




\begin{tabular}{lll}
\hline Behavior Therapy Education & $0(0 \%)$ & Not Met \\
Parent training & $0(0 \%)$ & Not Met \\
Classroom interventions discussed & $18(41.9 \%)$ & Not Met \\
$\begin{array}{l}\text { Mental Health or Developmental } \\
\text { Peds Referral }\end{array}$ & $6(14 \%)$ & N/A \\
$\begin{array}{l}\text { School Counseling Referral } \\
\text { Assess Response to Behavior }\end{array}$ & $0(0 \%)$ & Not Met \\
Therapy & $0(0 \%)$ & Not Met \\
$\begin{array}{l}\text { Discussion of Compliance with } \\
\text { BHT }\end{array}$ & $0(0 \%)$ & Met \\
$\begin{array}{l}\text { Asked if patient has ever seen a } \\
\text { counselor }\end{array}$ & $35(81.4 \%)$ & \\
$\begin{array}{l}\text { Patients that answered yes to ever } \\
\text { having seen a counselor }\end{array}$ & $19(44.2 \%)$ & N/A \\
& & \\
Key Component \#6 & & N/A \\
Change in drug & $4(9.3 \%)$ & N/A \\
Change in dose & $5(11.6 \%)$ & N/A \\
Drug discontinued & $1(2.3 \%)$ & Met \\
Assess side effects & $39(90.7 \%)$ & Met \\
Assess response to therapy & $40(93 \%)$ & Met \\
Discuss compliance & $38(88.4 \%)$ & \\
\hline
\end{tabular}

Note. Variables addressed in $>/=80 \%$ of encounters are determent to have "Met" the standard and variables addressed in $<80 \%$ of the encounters have "Not Met" the standard. 
Table 12

Documentation of ADHD Symptoms

\begin{tabular}{lll}
\hline $\begin{array}{l}\text { Inattentive Symptoms } \\
\text { (n=62) }\end{array}$ & Home & School \\
\hline Inattention & $25(40.3 \%)$ & $14(22.6 \%)$ \\
Decreased Concentration & $40(64.5 \%)$ & $17(27.4 \%)$ \\
Avoids tasks & $4(6.5 \%)$ & $4(6.5 \%)$ \\
Fails to finish & $14(22.6 \%)$ & $9(14.5 \%)$ \\
Does not listen & $2(3.2 \%)$ & $2(3.2 \%)$ \\
Difficulty organizing & $3(4.8 \%)$ & $2(3.2 \%)$ \\
Loses things & $2(3.2 \%)$ & $4(6.5 \%)$ \\
Easily Distracted & $4(6.5 \%)$ & $3(4.8 \%)$ \\
Forgetful & $4(6.5 \%)$ & $4(6.5 \%)$ \\
Makes careless mistakes & $2(3.2 \%)$ & $2(3.2 \%)$ \\
& & \\
Hyperactive/Impulsive & & \\
Symptoms (n=62) & & $6(9.7 \%)$ \\
Hyperactive & $42(67.7 \%)$ & $5(8.1 \%)$ \\
Impulsive & $23(37.1 \%)$ & $4(6.5 \%)$ \\
Fidgets & $5(8.1 \%)$ & $2(3.2 \%)$ \\
Leaves seat & $4(6.5 \%)$ & $2(3.2 \%)$ \\
Runs/climbs & $2(3.2 \%)$ & $2(3.2 \%)$ \\
On the go & $2(3.2 \%)$ & $2(3.2 \%)$ \\
Difficulty playing quietly & $2(3.2 \%)$ & $6(9.7 \%)$ \\
Talks excessively & $5(8.1 \%)$ & $3(4.8 \%)$ \\
Blurts out answers & $2(3.2 \%)$ & $2(3.2 \%)$ \\
Difficulty awaiting turn & $2(3.2 \%)$ & $2(3.2 \%)$ \\
Interrupts & $2(3.2 \%)$ & \\
\hline
\end{tabular}




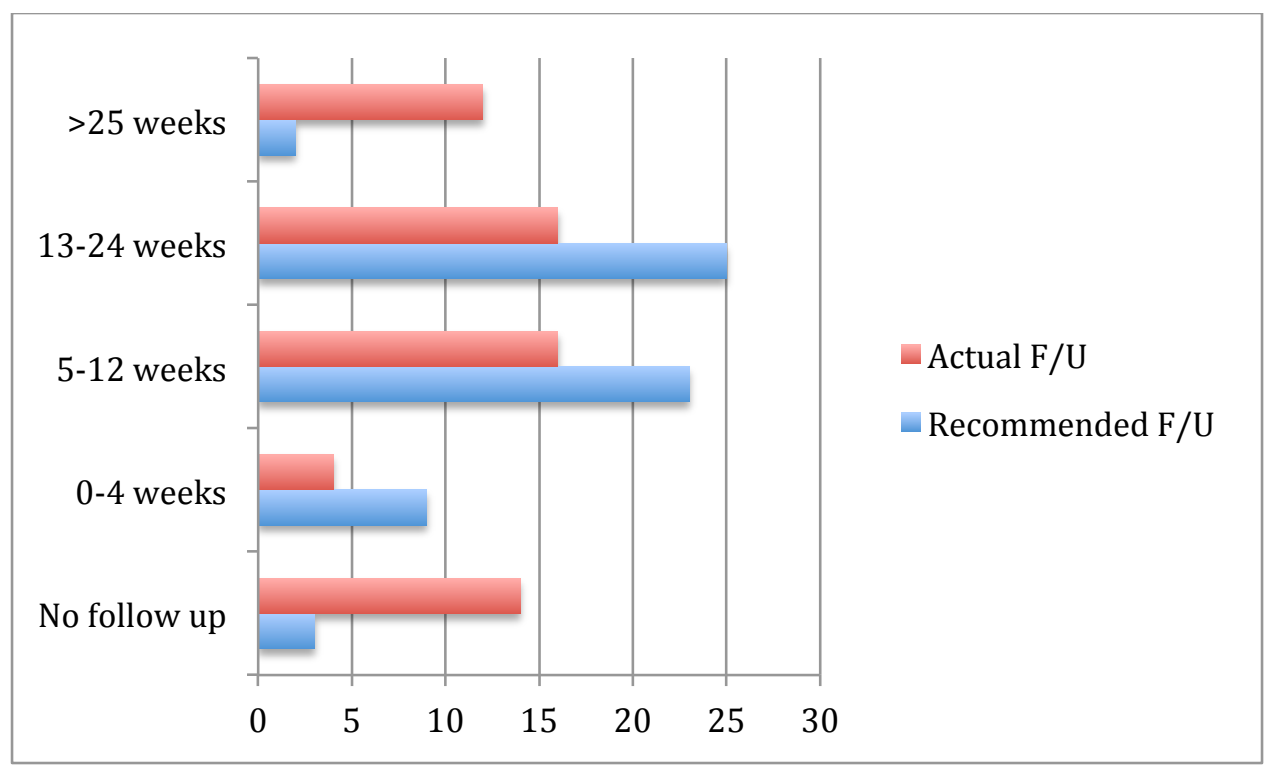

Figure 7. Recommended time to follow-up compared with actual face-to-face follow-up visit. 


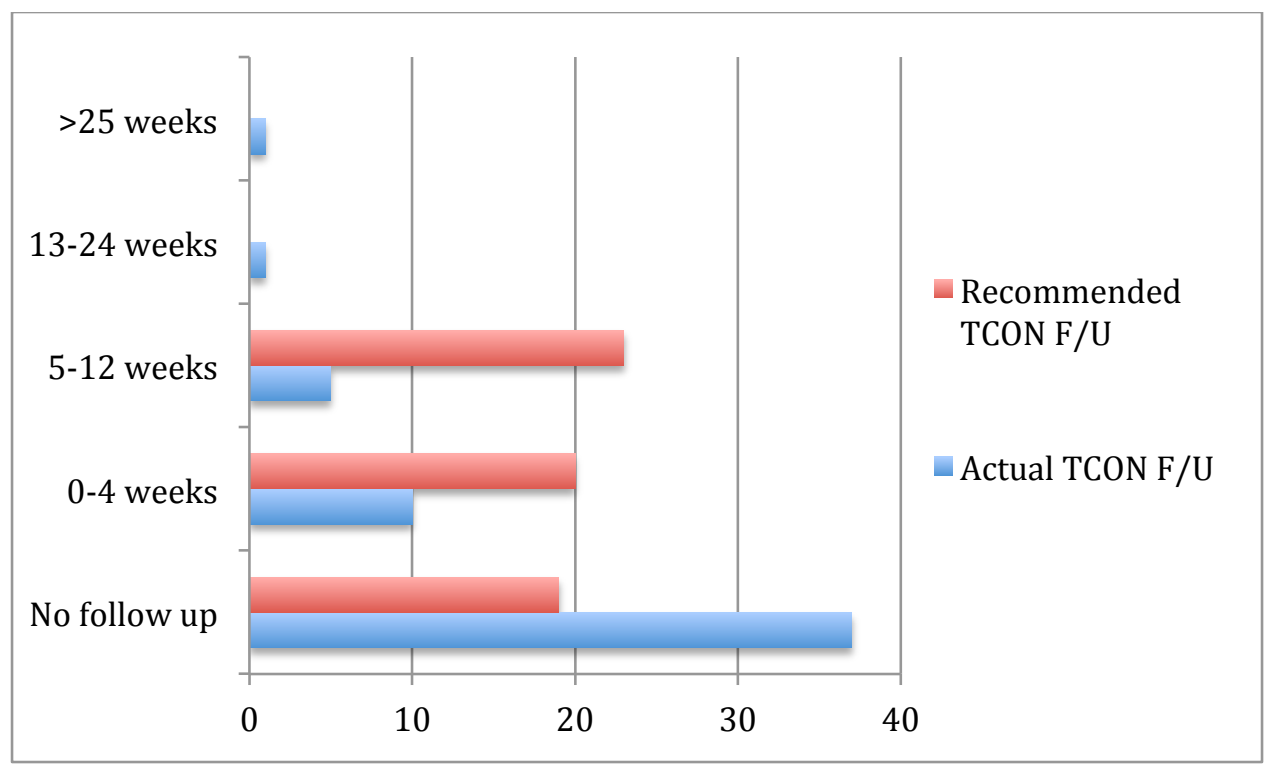

Figure 8. Recommended time to follow-up compared with actual face-to-face follow-up visit. 


\section{PROVIDER NOTE}

Initial ADHD Evaluation

Information collected from: parents, patient, and teachers

\section{Significant Past Medical History}

Pregnancy/Birth history:

Health history (including cardiac risk factors):

Developmental/behavioral history:

Prior ADHD diagnosis and/or treatment:

\section{Social History}

Lives with:

Parental Deployment:

Recent or pending relocation:

Stressors:

History of behavior therapy or counseling:

\section{School}

Current School:

Current Grade:

School contact:

Academic performance:

Social performance:

IEP or 504 plan:

Grades repeated:

\section{Family Medical History:}

ADHD, learning problems, mental health disorders

\section{History of present illness/Chief Concerns}

Duration of symptoms:

Sleep: bedtime, duration, snoring, bedtime routine

Diet:

Other issues:

\section{Allergies}

Current Allergies Reviewed.

\section{Medications}

None

\section{Review of Symptoms:}

Constitutional: Negative for unexplained weight loss, negative for fever HEENT: Negative for hearing problems, negative for visual disturbance Respiratory: Negative for cough, negative for snoring 
Cardiovascular: Negative for heart disease, negative for previous cardiac surgery

Gastrointestinal: Negative for constipation, negative for abdominal pain

Genitourinary: Negative for enuresis, negative for dysuria

Musculoskeletal: Negative for joint/bone/muscle pain, negative for restless feeling in legs at night

Endocrine: Negative for previous thyroid issues

Hematology: Negative for previous anemia

Skin: Negative for birthmarks, negative for skin lesions

Neurological: Negative for seizures, negative for previous head trauma, negative for fainting Psychiatric/Behavioral: Negative for anxiety, negative for depression, negative for psychosis, negative for tics, negative for stress/emotional trauma/abuse, negative for oppositional behaviors, negative for sleep disturbance

When taking meds as prescribed: no academic failure, reduced ability to pay attention, hyperactive behavior, socially inappropriate/disruptive behavior, or peer relationship problems

\section{Physical findings:}

Vital Signs: reviewed

General Appearance: Alert, well developed, well nourished, active

Head: No injuries or asymmetry noted

Neck: Supple, no lymphadenopathy

Eyes: conjunctiva normal, sclera normal, no discharge

Ears: External pinna: normal bilaterally

Nose: No discharge, no malformation

Mouth: MMM, lips normal, oropharynx and tonsils normal

Lungs: Clear to auscultation, no wheezing, rhonchi, crackles or increased respiratory effort

Cardiovascular: Reg rate and rhythm, no murmur/rub/gallop, S1/S2 normal, strong peripheral

pulses

Abdomen: Soft, nontender, nondistended

Skin: normal temperature to touch, no lesions visible

Neurologic: CN2-12 grossly intact, normal tone

\section{ADHD Diagnostic Assessment:}

Rating scale used:

Scores/interpretation:

Parent:

Teacher:

\section{Screening for Co-morbidities:}

Anxiety/Depression:

Oppositional Defiant Disorder:

Conduct Disorder:

\section{Onset, Settings, and Impairment:}

Symptoms present prior to age 12 years old

Symptoms present in 2 or more settings 
Symptoms interfere with or reduce quality of functioning Symptoms not explained by another mental disorder

\section{Assessment:}

Meets/Does not meet DSM-V criteria for ADHD- inattentive type, hyperactive/impulsive type, or combined type. Parent and teacher Vanderbilt rating scales support this diagnosis with significant scores in both inattentive and hyperactive/impulsive domains. No comorbid disorders identified at this time.

\section{Plan:}

1. Discussed diagnosis with parent and child at length, and educational resources provided. With consensus of patient and parent, will begin trial of XYZ medication to be given both on school, and non-school days. Discussed side effects including decreased appetite, sleep problems, stomach ache, headache, and common behaviors seen when the medication wears off. Call provider immediately if unusual side effects occur such as weight loss, increased heart rate or blood pressure, dizziness, hallucinations/mania, prolonged erection (males), or worsening tics. No family history of cardiac disease to indicate EKG screening. Provided 1 month of medication with titration instructions as follows: give 1 tablet in the morning for 3-7 days. If no improvement in target symptoms, increase to 2 tablets in the morning. Call provider with an update (to discuss medication response and side effects) in 1-2 weeks, sooner if needed. Schedule a follow-up appointment in 1 month.

2. Target goals established with the family, patient, and school include:

a. Home- Able to complete assigned homework in 30 minutes with less than 3 reminders to stay on task.

b. School- Able to stay in seat and work quietly when instructed by teacher.

3. Plans to reach these goals:

a. Encouraged parent to request that the child be evaluated by the school psychologist for establishment of a formal IEP or 504 plan.

b. Have teacher schedule frequent break-times with preferential seating and visual reminders of daily expectations.

c. Referral placed for outpatient behavior therapy to work with patient and parent on coping skills and management of ADHD.

Figure 9. Provider documentation template designed to include all key components of the AAP ADHD CPG. 


\section{Appendix A}

\section{Measures Used to Collect Data for Project}

\section{CHART ABSTRACTION FORM FOR OFFICE VISTTS}
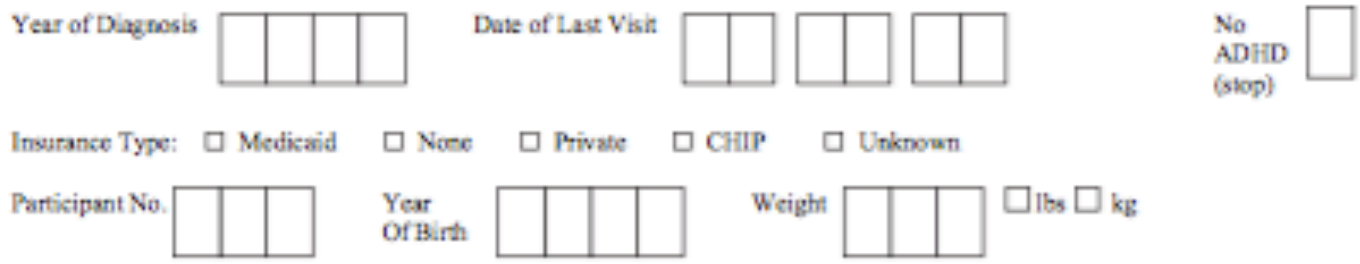

(stop)

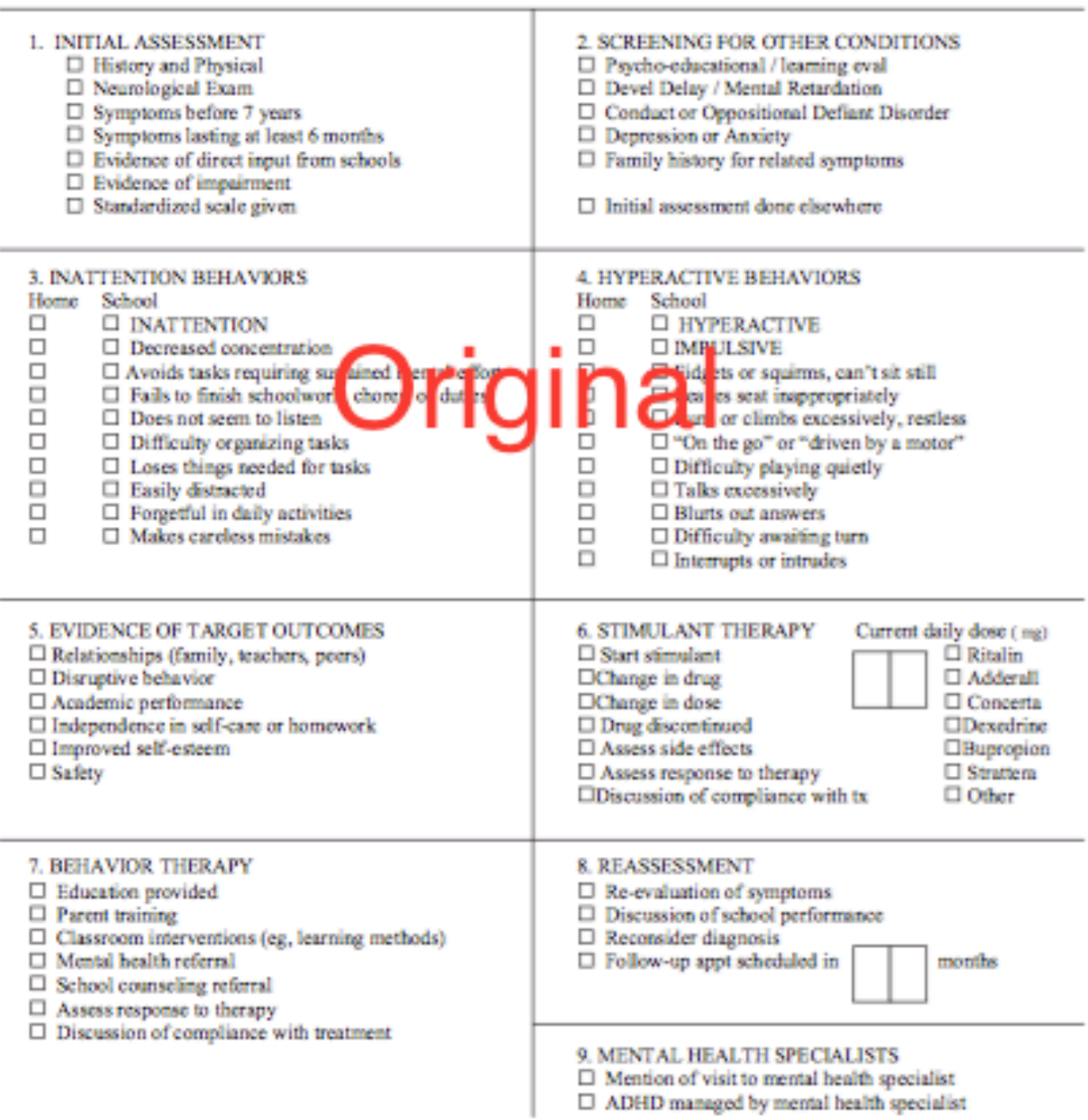

Figure A1. Original Chart Abstraction Tool prior to adaptation for present study. Permission for duplication and adaptation of tool granted by authors ((Vreeman, Madsen, Vreeman, Carroll, \& Downs, 2006). 


\section{Adapted Initial Visit Chart Abstraction Tool}

\begin{tabular}{|c|c|}
\hline $\begin{array}{l}\text { Year/Age of Diagnosis } \quad \text { Duration } \\
\text { Participant No. }\end{array}$ & - Race $\quad$ Rank \\
\hline $\begin{array}{l}\text { Initial Assessment } \\
\square \text { History and physical } \\
\square \text { Neurological exam } \\
\square \text { Symptoms before } 12 \text { years } \\
\square \text { Symptoms lasting at least } 6 \text { months } \\
\square \text { Evidence of impairment } \\
\square \text { Standardized scale given (home) } \\
\square \text { Standardized scale given (school) } \\
\square \text { BP } \\
\square \text { HR } \\
\square \text { Weight } \\
\square \text { Height } \\
\square \text { Initial assessment done elsewhere }\end{array}$ & $\begin{array}{l}\text { Screening for Other Conditions } \\
\square \text { Psycho-educational/learning eval } \\
\square \text { Devel delay/intellectual disability } \\
\square \text { Conduct or oppositional defiant disorder } \\
\square \text { Depression or anxiety } \\
\square \text { Family history for related symptoms } \\
\square \text { Sleep disorder } \\
\square \text { Tics } \\
\square \text { Hearing screen } \\
\square \text { Vision screen } \\
\square \text { Recent or pending relocation } \\
\square \text { Parental deployment documented } \\
\square \text { History of cardiac symptoms }\end{array}$ \\
\hline $\begin{array}{l}\text { Inattention Behaviors Documented } \\
\text { Home School } \\
\square \quad \square \text { Inattention } \\
\square \quad \square \text { Decreased concentration } \\
\square \quad \square \text { Avoids tasks req sustained mental effort } \\
\square \quad \square \text { Fails to finish schoolwork/chores/duties } \\
\square \quad \square \text { Does not seem to listen } \\
\square \quad \square \text { Difficulty organizing tasks } \\
\square \quad \square \text { Loses things needed for tasks } \\
\square \quad \square \text { Easily distracted } \\
\square \quad \square \text { Forgetful in daily activities } \\
\square \quad \square \text { Makes careless mistakes }\end{array}$ & $\begin{array}{l}\text { Hyperactive/Impulsive Behaviors Documented } \\
\text { Home School } \\
\square \quad \square \text { Hyperactive } \\
\square \quad \square \text { Impulsive } \\
\square \quad \square \text { Fidgets or squirms, can't sit still } \\
\square \quad \square \text { Leaves seat inappropriately } \\
\square \quad \square \text { Runs or climbs excessively, restless } \\
\square \quad \square \text { “On the go" or "driven by a motor" } \\
\square \quad \square \text { Difficulty playing quietly } \\
\square \quad \square \text { Talks excessively } \\
\square \quad \square \text { Blurts out answers } \\
\square \quad \square \text { Difficulty awaiting turn } \\
\square \quad \square \text { Interrupts or intrudes }\end{array}$ \\
\hline $\begin{array}{l}\text { Evidence of Target Outcomes } \\
\square \text { Relationships (family, teachers, peers) } \\
\square \text { Disruptive behavior } \\
\square \text { Academic performance } \\
\square \text { Independence in self-care or homework } \\
\square \text { Improved self-esteem } \\
\square \text { Safety }\end{array}$ & $\begin{array}{l}\text { Stimulant Therapy } \\
\square \text { Start stimulant } \\
\square \text { Change in drug } \\
\square \text { Change in dose } \\
\square \text { Drug discontinued } \\
\square \text { Assess side effects } \\
\square \text { Assess response to therapy } \\
\square \text { Discussion of compliance with tx } \\
\text { Name of medication and dose }\end{array}$ \\
\hline $\begin{array}{l}\text { Behavior Therapy } \\
\square \text { Education Provided } \\
\square \text { Parent training } \\
\square \text { Classroom interventions (learning methods) } \\
\square \text { Mental health referral } \\
\square \text { School counseling referral } \\
\square \text { Assess response to therapy } \\
\square \text { Discussion of compliance with treatment }\end{array}$ & $\begin{array}{l}\text { Chronic Care Model } \\
\square \text { Team coordination plan documented } \\
\square \text { Evidence of collaboration w/school } \\
\square \text { Follow-up appt scheduled in ___ months } \\
\square \text { Actual Follow-up appt } \\
\square \text { Mention of visit to mental health specialist } \\
\square \text { ADHD managed by mental health specialist } \\
\square \text { EFMP }\end{array}$ \\
\hline
\end{tabular}

Figure A2. Tool adapted to include updated CPG recommendations and DSM-V criteria. Permission for duplication and adaptation of tool granted by authors ((Vreeman, Madsen, Vreeman, Carroll, \& Downs, 2006). 


\section{Adapted Follow-up Visit Chart Abstraction Tool}

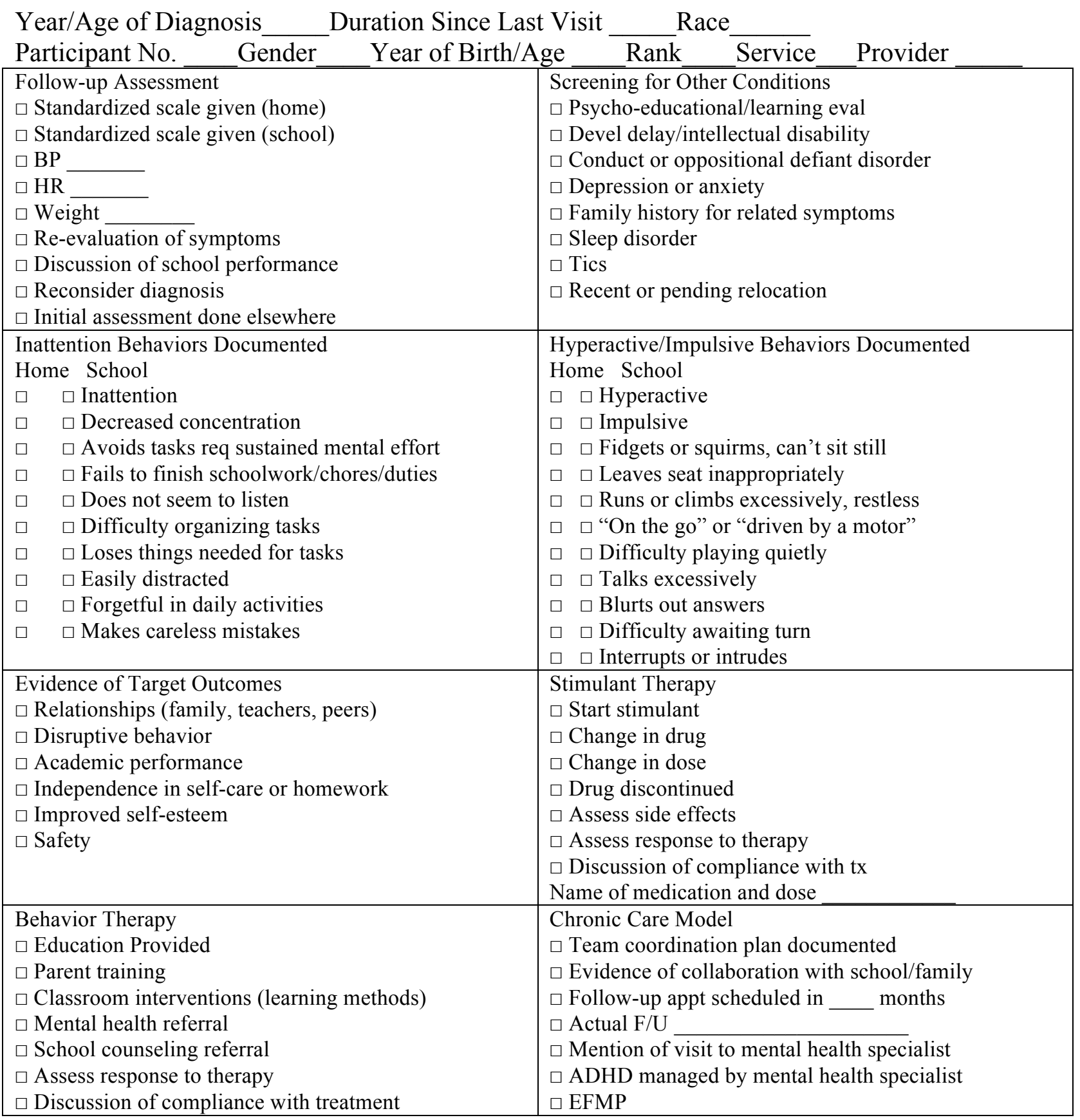

Figure A3. Tool adapted to include updated CPG recommendations and DSM-V criteria. Permission for duplication and adaptation of tool granted by authors ((Vreeman, Madsen, Vreeman, Carroll, \& Downs, 2006). 


\section{Original Provider Survey Tool}

Physician Name:

ID (Study Staff will assign):

\section{Physician Survey}

1. Are you a member of ABP: (circle one) $\mathrm{Y} N$ If Yes, ABP ID \#

2. Your Age

3. Sex: (circle one) M F

4. Race/Ethnicity: (please check) $\square$ American Indian or Alaskan $\square$ Black, not Hispanic/Latino

$\square$ Hispanic/Latino $\quad \square$ Native Asian or Pacific Islander $\quad \square$ White

$\square$ Biracial/Multiracial (describe):

5. How many years have you been in practice since you finished residency training (not counting fellowship training, if any)?

6. How would you describe your type of practice? (check one)

$\square$ Pediatric Partnership or Group

Multi-specialty Group

Solo Practice

HMO

Community Health Clinic

Other (please specify):

7. Approximately what percentage of your patient population receives Medicaid assistance for health care costs? $\%$

8. Please characterize your practice (circle one): Urban Suburban Rural

9. Approximately how many newly diagnosed ADHD children have you seen over the course of the past year?

10. Approximately how many ADHD children have you provided continued maintenance care for during the course of the past year? 


\section{$\underline{\text { ADHD Education }}$}

11. Have you conducted any quality improvement activities related to ADHD in the past year?

$\square$ Yes $\quad \square$ No

If yes, please indicate all types of activities:

$\square$ Chart Review

$\square$ Patient Survey

$\square$ Other:

12. Have you sought Maintenance of Certification (MOC) credit related to ADHD in the past year?

$\square$ Yes

$\square$ No

13. In the last year, how many hours have you spent in CME coursework that had content related to Attention Deficit Hyperactivity Disorder (ADHD)? hours

14. In the last year, how much time have you spent reading materials (e.g. journal articles, chapters, newsletters) related to ADHD? hours

\section{$\underline{\text { ADHD Assessment }}$}

15. How helpful do you think it is to collect behavior ratings using standardized rating scales from parents when evaluating a child for ADHD?

Not at all

Helpful

$$
\begin{aligned}
& \text { Not very } \\
& \text { Helpful }
\end{aligned}
$$
Somewhat
Helpful

Helpful

Very Helpful

16. During the past year, in approximately what percentage of cases did you collect standardized behavior rating data from parents when evaluating a child for ADHD? Place an $\mathrm{X}$ on the line below to indicate your response.

$\begin{array}{lllllllllll}0 & 10 & 20 & 30 & 40 & 50 & 60 & 70 & 80 & 90 & 100\end{array}$

17. How helpful do you think it is to collect behavior ratings using standardized rating scales from teachers when evaluating a child for ADHD?

1 2

3

4 5

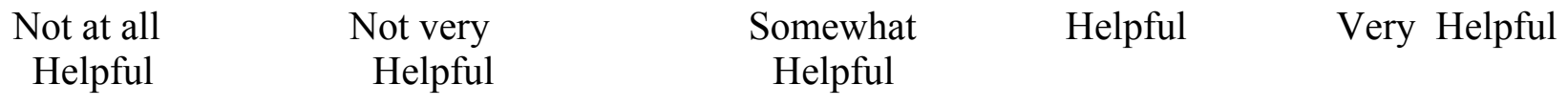


18. During the past year, in approximately what percentage of cases did you collect standardized behavior rating data from teachers when evaluating a child for ADHD? Place an $\mathrm{X}$ on the line below to indicate your response.

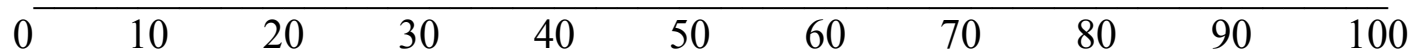

19. How important do you feel it is to use DSM-IV diagnostic criteria when assessing a child for ADHD?

$\begin{array}{lllll}1 & 3 & 4 & 5\end{array}$

Not at all important Somewhat important Sery important

20. During the past year, in approximately what percentage of cases did you use DSM-IV diagnostic criteria when assessing a child for ADHD? Place an X on the line below to indicate your response.

$\begin{array}{rllllllllll}0 & 10 & 20 & 30 & 40 & 50 & 60 & 70 & 80 & 90 & 100\end{array}$

21. During the past year, in approximately what percentage of cases did you refer an ADHD child to a mental health professional (e.g., psychiatrist, psychologist, social worker, school counselor) for additional assessment services related to ADHD or another comorbid disorder? Place an $\mathrm{X}$ on the line below to indicate your response.

\begin{tabular}{lllllllllll}
\hline 0 & 10 & 20 & 30 & 40 & 50 & 60 & 70 & 80 & 90 & 100
\end{tabular}

\section{ADHD Treatment}

22. In the past year, for newly diagnosed patients who you started on medication, on average how long after prescribing medication was it before you had any contact with your patients to monitor response to medication?

23. How important to the success of medication treatment for ADHD do you think it is to continually assess ADHD children's behavior at home and at school on a periodic basis?

1

Not at all important
2

Somewhat important
4

5

Very important 
24. Over the course of the last year, for what percentage of your patients did you implement some form of periodic monitoring using standardized parent rating scales when treating ADHD children? Place an X on the line below to indicate the percentage of children that you begin on medication with whom you did this?

\begin{tabular}{rrrrrrrrrrr}
\hline 0 & 10 & 20 & 30 & 40 & 50 & 60 & 70 & 80 & 90 & 100
\end{tabular}

25. On average, after you have established an effective medication and medication dosage for a child, about how often do you collect standardized parent rating scales for your patients?

26. Over the course of the last year, for what percentage of your patients did you implement some form of periodic monitoring using standardized teacher rating scales when treating ADHD children? Place an X on the line below to indicate the percentage of children that you begin on medication with whom you did this?

\begin{tabular}{lllllllllll}
\hline 0 & 10 & 20 & 30 & 40 & 50 & 60 & 70 & 80 & 90 & 100
\end{tabular}

27. On average, after you have established an effective medication and medication dosage for a child, about how often do you collect standardized teacher rating scales for your patients?

28. During the past year, in approximately what percentage of cases did you refer an ADHD child to a mental health professional (e.g., psychiatrist, psychologist, social worker, school counselor) for additional treatment services related to ADHD or another comorbid disorder? Place an $\mathrm{X}$ on the line below to indicate your response.

\begin{tabular}{lllllllllll}
\hline 0 & 10 & 20 & 30 & 40 & 50 & 60 & 70 & 80 & 90 & 100
\end{tabular}

29. Over the course of the past year, about how many times did you consult with a mental health professional about assessment issues related to an ADHD child under your care?

30. Over the course of the past year, about how many times did you consult with a mental health professional about treatment issues related to an ADHD child under your care?

31. On the following scale, please rate how comfortable you feel with computers?

Not at all Comfortable Somewhat Comfortable Very Comfortable $\begin{array}{llllllllll}1 & 2 & 3 & 4 & 5 & 6 & 7 & 8 & 9 & 10\end{array}$ 
32. How many hours a week do you spend on the internet (e.g., surfing the web, checking email)? hours

33. Do you have an email address? YES

NO

34.

\section{THANK YOU FOR COMPLETING YOUR SURVEY!}

Figure A4. Original provider survey used to assess provider compliance with the ADHD guideline. Permission to duplicate and adapt this survey was provided by the author (Epstein et al., 2011). 


\section{Adapted Provider Survey Tool}

Provider Name:

ID (Study Staff will assign):

\section{Provider Survey}

1. Are you a member of a professional organization? (circle one) $\mathrm{Y} \quad \mathrm{N}$

If Yes, name of organization

2. Your Age

3. Sex: (circle one) M F

4. Race/Ethnicity: (please check) $\square$ American Indian or Alaskan $\square$ Black, not Hispanic/Latino

$\square$ Hispanic/Latino $\square$ Native Asian or Pacific Islander $\square$ White

$\square$ Biracial/Multiracial (describe):

5. How many years have you been in practice since you finished residency training, physician assistant, or nurse practitioner training (not counting fellowship training, if any)?

6. How would you describe your type of practice? (check one)

\section{Pediatric Primary Care}

Family Health

Community Health Clinic

Other (please specify):

7. Please characterize your practice (circle one): Urban Suburban Rural

8. Approximately how many newly diagnosed ADHD children have you seen over the course of the past year?

9. Approximately how many ADHD children have you provided continued maintenance care for during the course of the past year? 


\section{$\underline{\text { ADHD Education }}$}

10. Have you conducted any quality improvement activities related to ADHD in the past year?

$\square$ Yes $\quad \square$ No

If Yes, please indicate all types of activities:

$$
\begin{aligned}
& \square \text { Chart Review } \\
& \square \text { Patient Survey } \\
& \square \text { Other: }
\end{aligned}
$$

11. Have you sought Maintenance of Certification (MOC) credit or continuing education credit related to ADHD in the past year?

$\square$ Yes $\quad \square$ No

12. In the last year, how many hours have you spent in CME coursework that had content related to Attention Deficit Hyperactivity Disorder (ADHD)? hours

13. In the last year, how much time have you spent reading materials (e.g. journal articles, chapters, newsletters) related to ADHD? hours

\section{$\underline{\text { ADHD Assessment }}$}

14. How difficult do you think it is to collect behavior ratings using standardized rating scales from parents when evaluating a child for ADHD?

$\begin{array}{ccccc}\text { Not at all } & \text { Not very } & \text { Somewhat } & \text { Difficult } & \text { Very Difficult } \\ \text { Difficult } & \text { Difficult } & \text { Difficult } & & \end{array}$

15. During the past year, in approximately what percentage of cases did you collect standardized behavior rating data from parents when evaluating a child for ADHD? Place an $\mathrm{X}$ on the line below to indicate your response.

\begin{tabular}{lllllllllll}
\hline 0 & 10 & 20 & 30 & 40 & 50 & 60 & 70 & 80 & 90 & 100
\end{tabular}

16. What barriers if any do you face related to collecting parent behavior rating scales for an initial ADHD evaluation?

17. How difficult do you think it is to collect behavior ratings using standardized rating scales from teachers when evaluating a child for ADHD?

$\begin{array}{ccccc}1 & 2 & 3 & 4 & 5 \\ \text { Not at all } & \text { Not very } & \text { Somewhat } & \text { Difficult } & \text { Very Difficult }\end{array}$


Difficult Difficult $\quad$ Difficult

18. During the past year, in approximately what percentage of cases did you collect standardized behavior rating data from teachers when evaluating a child for ADHD? Place an $\mathrm{X}$ on the line below to indicate your response.

\begin{tabular}{lllllllllll}
\hline 0 & 10 & 20 & 30 & 40 & 50 & 60 & 70 & 80 & 90 & 100
\end{tabular}

19. What barriers if any do you face related to collecting teacher behavior rating scales for an initial ADHD evaluation?

20. How useful do you feel it is to use DSM-V diagnostic criteria when assessing a child for ADHD?
1
2
3
4
5

Not at all useful

Somewhat useful

Very useful

21. During the past year, in approximately what percentage of cases did you use DSM-V diagnostic criteria when assessing a child for ADHD? Place an X on the line below to indicate your response.

\begin{tabular}{lllllllllll}
\hline 0 & 10 & 20 & 30 & 40 & 50 & 60 & 70 & 80 & 90 & 100
\end{tabular}

22. What barriers if any do you face related to the use of DSM-V diagnostic criteria when assessing a child for ADHD?

23. During the past year, in approximately what percentage of cases did you refer an ADHD child to a mental health professional (e.g., psychiatrist, psychologist, social worker, school counselor) for additional assessment services related to ADHD or another comorbid disorder? Place an $\mathrm{X}$ on the line below to indicate your response.

\begin{tabular}{lllllllllll}
\hline 0 & 10 & 20 & 30 & 40 & 50 & 60 & 70 & 80 & 90 & 100
\end{tabular}

24. What barriers if any do you face related to referring an ADHD child to a mental health professional (e.g., psychiatrist, psychologist, social worker, school counselor) for additional assessment services related to ADHD or another comorbid disorder?

\section{$\underline{\text { ADHD Treatment }}$}

25. In the past year, for newly diagnosed patients who you started on medication, on average how long after prescribing medication was it before you had any contact with your patients to monitor response to medication? 
26. Please describe any barriers that you may have experienced related to having contact with your patients to monitor response to medication?

27. How important to the success of medication treatment for ADHD do you think it is to continually assess ADHD children's behavior at home and at school on a periodic basis?
1
2
3
4
5

Not at all important

Somewhat important

Very important

28. Over the course of the last year, for what percentage of your patients did you implement some form of periodic monitoring using standardized parent rating scales when treating ADHD children? Place an X on the line below to indicate the percentage of children that you begin on medication with whom you did this?

\begin{tabular}{lllllllllll}
\hline 0 & 10 & 20 & 30 & 40 & 50 & 60 & 70 & 80 & 90 & 100
\end{tabular}

29. Please describe any barriers that you have faced related to collecting standardized parent rating scales for your patients for periodic monitoring.

30. On average, after you have established an effective medication and medication dosage for a child, about how often do you collect standardized parent rating scales for your patients?

31. Over the course of the last year, for what percentage of your patients did you implement some form of periodic monitoring using standardized teacher rating scales when treating ADHD children? Place an X on the line below to indicate the percentage of children that you begin on medication with whom you did this?

\begin{tabular}{lllllllllll}
\hline 0 & 10 & 20 & 30 & 40 & 50 & 60 & 70 & 80 & 90 & 100
\end{tabular}

32. Please describe any barriers that you have faced related to collecting standardized teacher rating scales for your patients for periodic monitoring.

33. On average, after you have established an effective medication and medication dosage for a child, about how often do you collect standardized teacher rating scales for your patients?

34. During the past year, in approximately what percentage of cases did you refer an ADHD child to a mental health professional (e.g., psychiatrist, psychologist, social worker, school counselor) for additional treatment services related to ADHD or another comorbid disorder? Place an $\mathrm{X}$ on the line below to indicate your response. 


\begin{tabular}{lllllllllll}
\hline 0 & 10 & 20 & 30 & 40 & 50 & 60 & 70 & 80 & 90 & 100
\end{tabular}

35. Please describe any barriers that you have faced related to referring a child with ADHD to a mental health professional for additional treatment services related to ADHD or another comorbid disorder.

36. Over the course of the past year, about how many times did you consult with a mental health professional about assessment issues related to an ADHD child under your care?

37. Over the course of the past year, about how many times did you consult with a mental health professional about treatment issues related to an ADHD child under your care?

38. Please provide any additional comments related to barriers in caring for children with ADHD.

\section{THANK YOU FOR COMPLETING YOUR SURVEY!}

Figure A5. The provider survey was adapted to collect information regarding perceived barriers to ADHD guideline adherence and to obtain baseline demographic data about the participating providers. Permission to duplicate and adapt this survey was provided by the author (Epstein et al., 2011). Adapted questions have been highlighted. 


\section{Appendix B}

\section{Literature Review Table}

\begin{tabular}{|c|c|c|c|c|}
\hline $\begin{array}{l}\text { AAP } \\
\text { CPG } \\
(2011 \\
)\end{array}$ & $\begin{array}{l}\text { CPG with expanded age range, expanded } \\
\text { scope, and a process of care for diagnosis and } \\
\text { treatment } \\
\text {-chronic care model } \\
\text {-medical home model } \\
\text {-emphasis on CPG }\end{array}$ & $\begin{array}{l}\text {-Multilevel, } \\
\text { systematic } \\
\text { approach to } \\
\text { identify } \\
\text { literature } \\
\text { that build } \\
\text { the } \\
\text { evidence } \\
\text { base for } \\
\text { both } \\
\text { diagnosis } \\
\text { and } \\
\text { treatment } \\
\text { - Scoping } \\
\text { review of lit } \\
\text { then } \\
\text { summarized } \\
\text { the primary } \\
\text { findings } \\
\text { that met } \\
\text { inclusion } \\
\text { criteria } \\
\text { - Evidence } \\
\text { tables } \\
\text { created, } \\
\text { which were } \\
\text { reviewed by } \\
\text { content } \\
\text { experts to } \\
\text { identify } \\
\text { gaps/missed } \\
\text { articles } \\
\text { - Articles } \\
\text { from } \\
\text { medicine, } \\
\text { psychology, } \\
\text { and } \\
\text { education } \\
\text { domains }\end{array}$ & $\begin{array}{l}\text { - Evidence } \\
\text { quality } \\
\text { integrated } \\
\text { with } \\
\text { anticipated } \\
\text { balance } \\
\text { bw } \\
\text { benefits } \\
\text { and harms } \\
\text { if policy is } \\
\text { conducted } \\
\text { lead to } \\
\text { designatio } \\
\text { n of strong } \\
\text { recommen } \\
\text { dation, } \\
\text { option, or } \\
\text { no } \\
\text { recommen } \\
\text { dation } \\
\text { - } \\
\text { Extensive } \\
\text { peer } \\
\text { review }\end{array}$ & $\begin{array}{l}\text { - } \\
\text { Recognizes } \\
\text { evaluation, } \\
\text { diagnosis, } \\
\text { and } \\
\text { treatment as } \\
\text { continuous } \\
\text { process } \\
\text { - Guideline } \\
\text { recommend } \\
\text { ations } \\
\text { based on } \\
\text { clear } \\
\text { characteriza } \\
\text { tion of } \\
\text { evidence. } \\
\text { - Practice of } \\
\text { care } \\
\text { algorithm } \\
\text { provides } \\
\text { more detail } \\
\text { about how } \\
\text { to } \\
\text { implement } \\
\text { guidelines } \\
\text { is based } \\
\text { less on } \\
\text { available } \\
\text { evidence } \\
\text { and more } \\
\text { on } \\
\text { consensus } \\
\text { of the } \\
\text { committee } \\
\text { members. } \\
\text { - When data } \\
\text { were } \\
\text { lacking, a } \\
\text { combinatio } \\
\text { n of } \\
\text { evidence } \\
\text { and expert } \\
\end{array}$ \\
\hline
\end{tabular}




\begin{tabular}{|c|c|c|c|c|}
\hline & & & & $\begin{array}{l}\text { consensus } \\
\text { was used }\end{array}$ \\
\hline $\begin{array}{l}\text { Akinb } \\
\text { ami } \\
(2011 \\
\text { ) }\end{array}$ & $\begin{array}{l}\text { ADHD 5-17 yrs US 1998- } \\
2009 \text { - NCHS Data Brief }\end{array}$ & $\begin{array}{l}\text { NHIS data } \\
\text { collected by } \\
\text { interviewer } \\
\text { s from the } \\
\text { US Census } \\
\text { Bureau for } \\
\text { CDC's } \\
\text { national } \\
\text { center for } \\
\text { health } \\
\text { statistics } \\
\text { Data } \\
\text { collected in } \\
\text { homes- } \\
\text { civilian, } \\
\text { non- } \\
\text { institutional } \\
\text { ized US } \\
\text { population }\end{array}$ & $\begin{array}{l}\text { SUDANN } \\
\text { software } \\
\text { Taylor } \\
\text { series } \\
\text { linearizati } \\
\text { on method } \\
\text { for } \\
\text { variance }\end{array}$ & $\begin{array}{l}\text {-ADHD is } \\
\text { one of the } \\
\text { most } \\
\text { common } \\
\text { mental } \\
\text { health } \\
\text { disorders of } \\
\text { childhood } \\
\text { affecting up } \\
\text { to } 11 \% \text { of } \\
\text { US children } \\
\text {-Symptoms } \\
\text { begin in } \\
\text { childhood } \\
\text { and often } \\
\text { persist into } \\
\text { adulthood } \\
\text { with } \\
\text { functional } \\
\text { impairment } \\
\text { in } \\
\text { academic, } \\
\text { family, and } \\
\text { social } \\
\text { settings } \\
\text { increasing } \\
\text { prevalence } \\
\text { over the last } \\
\text { decade }\end{array}$ \\
\hline $\begin{array}{l}\text { Baum } \\
(2013 \\
)\end{array}$ & $\begin{array}{l}\text { Healthcare Reform, Quality, and Technology: } \\
\text { ADHD as a Case Study }\end{array}$ & $\begin{array}{l}\text { Highlights } \\
\text { legislative } \\
\text { reforms and } \\
\text { reviews } \\
\text { technologie } \\
\text { s that may } \\
\text { play a role } \\
\text { in the } \\
\text { implementa } \\
\text { tion of } \\
\text { these } \\
\text { reforms }\end{array}$ & & $\begin{array}{l}\text { Meaningful } \\
\text { changes } \\
\text { have been } \\
\text { slow, } \\
\text { especially } \\
\text { when } \\
\text { compared } \\
\text { to the pace } \\
\text { of } \\
\text { technology } \\
\text { developmen } \\
\text { t (mental } \\
\text { health } \\
\text { care). } \\
\text { Peds has }\end{array}$ \\
\hline
\end{tabular}




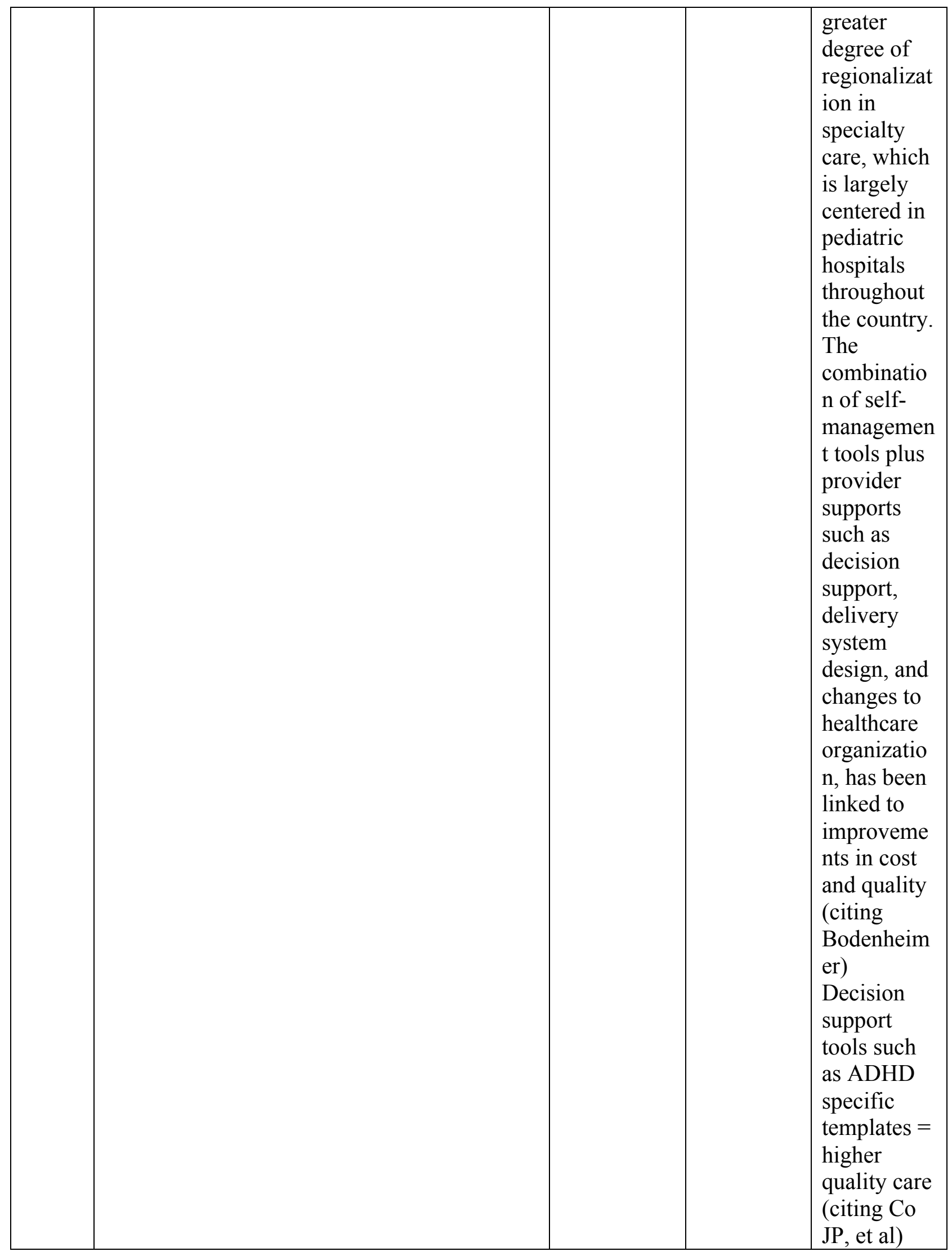




\begin{tabular}{|c|c|c|c|c|}
\hline & & & & $\begin{array}{l}\text { Videoconfe } \\
\text { rencing- } \\
\text { satisfaction } \\
\text { comparable } \\
\text { to face-to- } \\
\text { face } \\
\text { Online } \\
\text { therapies } \\
\text { like triple } \\
\text { p- positive } \\
\text { parenting } \\
\text { program } \\
\text { Web portals } \\
\text { for parents } \\
\text { and } \\
\text { teachers to } \\
\text { input info }\end{array}$ \\
\hline $\begin{array}{l}\text { Bhata } \\
\text { ra } \\
(2005 \\
)\end{array}$ & $\begin{array}{l}\text { Acceptability of a web-based adhd scale by } \\
\text { teachers }\end{array}$ & $\begin{array}{l}\text { Qualitative, } \\
\text { pilot study- } \\
\text { weekly } \\
\text { monitoring } \\
19 \text { teachers }\end{array}$ & $\begin{array}{l}\text { Very small } \\
\text { sample } \\
\text { size, not } \\
\text { blinded, } \\
\text { no } \\
\text { controls }\end{array}$ & $\begin{array}{l}89.5 \% \text { of } \\
\text { teachers } \\
\text { rated } \\
\text { program to } \\
\text { be easier, } \\
\text { shorter, } \\
\text { simpler, } \\
\text { and more } \\
\text { informative } \\
\text { than paper- } \\
\text { based } \\
\text { scales. } \\
\text { Saves time, } \\
\text { more } \\
\text { flexible and } \\
\text { efficient }\end{array}$ \\
\hline $\begin{array}{l}\text { Carrol } \\
1 \\
(2013 \\
)\end{array}$ & $\begin{array}{l}\text { Use of a Computerized Decision Aid for } \\
\text { ADHD Diagnosis: A Randomized Controlled } \\
\text { Trial } \\
\text { Clinical decision support system... computer } \\
\text { system with pt pre-screening then physician } \\
\text { check boxes }\end{array}$ & $\begin{array}{l}\text { Cluster } \\
\text { RTC, 6-12 } \\
\text { yr olds, } 4 \\
\text { practices } \\
\mathrm{N}=84 \\
\text { charts } \\
\text { reviewed }\end{array}$ & & $\begin{array}{l}\text { Increase in } \\
\text { structured } \\
\text { diagnostic } \\
\text { assessments } \\
\text { in } \\
\text { intervention } \\
\text { group } \\
\text { compared } \\
\text { with } \\
\text { controlled } \\
\text { group (8.0, } \\
\text { 95\% CI, } \\
1.6-40.6) .\end{array}$ \\
\hline
\end{tabular}




\begin{tabular}{|c|c|c|c|c|}
\hline $\begin{array}{l}\text { Chan } \\
(2005 \\
)\end{array}$ & $\begin{array}{l}\text { Diagnostic Practices for ADHD: A national } \\
\text { survey of PCPs }\end{array}$ & $\begin{array}{l}\mathrm{N}=861 \\
\text { Baseline } \\
\text { practice } \\
\text { variability } \\
\text { prior to } \\
\text { release of } \\
\text { the AAP } \\
\text { guidelines }\end{array}$ & $\begin{array}{l}53 \\
\text { question } \\
\text { survey } \\
\text { tested and } \\
\text { approved } \\
\text { by AAP } \\
\text { likert scale } \\
\text { cross- } \\
\text { tabulations } \\
\text { with chi- } \\
\text { square test } \\
\text { This study } \\
\text { does not } \\
\text { compare } \\
\text { self-report } \\
\text { with } \\
\text { findings } \\
\text { from a } \\
\text { chart } \\
\text { review }\end{array}$ & $\begin{array}{l}\text { Great } \\
\text { variability } \\
\text { in } \\
\text { evaluation } \\
\text { practices } \\
\text { prior to } \\
\text { release of } \\
\text { CPG } \\
58 \% \text { used } \\
\text { formal } \\
\text { diagnostic } \\
\text { criteria, but } \\
\text { only } 28 \% \\
\text { used DSM } \\
83 \% \text { used } \\
\text { teacher/sch } \\
\text { ool info } \\
70 \% \text { used } \\
\text { ADHD- } \\
\text { specific } \\
\text { rating } \\
\text { scales } \\
60 \% \text { used } \\
\text { global } \\
\text { rating } \\
\text { scales } \\
25 \% \\
\text { obtained } \\
\text { screening } \\
\text { labs } \\
74-91 \% \\
\text { assessed for } \\
\text { comorbid } \\
\text { conditions } \\
\text { a minority } \\
\text { of the } \\
\text { sample } \\
\text { reported } \\
\text { overall } \\
\text { diagnostic } \\
\text { practices } \\
\text { consistent } \\
\text { with at least } \\
4 \text { of the } 6 \\
\text { recommend } \\
\text { ations in }\end{array}$ \\
\hline
\end{tabular}




\begin{tabular}{|c|c|c|c|}
\hline & & & the $\mathrm{CPG}$ \\
\hline $\begin{array}{l}\text { Dreye } \\
\mathrm{r} \\
(2010 \\
)\end{array}$ & $\begin{array}{l}\text { Parental Adherence to Clinical } \\
\text { recommendations in an adhd evaluation clinic } \\
\text { Perceived barriers to parental adherence with } \\
\text { child psych recommendations }\end{array}$ & $\begin{array}{l}\mathrm{N}=80 \\
\text { caregivers } \\
\text { Phone } \\
\text { interview 4- } \\
6 \text { weeks } \\
\text { after eval } \\
\text { feedback }\end{array}$ & $\begin{array}{l}\text { adherence } \\
81.5 \% \text { of } \\
\text { recommend } \\
\text { ations, least } \\
\text { likely to } \\
\text { follow } \\
\text { through on } \\
\text { recommend } \\
\text { ation for } \\
\text { psych } \\
\text { services } \\
\text { (parental } \\
\text { behavior } \\
\text { training, } \\
\text { therapy). } \\
\text { Common } \\
\text { barriers- } \\
\text { lack of time } \\
\text { and } \\
\text { perceptions } \\
\text { that the } \\
\text { child's } \\
\text { teacher was } \\
\text { uncooperati } \\
\text { ve with } \\
\text { implementi } \\
\text { ng school- } \\
\text { based } \\
\text { recommend } \\
\text { ations }\end{array}$ \\
\hline $\begin{array}{l}\text { Epstei } \\
\mathrm{n} \\
(2008 \\
)\end{array}$ & $\begin{array}{l}\text { Community-wide intervention to improve the } \\
\text { adhd assessment and treatment practices of } \\
\text { community physicians }\end{array}$ & $\begin{array}{l}19 \text { practices } \\
\text { with } 84 \\
\text { pcps trained } \\
\text { and } \\
\text { received pre } \\
\text { and post } \\
\text { training } \\
\text { adherence } \\
\text { eval }\end{array}$ & $\begin{array}{l}\text { Parent and } \\
\text { teacher } \\
\text { rating } \\
\text { scales } \\
\text { improved } \\
\text { from } 52 \% \\
\text { to almost } \\
100 \% \text {; } \\
\text { systematic } \\
\text { monitoring } \\
\text { of med } \\
\text { response- } \\
9 \% \text { to } 40 \%\end{array}$ \\
\hline $\begin{array}{l}\text { Epstei } \\
\mathrm{n}\end{array}$ & $\begin{array}{l}\text { Sustained improvement in pediatricians' adhd } \\
\text { practice behaviors in the context of a }\end{array}$ & $\begin{array}{l}14 \\
\text { practices } / 38\end{array}$ & $\begin{array}{l}\text { Improveme } \\
\text { nts were }\end{array}$ \\
\hline
\end{tabular}




\begin{tabular}{|c|c|c|c|c|}
\hline $\begin{array}{l}(2010 \\
)\end{array}$ & $\begin{array}{l}\text { community based quality improvement } \\
\text { initiative. }\end{array}$ & $\begin{array}{l}\text { pcps- } \\
\text { followed } 2 \\
\text { years after } \\
\text { intervention } \\
\text { via chart } \\
\text { review }\end{array}$ & & sustained \\
\hline $\begin{array}{l}\text { Epstei } \\
\mathrm{n} \\
(2014 \\
)\end{array}$ & $\begin{array}{l}\text { Presents variability for adhd care (practice- } \\
\text { level, pediatrician-level, patient-level) }\end{array}$ & $\begin{array}{l}\text { Chart } \\
\text { review } \\
\text { random } \\
\text { sample } \\
1594 \mathrm{pt} \\
\text { charts, } 188 \\
\text { pediatrician } \\
\mathrm{s}, 50 \\
\text { practices }\end{array}$ & $\begin{array}{l}\text { Appears to } \\
\text { be multi- } \\
\text { level } \\
\text { framework } \\
\text {, although } \\
\text { it is not } \\
\text { stated } \\
\text { directly. } \\
\text { Discusses } \\
\text { physician/ } \\
\text { practice } \\
\text { level, } \\
\text { system- } \\
\text { level, } \\
\text { communit } \\
\text { y level, } \\
\text { health plan } \\
\text { level } \\
\text { interventio } \\
\text { ns } \\
\text { Authors } \\
\text { state that } \\
\text { although } \\
\text { guidelines } \\
\text { are an } \\
\text { important } \\
\text { first step, } \\
\text { additional } \\
\text { efforts, } \\
\text { likely } \\
\text { initiated or } \\
\text { incentivize } \\
\text { d outside } \\
\text { of the } \\
\text { practice, } \\
\text { are } \\
\text { required to } \\
\text { improve } \\
\text { the quality } \\
\text { of care }\end{array}$ & $\begin{array}{l}\text { DSM } \\
\text { criteria } \\
\text { documented } \\
70.4 \% \text { of } \\
\text { pts } \\
93 \% \text { pts } \\
\text { receiving } \\
\text { medication } \\
\text { 13\% pts } \\
\text { receiving } \\
\text { psychosoci } \\
\text { al treatment } \\
\text { parent- } \\
\text { teacher } \\
\text { rating } \\
\text { scales } \\
\text { rarely } \\
\text { collected to } \\
\text { monitor } \\
\text { treatment } \\
\text { response or } \\
\text { side effects } \\
\text { fewer than } \\
\text { half } 47 \% \\
\text { that were } \\
\text { prescribed } \\
\text { meds had } \\
\text { contact } \\
\text { with peds } \\
\text { within the } \\
\text { first month } \\
\text { There is a } \\
\text { great need } \\
\text { to improve } \\
\text { the quality }\end{array}$ \\
\hline
\end{tabular}




\begin{tabular}{|c|c|c|c|c|}
\hline & & & $\begin{array}{l}\text { delivered } \\
\text { in } \\
\text { pediatric } \\
\text { settings. } \\
\text { Such } \\
\text { efforts } \\
\text { may take } \\
\text { the form } \\
\text { of quality } \\
\text { improvem } \\
\text { ent, } \\
\text { clinical } \\
\text { decision } \\
\text { support } \\
\text { tools, } \\
\text { using pay- } \\
\text { for- } \\
\text { performan } \\
\text { ce } \\
\text { incentives, } \\
\text { and } \\
\text { partnering } \\
\text { with } \\
\text { mental } \\
\text { health } \\
\text { profession } \\
\text { als }\end{array}$ & $\begin{array}{l}\text { of ADHD } \\
\text { care } \\
\text { received by } \\
\text { children in } \\
\text { community } \\
\text { based } \\
\text { pediatric } \\
\text { settings. }\end{array}$ \\
\hline $\begin{array}{l}\text { Epstei } \\
\mathrm{n} \\
(2011 \\
)\end{array}$ & $\begin{array}{l}\text { Use of an Internet Portal to Improve } \\
\text { Community-Based Pediatric ADHD Care: A } \\
\text { Cluster Randomized Trial } \\
\text { Objective: to determine effectiveness of a QI } \\
\text { program to improve pediatricians' adherence } \\
\text { to existing, EB ADHD guidelines }\end{array}$ & $\begin{array}{l}49 \\
\text { community } \\
\text { based } \\
\text { pediatrician } \\
\text { s at } 8 \\
\text { practices } \\
\text { chart } \\
\text { review for } \\
\text { random } \\
\text { sample of } \\
\text { pts with } \\
\text { ADHD } \\
\text { examined at } \\
\text { baseline } \\
\text { and } 6 \text { mo. } \\
4 \text { sessions } \\
\text { of training, } \\
\text { then access } \\
\text { to internet }\end{array}$ & & $\begin{array}{l}\text { Improved } \\
\text { adherence } \\
\text { to CPG in } \\
\text { intervention } \\
\text { group } \\
\text { rating } \\
\text { scales; } \\
\text { parent } \\
\text { (Cohen's } \\
d=0.69) \text {, } \\
\text { and teacher } \\
\text { (d=0.68), } \\
\text { DSM } \\
\text { criteria } \\
\text { (d=0.85), } \\
\text { treatment } \\
\text { response } \\
\text { (d=1.01) }\end{array}$ \\
\hline
\end{tabular}




\begin{tabular}{|c|c|c|c|}
\hline & & $\begin{array}{l}\text { portal with } \\
\text { parent/teach } \\
\text { er/PCM } \\
\text { input }\end{array}$ & \\
\hline $\begin{array}{l}\text { Foy } \\
(2010 \\
)\end{array}$ & $\begin{array}{l}\text { Strategies for preparing a primary care } \\
\text { practice for provision of enhanced mental } \\
\text { health services } \\
\text {-medical home } \\
\text {-chronic care model }\end{array}$ & & $\begin{array}{l}\text { literature } \\
\text { focus on } \\
\text { medical } \\
\text { rather than } \\
\text { mental } \\
\text { health } \\
\text { conditions } \\
\text { and adults } \\
\text { rather than } \\
\text { children } \\
\text { (citing } \\
\text { Wagner) } \\
\text {-Integrated } \\
\text { care system } \\
\text { model } \\
\text { (systematic } \\
\text { screening, } \\
\text { coordinatio } \\
\text { n of care } \\
\text { with mental } \\
\text { health team, } \\
\text { patient } \\
\text { engagement } \\
\text { in care) }\end{array}$ \\
\hline $\begin{array}{l}\text { Fried } \\
\text { man } \\
(2006\end{array}$ & $\begin{array}{l}\text { ADHD, medication, and the military service: } \\
\text { a pediatrician's dilemma }\end{array}$ & Case report & $\begin{array}{l}\text { Hesitance } \\
\text { of young } \\
\text { adults to } \\
\text { disclose } \\
\text { history of } \\
\text { ADHD and } \\
\text { prior } \\
\text { medication } \\
\text { use due to } \\
\text { military } \\
\text { stigma }\end{array}$ \\
\hline $\begin{array}{l}\text { Geltm } \\
\text { an } \\
(2015 \\
)\end{array}$ & $\begin{array}{l}\text { Implement and assess an electronic registry of } \\
\text { patients with ADHD combined with care } \\
\text { coordination by a planned care team }\end{array}$ & $\begin{array}{l}\text { QI- } 2 \\
\text { intervention } \\
, 2 \text { control } \\
\text { clinics. } \\
\text { Outcome } \\
\text { measures } 2 \\
\text { recommend }\end{array}$ & $\begin{array}{l}\text { Modest } \\
\text { improveme } \\
\text { nt in } \\
\text { diagnostic } \\
\text { and } \\
\text { treatment } \\
\text { process }\end{array}$ \\
\hline
\end{tabular}




\begin{tabular}{|c|c|c|c|}
\hline & & $\begin{array}{l}\text { ed clinical } \\
\text { follow-ups } \\
\text { based on } \\
\text { HEDIS } \\
\text { measures } \\
\text { and use of } \\
\text { Vanderbilt } \\
\text { rating } \\
\text { scales } \\
\text { Quasiexperi } \\
\text { mental } \\
\text { strategy } \\
\mathrm{N}=329\end{array}$ & $\begin{array}{l}\text { Focus on } \\
\text { system } \\
\text { changes } \\
\text { using } \\
\text { elements of } \\
\text { chronic } \\
\text { care model } \\
\text { (registries } \\
\text { and planned } \\
\text { care teams) } \\
\text { rather than } \\
\text { focusing on } \\
\text { physician } \\
\text { behaviors }\end{array}$ \\
\hline $\begin{array}{l}\text { Gordo } \\
\text { n } \\
(2016 \\
)\end{array}$ & $\begin{array}{l}\text { Comparison of performance on ADHD } \\
\text { quality of care indicators: practitioner self- } \\
\text { report verses chart review }\end{array}$ & $\begin{array}{l}\mathrm{N}=1599 \\
\text { charts } \\
\text { reviewed }\end{array}$ & $\begin{array}{l}\text { Higher } \\
\text { provider } \\
\text { self-report } \\
\text { in every } \\
\text { performanc } \\
\text { e category } \\
\text { when } \\
\text { compared } \\
\text { with chart } \\
\text { review }\end{array}$ \\
\hline $\begin{array}{l}\text { Hisle- } \\
\text { Gorm } \\
\text { an }\end{array}$ & $\begin{array}{l}\text { ADHD and medication use by children during } \\
\text { parental military deployments }\end{array}$ & & $\begin{array}{l}\text { Children } \\
\text { with } \\
\text { ADHD had } \\
254,697 \\
\text { mental and } \\
\text { behavioral } \\
\text { health visits } \\
\text { during FY } \\
2006-2007 \text {, } \\
\text { with visits } \\
\text { for ADHD } \\
\text { accounting } \\
\text { for } 65 \% \text { of } \\
\text { visits } \\
\text { categorized } \\
\text { as mental } \\
\text { and } \\
\text { behavioral } \\
\text { health care. }\end{array}$ \\
\hline Krull & Krull, K. R., (2016). Attention deficit & & Advances \\
\hline
\end{tabular}




\begin{tabular}{|c|c|c|c|}
\hline $\begin{array}{l}\text { KR } \\
(2016 \\
)\end{array}$ & $\begin{array}{l}\text { hyperactivity disorder in children and } \\
\text { adolescents: Epidemiology and pathogenesis. } \\
\text { Retrieved from http://www-uptodate- } \\
\text { com.proxy.its.virginia.edu/contents/attention- } \\
\text { deficit-hyperactivity-disorder-in-children- } \\
\text { and-adolescents-epidemiology-and- } \\
\text { pathogenesis?source=search result\&search=a } \\
\text { dhd\&selectedTitle=7\%7E150 on May } 4, \\
2016 .\end{array}$ & & $\begin{array}{l}\text { in } \\
\text { neuroimagi } \\
\text { ng and } \\
\text { neuropsych } \\
\text { ological } \\
\text { testing in } \\
\text { children } \\
\text { with } \\
\text { ADHD also } \\
\text { identify } \\
\text { difficulties } \\
\text { with } \\
\text { forward } \\
\text { planning, } \\
\text { abstract } \\
\text { reasoning, } \\
\text { mental } \\
\text { flexibility, } \\
\text { working } \\
\text { memory, } \\
\text { and } \\
\text { response } \\
\text { inhibition }\end{array}$ \\
\hline $\begin{array}{l}\text { Leslie } \\
(2004 \\
)\end{array}$ & $\begin{array}{l}\text { Implementing the AAP ADHD diagnostic } \\
\text { guideline in primary care setting }\end{array}$ & 7 offices & $\begin{array}{l}\text { Education } \\
\text { protocol } \\
\text { and } \\
\text { measured } \\
\text { response. } \\
\text { Barriers } \\
\text { also noted } \\
\text { by pcps } \\
\text { Limited } \\
\text { information } \\
\text { in the } \\
\text { guidelines } \\
\text { regarding } \\
\text { the use of } \\
\text { specific } \\
\text { ADHD } \\
\text { rating } \\
\text { scales, } \\
\text { families' } \\
\text { need for } \\
\text { education } \\
\text { regarding } \\
\text { ADHD and }\end{array}$ \\
\hline
\end{tabular}




\begin{tabular}{|c|c|c|c|}
\hline & & & $\begin{array}{l}\text { support, } \\
\text { characteristi } \\
\text { cs of } \\
\text { physical } \\
\text { health and } \\
\text { mental } \\
\text { health plans } \\
\text { that limited } \\
\text { care for } \\
\text { children } \\
\text { with } \\
\text { ADHD, and } \\
\text { limited } \\
\text { knowledge } \\
\text { and use of } \\
\text { potential } \\
\text { community } \\
\text { resources }\end{array}$ \\
\hline $\begin{array}{l}\text { Marsh } \\
\text { all } \\
(2011 \\
)\end{array}$ & $\begin{array}{l}\text { Patient-centered medical home: an emerging } \\
\text { primary care model and the military health } \\
\text { system }\end{array}$ & & \\
\hline $\begin{array}{l}\text { McEll } \\
\text { igott } \\
(2014 \\
)\end{array}$ & $\begin{array}{l}\text { Examine practice patterns in the management } \\
\text { of adhd in a pediatric research network }\end{array}$ & $\begin{array}{l}\text { 23-question } \\
\text { survey } \\
\text { developed } \\
\text { based on } \\
\text { AAP } 2001 \\
\text { CPG to } \\
\text { assess } \\
\text { provider- } \\
\text { reported } \\
\text { practice } \\
\text { patterns in } \\
\text { the } \\
\text { diagnosis } \\
\text { and } \\
\text { managemen } \\
\text { t of ADHD } \\
16 \text { pediatric } \\
\text { practices in } \\
\text { SC, } \\
260,000 \\
\text { annual } \\
\text { visits }\end{array}$ & $\begin{array}{l}\text { Current } \\
\text { data limited } \\
\text { on } \\
\text { compliance } \\
\text { with cpg } \\
\text { Differences } \\
\text { in practice } \\
\text { patterns } \\
\text { exist by } \\
\text { practitioner } \\
\text { experience, } \\
\text { location, } \\
\text { and practice } \\
\text { type } \\
\text { Additional } \\
\text { testing } \\
\text { (labs, ECG) } \\
\text { performed } \\
\text { infrequentl } \\
\text { y, but } \\
\text { possibly } \\
\text { more than } \\
\text { recommend } \\
\text { ed }\end{array}$ \\
\hline
\end{tabular}




\begin{tabular}{|c|c|c|c|}
\hline & & & $\begin{array}{l}80 \% \\
\text { reported } \\
\text { compliance } \\
\text { with } \\
\text { rescreening } \\
\text { with a } \\
\text { standardize } \\
\text { d tool }\end{array}$ \\
\hline $\begin{array}{l}\text { Myers } \\
(2015 \\
)\end{array}$ & $\begin{array}{l}\text { Effectiveness of a telehealth service delivery } \\
\text { model for treating adhd: a community based } \\
\text { ret }\end{array}$ & $\begin{array}{l}223 \mathrm{kids} / 88 \\
\mathrm{pcps} / 7 \\
\text { communitie } \\
\mathrm{s}\end{array}$ & $\begin{array}{l}\text { Telehealth } \\
\text { service } \\
\text { model } \\
\text { improved } \\
\text { significantl } \\
\text { y more than } \\
\text { children in } \\
\text { augmented } \\
\text { primary } \\
\text { care arm }\end{array}$ \\
\hline $\begin{array}{l}\text { Nelso } \\
\mathrm{n} \\
(2012 \\
)\end{array}$ & $\begin{array}{l}\text { Telemedicine and adherence to national } \\
\text { guidelines for ADHD evaluation } \\
\text { Real-time videoconferencing linked pts, } \\
\text { families, and specialty mental health team } \\
\text { Adherence to AAP CPG was tracked }\end{array}$ & $\begin{array}{l}\text { Case study } \\
\mathrm{N}=22 \mathrm{pts} \\
\text { mean age } \\
9.3 \mathrm{yrs} \\
69 \\
\text { telemedicin } \\
\text { e visits } \\
\text { across } 13 \\
\text { different } \\
\text { school } \\
\text { related sites }\end{array}$ & $\begin{array}{l}\text { School- } \\
\text { based } \\
\text { telemedicin } \\
\text { e clinic } \\
\text { allowed } \\
\text { increased } \\
\text { communica } \\
\text { tion across } \\
\text { the school } \\
\text { and } \\
\text { specialty } \\
\text { mental } \\
\text { health } \\
\text { systems and } \\
\text { facilitated } \\
\text { greater } \\
\text { input across } \\
\text { child, } \\
\text { parent, } \\
\text { school } \\
\text { personnel, } \\
\text { and MH } \\
\text { professiona } \\
\text { ls. }\end{array}$ \\
\hline $\begin{array}{l}\text { Office } \\
\text { of } \\
\text { Disea } \\
\text { se }\end{array}$ & $\begin{array}{l}\text { Healthy people 2020: Mental health and } \\
\text { mental disorders }\end{array}$ & & \\
\hline
\end{tabular}




\begin{tabular}{|c|c|c|c|}
\hline $\begin{array}{l}\text { Preve } \\
\text { ntion } \\
\text { and } \\
\text { Healt } \\
\text { h } \\
\text { Prom } \\
\text { otion } \\
(2015 \\
\text { ) }\end{array}$ & & & \\
\hline $\begin{array}{l}\text { Olson } \\
(2005 \\
)\end{array}$ & $\begin{array}{l}\text { Improving guideline adherence for the } \\
\text { diagnosis of adhd in an ambulatory pediatric } \\
\text { setting } \\
\text { Implement a formalized diagnostic protocol } \\
\text { for ADHD and study whether this protocol } \\
\text { improved adherence to CPG } \\
\text { Completion of semistructured interview and } \\
\text { mandatory rating scales for home and school. }\end{array}$ & $\begin{array}{l}\text { Quasi- } \\
\text { experiment } \\
\text { al } \\
\text { retrospectiv } \\
\text { e record } \\
\text { review } \\
\mathrm{N}=63 \text { pts }\end{array}$ & $\begin{array}{l}\text { Only } 4 \% \text { of } \\
\text { providers } \\
\text { adhered to } \\
\text { all } 4 \text { criteria } \\
\text { in aap } \\
\text { guidelines } \\
\text { compared } \\
\text { to } 82 \% \text { in } \\
\text { after group } \\
\text { (p<.001). } \\
\text { significant } \\
\text { improveme } \\
\text { nt observed } \\
\text { across each } \\
\text { of the } 4 \\
\text { criteria }\end{array}$ \\
\hline $\begin{array}{l}\text { Polah } \\
\text { a } \\
(2005 \\
)\end{array}$ & $\begin{array}{l}\text { The assessment of adhd in rural primary care: } \\
\text { the portability of the aap guidelines to the real } \\
\text { world }\end{array}$ & $\begin{array}{l}2 \text { practices, } \\
101 \mathrm{pts}\end{array}$ & $\begin{array}{l}\text { Significant } \\
\text { improveme } \\
\text { nt with } \\
\text { training on } \\
\text { CPG and } \\
\text { supporting } \\
\text { materials }\end{array}$ \\
\hline $\begin{array}{l}\text { Rusht } \\
\text { on } \\
(2004 \\
)\end{array}$ & $\begin{array}{l}\text { Use of practice guidelines in the primary care } \\
\text { of children with attention- } \\
\text { deficit/hyperactivity disorder. } \\
\text { Rushton JL; Fant KE; Clark SJ. } \\
\text { Pediatrics. 114(1):e23-8, 2004 Jul. }\end{array}$ & $\begin{array}{l}\mathrm{N}=1374 \\
\mathrm{pcps}\end{array}$ & $\begin{array}{l}\text { Pcp survey } \\
\text { to evaluate } \\
\text { guideline } \\
\text { adherence }\end{array}$ \\
\hline $\begin{array}{l}\text { Visser } \\
(2015 \\
)\end{array}$ & $\begin{array}{l}\text { To describe the parent-reported prevalence of } \\
\text { treatments for attention deficit/hyperactivity } \\
\text { disorder (ADHD) among a national sample of } \\
\text { children with special health care needs } \\
\text { (CSHCN), and assess the alignment of } \\
\text { ADHD treatment with current American } \\
\text { Academy of Pediatrics guidelines. }\end{array}$ & $\begin{array}{l}\text { Parent- } \\
\text { reported } \\
\text { data from } \\
\text { the } 2009- \\
2010 \\
\text { National } \\
\text { Survey of } \\
\text { Children }\end{array}$ & $\begin{array}{l}\text { These } \\
\text { estimates } \\
\text { provide a } \\
\text { benchmark } \\
\text { of clinical } \\
\text { practice for } \\
\text { the period } \\
\text { directly }\end{array}$ \\
\hline
\end{tabular}




\begin{tabular}{|c|c|c|c|}
\hline & 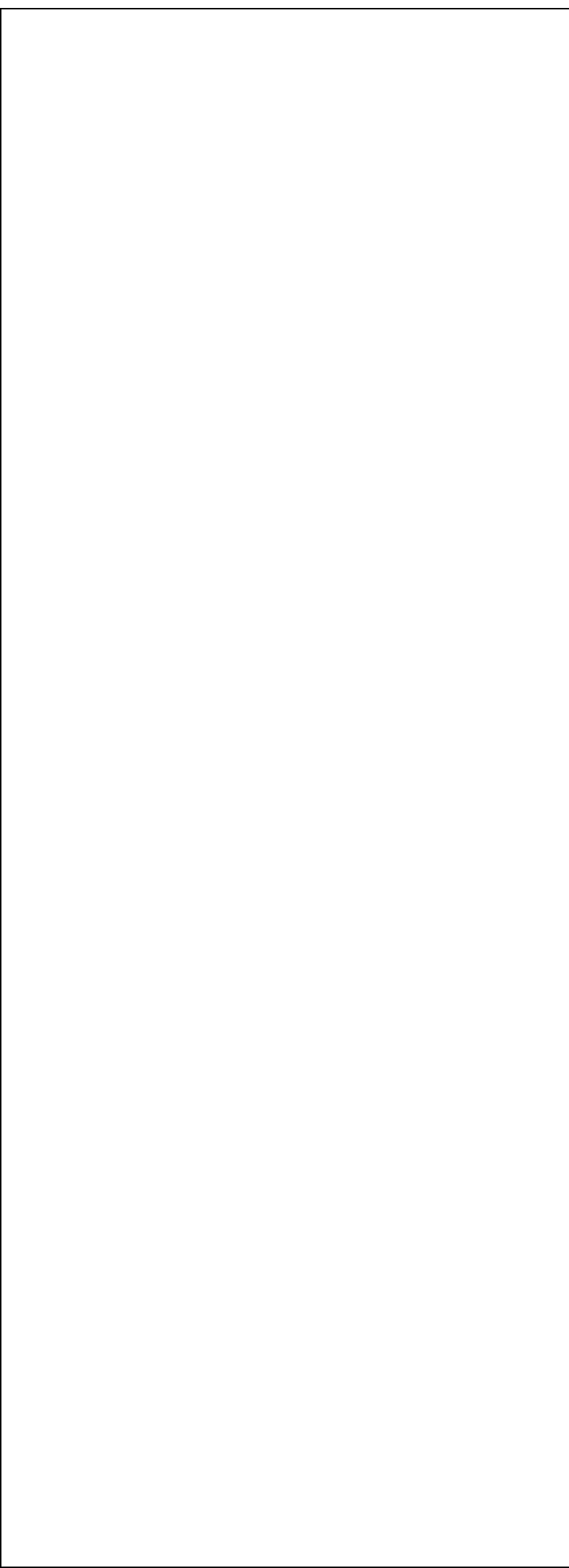 & $\begin{array}{l}\text { with } \\
\text { Special } \\
\text { Health Care } \\
\text { Needs } \\
\text { allowed for } \\
\text { weighted } \\
\text { national and } \\
\text { state-based } \\
\text { prevalence } \\
\text { estimates of } \\
\text { medication, } \\
\text { behavioral } \\
\text { therapy, } \\
\text { and dietary } \\
\text { supplement } \\
\text { use for } \\
\text { ADHD } \\
\text { treatment } \\
\text { among } \\
\text { CSHCN } \\
\text { aged 4- } \\
17 \text { years } \\
\text { with current } \\
\text { ADHD. }\end{array}$ & $\begin{array}{l}\text { preceding } \\
\text { issuance of } \\
\text { the } \\
\text { American } \\
\text { Academy } \\
\text { of } \\
\text { Pediatrics' } \\
\text { 2011 } \\
\text { ADHD } \\
\text { guidelines. } \\
\text { Most } \\
\text { children } \\
\text { with } \\
\text { ADHD } \\
\text { received } \\
\text { medication } \\
\text { treatment or } \\
\text { behavioral } \\
\text { therapy; } \\
\text { just under } \\
\text { one-third } \\
\text { received } \\
\text { both. } \\
\text { Multimodal } \\
\text { treatment } \\
\text { was most } \\
\text { common } \\
\text { for CSHCN } \\
\text { with severe } \\
\text { ADHD and } \\
\text { those with } \\
\text { comorbiditi } \\
\text { es. } \\
\text { Approximat } \\
\text { ely one-half } \\
\text { of } \\
\text { preschooler } \\
\text { s received } \\
\text { behavioral } \\
\text { therapy, the } \\
\text { recommend } \\
\text { ed first-line } \\
\text { treatment } \\
\text { for this age } \\
\text { group. }\end{array}$ \\
\hline Visser & Diagnostic experiences of children with adhd & & \\
\hline
\end{tabular}




\begin{tabular}{|c|c|c|c|}
\hline (2015 & & & \\
\hline $\begin{array}{l}\text { Vree } \\
\operatorname{man} \\
(2006\end{array}$ & $\begin{array}{l}\text { Compliance with guidelines for adhd: a pilot } \\
\text { study of an evaluation tool } \\
\text { Chart extraction form }\end{array}$ & $\begin{array}{l}57 \text { charts } \\
\text { reviewed }\end{array}$ & $\begin{array}{l}1 \text { page tool } \\
\text { could } \\
\text { reliably } \\
\text { evaluate } \\
\text { compliance } \\
\text { with } \\
\text { ADHD } \\
\text { diagnosis } \\
\text { and } \\
\text { treatment } \\
\text { guidelines. } \\
\text { Tool had } \\
\text { strong } \\
\text { inter-rater } \\
\text { reliability } \\
\text { with k of } \\
0.81 . \text { Pilot } \\
\text { testing for } \\
57 \text { pts } \\
\text { showed } \\
\text { only } 12 \% \\
\text { documented } \\
\text { full } \\
\text { compliance } \\
\text { with } \\
\text { assessment } \\
\text { guidelines } \\
\text { and } 44 \% \\
\text { with } \\
\text { treatment } \\
\text { guidelines. }\end{array}$ \\
\hline $\begin{array}{l}\text { Wolra } \\
\text { ich } \\
(2011 \\
\text { ) }\end{array}$ & $\begin{array}{l}\text { Implementing the key action statements: An } \\
\text { algorithm and explanation for process of care } \\
\text { for the evaluation, diagnosis, treatment, and } \\
\text { monitoring of adhd in children and } \\
\text { adolescents }\end{array}$ & $\begin{array}{l}\text { Consistent } \\
\text { with CPG } \\
\text { and based } \\
\text { on practical } \\
\text { experience } \\
\text { and advice } \\
\text { of clinicians } \\
\text { experienced } \\
\text { in the } \\
\text { diagnosis } \\
\text { and } \\
\text { managemen } \\
\mathrm{t} \text { of ADHD }\end{array}$ & $\begin{array}{l}\text { Compared } \\
\text { with } \\
\text { clinical } \\
\text { interviews, } \\
\text { standardize } \\
\mathrm{d} \\
\text { psychologic } \\
\text { al tests, } \\
\text { such as } \\
\text { computeriz } \\
\text { ed tests of } \\
\text { attention, } \\
\text { have not }\end{array}$ \\
\hline
\end{tabular}




\begin{tabular}{|l|l|l|l|l|}
\hline & $\begin{array}{l}\text { in children } \\
\text { and } \\
\text { adolescents }\end{array}$ & & $\begin{array}{l}\text { been found } \\
\text { to reliably } \\
\text { differentiate } \\
\text { between } \\
\text { youth with } \\
\text { and without } \\
\text { ADHD }\end{array}$ \\
\hline
\end{tabular}


IRB Approval Forms

\section{Appendix C}

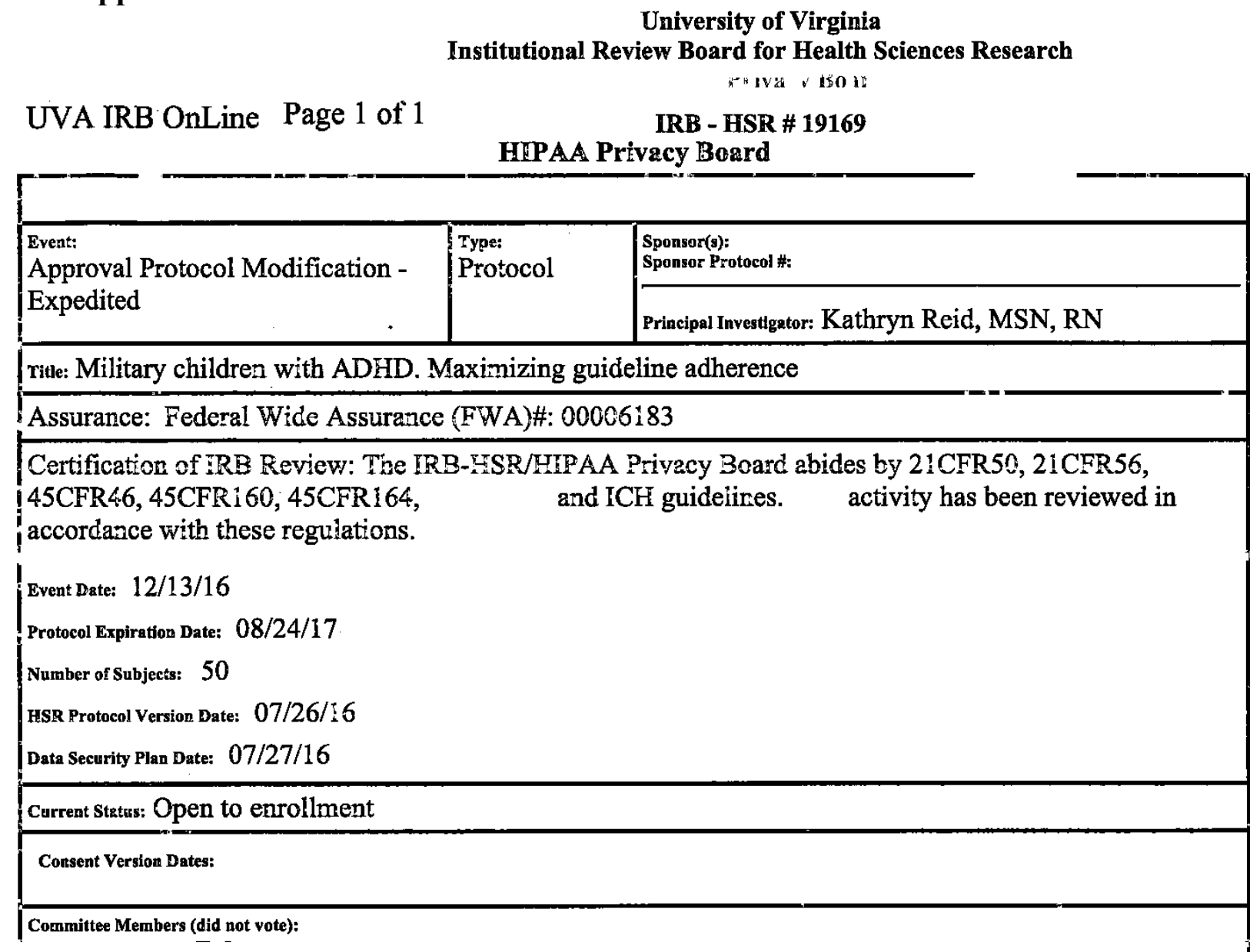

4 The IR II IR IIIP Privact of robuses

(1) $\quad+\mathrm{K}$ 
Comments: The IRB determined this modification met the criteria for approval per the federal regulations.

Modification expedited: minimal risk/minor changes.

With this modification the protocol is opened to enrollment.

Outside institutional approval from DHA Privacy Board (entity which approves use of data from Tyndall Air Force Base, 325th Medical Group) on file.

ISPRO approval on file.

The IRB-HSR official noted below certifies that the information provided above is correct and that, as required, future reviews will be performed and certification will be provided.

Name: Margaret W. Ball, BSN, MEd, CIP

Title: Member, Institutional Review Board for Health

Sciences Research

Phone: 434-924-9634

Fax: 434-924-2932

Name and Address of Institution:

Institutional Review Board for Health Sciences

Research

PO Box 800483

University of Virginia

Charlottesville, VA 22908

Approval:

Date:

(C) 2016 by the Rector and Visitors of the University of Virginia. A!l rights reserved.

$12 / 13 / 16$ at $12: 04 \mathrm{PM}$

https://www.irb.virginia.edu/index.cfm?fuseAction=hsr_HTMLReports.reportProtocolAs... $\quad$ 12/13/2016 I 


\section{Cover Letter to $325^{\text {th }}$ MDG Commander}

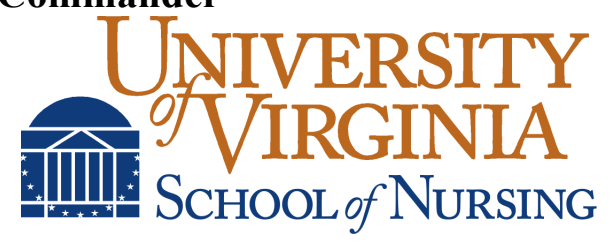

04 October 2016

SCOTT M. MCKIM, Col, USAF, BSC

Commander, 325th Medical Group

Tyndall AFB FL 32403

Captain Kelley M Henson, USAF

Doctoral of Nursing Practice Student

AFIT/University of Virginia

School of Nursing

225 Jeanette Lancaster Way

Charlottesville VA 22903

Dear Colonel McKim

I am currently an AFIT student, completing my doctorate of nursing practice at the University of Virginia (UVA). As a requirement for completion of the program, I am required to conduct a research project or quality improvement study. Prior to my selection for AFIT, I was stationed at Tyndall AFB, serving as a pediatric nurse practitioner, and the pediatric element leader from 2013-2015. While caring for the population at Tyndall, I implemented a program to assess and treat pediatric attention deficit hyperactivity disorder according to the current clinical practice guidelines. This program enabled the clinic to recapture approximately $\$ 3,000$ spent per child for off base evaluation. The purpose of my doctoral project will be to assess current provider adherence to the guideline, 24 months after implementation in the clinic. I am writing to request your endorsement in my endeavor to provide the highest quality of care to the children our military members. I have included a memorandum to briefly describe the project and demonstrate command support, which will be routed to the Human Research Protection Official (HRPO) as part of the application for study approval. As stated in the following memorandum, this project has been reviewed and approved by the University of Virginia Institutional Review Board for Health Sciences Research. Thank you for your time and support, and feel free to contact me with any questions and/or concerns via email kmh3fq@virginia.edu or phone at 931239-6599.

Sincerely,

//Signed//

KELLEY M. HENSON, Capt, USAF

Pediatric Nurse Practitioner 


\title{
$325^{\text {th }}$ MDG Commander Letter of Support
}

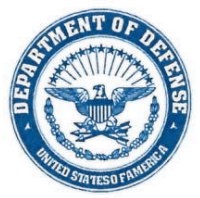

\author{
DEPARTMENT OF THE AIR FORCE \\ 325TH FIGHTER WING (ACC) \\ TYNDALL AIR FORCE BASE FLORIDA
}

OCT 312016

MEMORANDUM FOR HQ USAF/AFMSA/SGE-C

FROM: $325 \mathrm{MDG} / \mathrm{CC}$

SUBJECT: Letter of Support for Human Subjects Research Participation

1. The University of Virginia is conducting a quality improvement project entitled "Military Children with Attention Deficit Hyperactivity Disorder (ADHD): Maximizing Adherence to Clinical Practice Guidelines." This project will evaluate the current status of provider adherence to the ADHD CPG in the pediatric primary care clinic at Tyndall AFB, $325 \mathrm{MDG}, 24$ months after a targeted educational intervention. In keeping with the quality improvement framework of "Plan-Do-Study-Act" (PDSA) this project will additionally incorporate a session for providers to evaluate performance, identify existing barriers that impede guideline adherence, and address areas for improvement through the use of evidence-based interventions.

a. Evaluation of guideline adherence will be conducted using a quantitative, retrospective, chart review of a convenience sample $(n=50)$ of patients empaneled to the selected military pediatric clinic from January through August 2016. Records will be reviewed using an adapted, validated abstraction tool. This project has been reviewed and approved by the University of Virginia Institutional Review Board for Health Sciences Research.

b. All collected data will be de-identified and secured. Demographic data will be recorded and reported to characterize the sample. Each of the six guideline components will be scored related to adherence to the ADHD CPG as follows: "met $=1$ ", "not met $=2$ ", or "N/A = 3." Frequency distributions and percentages of adherence will be provided. Additional anecdotal notes that may explain any deviation from the guideline will also be recorded. After data analysis, a meeting will be held with the pediatric providers to identify common themes related to strengths and perceived barriers. Selected interventions to improve CPG adherence will be taken through the 4 steps of the "Plan-Do-Study-Act" quality improvement model during the meeting, and the findings from this meeting will be highlighted.

c. This project, including the process and findings, addresses a critically important gap in the diagnosis and treatment of military children with ADHD. This pediatric population is particularly vulnerable due to transiency of care associated with frequent family relocations and parental deployments. Facilitating adherence to CPG will foster improved behavioral, academic, and physiological outcomes for these children and their families. Finally, this project highlights the important role of the DNP-prepared APRN in fostering evidence-based practice and outcome improvement.

2. In accordance with DODI 3216.02 and AFI 40-402, Enclosure 3, Section 7.e.1., I support the review of medical records of pediatric patients with $\mathrm{ADHD}$ empaneled to Tyndall AFB pediatric 
clinic for the above mentioned quality improvement. I have determined that since all collected will be de-identified, the risk of violation of subject privacy and confidentiality is minimal, command resources are sufficient to support this activity and that it will not adversely impact clinical care or command mission.

3. Should you have any questions, the POC for this is Capt Kelley Henson. She can be reached by email at kmh3fq@virginia.edu or by phone at (931) 239-6599.

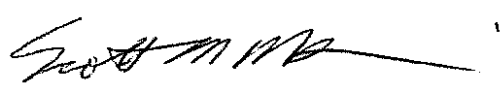

SCOTT M. MCKIM, Colonel, USAF, BSC Commander 


\section{Defense Health Agency Approval}

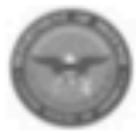

Defense Health Agency Data Sharing Agreement Application

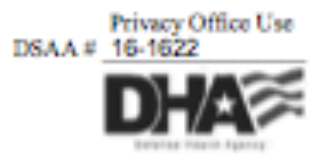

\section{Table of Contents}

Click a heading below to advance divectly to the desired DSA section:

PROJECT TILE

SECTION 1. Page 2

CONTACT INFORMATION

SECTION 2. Page 2

SUPPORT ARRANGIEMENTS

SECTION 3. Page 3

PROJECT DESCRIPTION / JUSTIEICATION FOR DATA USE

SECTION 4. Page. 3

DATA DE-IDENTHEICATION, PUBLISHING AND REPORTING

SECTOON S. Bage 4

DATA FLOW, USE AND MANAGEMENT

SECTION 6, Page 5

RESEARCH REQUESTS

SECTION 7, Page 6

SOURCE AND TYPE OF DATA

SECTION 8, Page 7

ADDIIONAL INFORMATION

SECTION 9, Page 8

SYSTEM SECURITY INFORMATION

SECTION 10 . Page 8

APPLICABLE SUPPORTING DXCUMENTATION

SECTION 11 . Page 8

CERTHEICATIONS

SECTION 12. Bage 9

RESPONSIBILIMES

APPENDIX A. Page 10

DE-IDENTIFIED, SENSITIVE AND PROPRIETARY DATA

APPENDLX B, Page 11

EXAMPLE DATA FLOW

APPENDIX C. Page 12

BUSINESS ASSOCLATE FUNCTIONS AND SERVICES

ARPENDIX D. Page 13

DEEINTIONS, ACRONYMS AND REGLULATORY REOUIREMENTS

APPENDIXE. Page 14 


\section{Defense Health Agency}

\section{Data Sharing Agreement Application}

The Data Sharing Agreement Application (DSAA) is designed to assist the Defense Health Agency (DHA) Privacy and Civil Liberties Office (Privacy Office) with its consideration of prospective data uses involving DHA data. Each application is reviewed to confirm that the potential data use, described therein, complies with the asplicable privacy and security regulatory requirements.

Both the Applieant and the Government Sponsor, defined below, must complete this application. As the DSAA is project or contract-specifie, not individual data user-specific, only the names of the Applicant and Government Sponsor should be specifically refereneed. Upon approval, this application will be incorporated into a Data Sharing Agreement (DSA)-

The Privacy Office neither grants system access, nor provides data extractions; bowever, prior to gaining access to, or an extraction of the data, the appropriate program office may require an executed DSA.

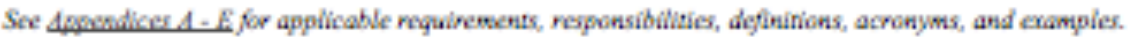

\section{PROJECT TITLE}

Military Children with Attention Deficit Hyperactivity Disorder (ADHD): Maximizing Adherence to Cliniesl Practiee Guidelines

\section{CONTACT INFORMATION}

a. Applieant: See donendix Af for a full description of nespowsibilities

If contractors will aceess the data, the Applicant must be froen the primary contracting organization.

(i) Indicate the type of Applicant:

$\square$ Contractor $\square$ Government Employee or Service member $\square$ Researcher in DoD-Supported Study

$\square$ Academic Researcher $\square$ Other (Describe):

(ii) Enter Applicant's Professional Contact Information:

\begin{tabular}{|c|c|c|c|}
\hline \multicolumn{2}{|l|}{ Applicant Name } & \multicolumn{2}{|c|}{ Title or Rsok } \\
\hline \multicolumn{2}{|l|}{ Kelley M. Hersion } & \multicolumn{2}{|c|}{ Captzin } \\
\hline \multicolumn{2}{|l|}{ Company or Organization } & \multicolumn{2}{|c|}{ Street Address } \\
\hline \multicolumn{2}{|l|}{ Air Force Institute of Technology (AFIT) } & \multicolumn{2}{|c|}{3153 Crossfield Lane } \\
\hline City & State & Zip & Country \\
\hline Charbotesville & $\mathrm{VA}$ & 22911 & USA \\
\hline Phone Number & & \multicolumn{2}{|c|}{ E-mail Address } \\
\hline 931.239 .6599 & & \multicolumn{2}{|c|}{$\mathrm{kmh} 3 \mathrm{fq} @$ virginiz edt } \\
\hline
\end{tabular}

b. Government Sponsor :See Apamilix 4 for a full descripnion of respossibulinies

(i) Enter Government Sponsor's Professional Contact Information:

Goverument Sporsor Name

Title or Rank

Office $\propto$ Agency

Street Address

City

State

Zip

Country

Phone Number

E-mail Address 
Privacy Orfsee trie

DSAA \& 16-1E22

3. SUPPORT ARRANGEMENTS

a. Select the type of arrangement under which this project was awarded, and provide the arrangement number:

$\square$ Contract $\quad \square$ Grant $\square$ Cooperative Research and Development Agreement (CRADA)

$\square$ Other: Describe asy orher type of amangenent, or if support arangement is not agolicable (i.e. gorernment onily)

b. Support Arrangement Number, if applicuble:

c. Period of Performance (PoP) Dates:

(Not sypooried by contruet? List expected stant and campletion dates.)

PoP Start:

PoP End:

d. Other Primary Coetractors: (Each primary cantracting onganization using the data is required to ssbmit a separate DSAA)

e. Subcontracting Organizations

(i) List each subcontracting organization that will have access to ot use of the data:

(ii) Briefly describe how subcontractor(s) will use the data:

f. The support arrangement referenced above includes business associate agreement language: $\square$ Yes $\square$ No

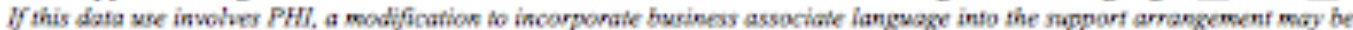
reywired before the DSAA is apporond. Language may be found as the Privacy Office webiste

\section{PROJECT DESCRIPTION/ JLSTIFICATION FOR DATA LSE}

Deseribe the intended data use, including a justifieation of why the data are needed.

If this response exceeds the space arailabile, attach adtitional poges.

The quality impoovement project is required for successful completion of the doctoral of nursing practioe program at the University of Virginis.

The parpose of this project is two-fold: 1) to assess current adherence with the ANP ADHD CPG among pediatric providers in a military elinic, 2) findings as well as identified bartiers will be disseminated to the providers to encourage ongoing cuality improvement effors using the "Plan-Do-Study-Aer" model.

There are no studies evaluating ADHD treatment or CPG adherence in the military sector, and recent clinical observations suggest that military children with ADHD may not be receiving evidense based care. $\mathrm{A}$ retrospective cobort study of 413,665 military children ages 48 years was cooducted to determine if children ADHD have an increase in mental healith visits and mobication ehanges during parental deployment (Hisel-Gormon, Eide, Coll, \& Gorman, 2014). The study identified an ADHD prevalence rate of S\%, which is consistent with the reported national peevalence rate. Only $55.9 \%$ of children in the study were prescribed ADHD medications. Children with ADHD and a deployed parent had a $13 \%$ inerease in mental health visits and a decrease in medication ehanges (Hsel-Gormon, Fide, Coll, \& Gorman, 2014). It is unclear why these children are accessing mental heakth care more frecoently yet receiving fewer changes in medication dosages daring parental deployment. The peroentage of patients receiving a medication for ADHD is also low considering that medication is the most effective teratment. Of note, this data related to madication prescriptions is likely a peor representation of the pediatric ADHD population as a whole among military children since the study only included children 4.8 years of age. Further studies are needed to measure gaideline adherence in military children with $\mathrm{ADHD}$.

The key variable of the study is ADHD guideline aftherence. Adherence will be evaluated bosed on the presence of each of the 6 components of the ANP ADHD CPG (2011)

1. The primary care clinician should initiate an evaluation for ADHD in any child ages 4-18 years peesenting with acodemic $\propto$ behwivenl problems and symptoms of insttertion, hyperactivity, or impulsivity

2 Diagnosis should be made based on DSM criveriz, using validated instrument sach as the Vanderbilt Scale

3. Identify possible co-morbidities

4. Treat ADHD as a chronic condition, and follow the chenie eare and medieal home models; establish a matsagenent team with

a coordination plan and collaborstion with family, child, and school to identify target gosis

5. Treatment recommendations based on age:

a. Treat preschool-aged children with behavior therapy as first-line; may preseribe methylphenside if no improvement

b. Elementary school-aged chiliden should be treated with madication andlor betisvioe theragy

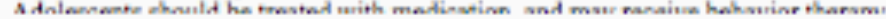




\section{DATA DE-IDENTIFICATION, PUBL.ISHING AND REPORTING}

a. If the use or storage of data involves variables that have been de-identified according to DoD 6025.18-R, complete this section; otherwise, skip to section Sb. (See. Aprosedix 8 for more iglormuntion)

(1) Indicate the intended de-identification method:

$\square$ Expert Determination $\quad \square$ Safe Harbor $\quad \square$ Combination (Expert Determination \& Safe Harbor)

(ii) Deseribe data de-identification steps (i.e., encryption, fedaction, small cell size eradication):

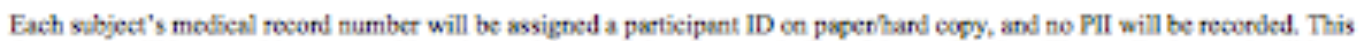
document will be stored in a secured location and destroyed upon complation of data collection. The modical record will be accessed via AHLTA on a DoD secured computer. The PI will analyze the medical recond in comparison to the guideline coerponents, and recond imferpectation of atherenee on a vassated chart abstraction tool. These findings will then be tramsferred into an excel spreadsheet. Demographic data will be recoeded and reporied as descriptive statistics to characterize the sample. Each of the 6 variables will receive an entry for "met $=1$ ", "not met $=2 ", o c$ "N/A $"=3$. The completed excel spreadsheet will be imporied into SPS5 v23 for anslysis to be reported as frequency distributions and pertentages of adherence to the specife guidelines based on the chart abstraction tool. Additional anecdotal notes will be recorded that may explain any deviation from the guideline so this may be accounted for in the final analysis.

(iii) Indieate the parties who intend to de-identify the data, and list their HIPAA defined qualifieations:

Kelley M. Henson, P1, has completed required CTII training for protection of human subjects in research. Proposal scrutinized by the University of Virginia's Institutional Review Board (IRB), and approved.

(iv) Justify any use of proprietary and sensitive data (e.g., pharmacy dispensing/ingredient cost): N/A

(v) If applicable, list any remaining identifiers associated with the 18 HIPAA categories of PHI: $\mathrm{N} / \mathrm{A}$

b. Publishing, Reporting of Other Data Release

(i) Describe the audience to whom the data will be reported DNP Faculty at the Univensty of Vinginis Sthool of Nursing, pediatric elinical staff at Tynda] AFB, FL

(ii) Indicate the type of information that will be published, reported, of otherwise released A final study report will be submitted for publication in a journal such as the Joumal of Pediatric Healthcare. 
Privacy Orfoe tise DSAA E 1E-1E22

6. DATA FLOW, USE AND MANAGEMENT

a. Describe the intended flow, use, and storage of the data (from time of receipt through the project's duration). Inelude diagrams and/oe illustrations as separate attachments, if necessary (Sex the example in spacndir 0 )

Each subject's medical recond number will be assigned a participant ID, and no PII will be recorded on the chart abstraction tool. Assignment of the participant ID will cocur on paper, and will be stored in a secured location. This form will be destroyed upon cormpletson of dats collection.

Data from chart review will be reconded on the chart abstraction tool, then transfernd into an excel sjocadshect. Demographic data will be recorded and reported as descripcive statistics to characterize the sample. Each of the 6 variables will receive an entry for "met

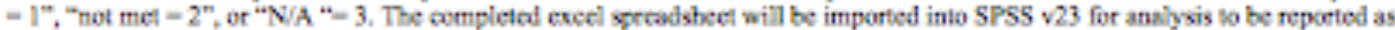
frequency distributions and peroentages of alherence to the specife guidelines based on the chart abstraction tool. Adetional aneodotal notes will be recorded that may explain any deviatoon from the grideline so this may be accounted for in the final analysis.

b. Check any item(s) below that apply to the data use:

(i) $\square$ Data will be aceessed by login using the following access level: ArtTA login

(ii) $\square$ Data will be received as an extraction provided by:

(iii) Equipment intended for data use is: $\mathbb{Z}$ Government Furnished Equipment (GFE)

$\square$ Non-Government Furnished Equipment

(iv) How often will data be obtained? $\square$ Daily $\square$ Monthly $\square$ Yearly $\square$ As needed (explain) 
Privacy Orfice tise DSAA $* 16-1622$

\section{RESE.ARCI REQUESTS}

Complete this section if data will be used for a systematic investigation, intended for generalizable knowledge involving information about individuals. Otherwise, skip to the next section.

- The protocol must be approved by an Institutional Review Beard (IRB)

- If the protocol was reviewed by a non-DoD primary IRB, the DHA Human Research Protections Program (HRPP) must review the research documentation

- The Sponsor must ensure that any publication/relesse complies with DoD requirements

- For more information, visit the DHA Human Research Protection Program web page

- If this request involves the use of PII, the DHA Privacy Board will be advised. For more information about the DHA Privacy Board process, visit the DHA Privacy Boned weh pange

a. Principal lnvestigatoe Information

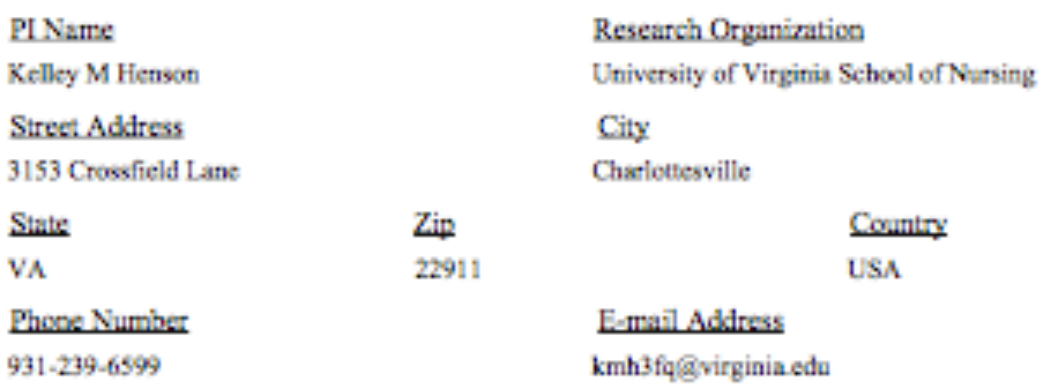

b. Protocol Information

(i) Title of Rescarch Project Protocol

Milisary Children with Attention Defieit Hyperaetivity Disorder (ADHD) Maximizing Adherenes to Clinieal Practice Guidelines

(ii) Name of Primary IRB:

University of Virginia Institutional Review Bosed for Heslth Seiences Researth

(iii) If the primary IRB is outside of the DoD, provide the DHA HRPP Protocol Review Determination reference number:

(iv) If this data use involves a survey of 10 more individuals, indieate the survey license information below: Survey License Number:

Survey License Expiration Date:

(v) If this protocol has changed, and will modify a previously executed DSA, describe the protocol changes: 
Privacy Onfoe Use

8. SOURCE AND TYPE OF DATA

a. Indicate the DHA system(s) from which the data will be obtained:

- Data must be limited to the minimum necessary for accornplishing the described purpose. (Sec.Appendix E)

- The type of agreement (PII excluding PII, PHI, Limited Deta Set or De-identified) is determined by the specific data elements reguested, or by the type of data that may be aceessed via direct login.

\begin{tabular}{|c|c|c|c|c|}
\hline MDR & $\square \mathrm{M} 2$ & $\square$ TMDS & 7) AHLTA & $\mathrm{CHCS}$ \\
\hline PDTS & $\square$ PEPR & $\square$ ESSENCE & $\square$ DMHRSi & Essentri \\
\hline
\end{tabular}

$\square$ Other (specify):

b. Identify whether the data will include only a set of specific data elements, or if all the data elements from a system file are needed. Check any that apply and provide details as direeted.

(i) $D$ This request includes specifie data elements from the following system(s):

Medical record will be examined and conpared with the geideline ssing a chart abotrsetion tool to measure alherese. Documentation of the key componenss may be found in the history of present illness, physical exam, patient education

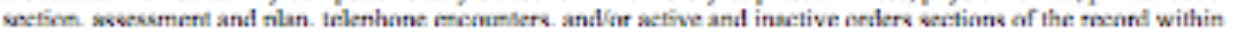

(ii) $\square$ This request includes all data in the following system(s):

(iii) Provide justifieation for requesting the use of all data within a system:

c. Specify files and data elements. Download and attach the applieable Data Request Template (DRT).

Data spectification in another format is acceptable

- DRT Military Health Systam Data Repository (MDR) Fixtractions (F-able MACROS to nrimf only decired wariables)

- General Data Request Template (to list extracted data from sysiems other than MDR)

- DRT_Access by Login (o list data intendad to ohtain via dirast login)

d. The Privacy Office does not confirm compliance fot non-DHA systems.

Permissians fo use non-DHA data should be abtained from the respective sastem manogers

(i) If the DHA data will be merged, linked, ot otherwise associated with data from any other sources outside of DHA, explain why, and by what method the DHA and non-DHA data will be associated?

N/A

(ii) List the non-DHA systems:

N/A 
Privacy Orfoe tise DSAA $=16-1622$

9. ADDITIONAL INFORMATION

If Pll will be electronically collected, maintained, used, or disseminated, provide the following information:

a. Storage database/system name:

$\mathrm{N} / \mathrm{A}$

b. System of Records Notice (SORN) number, applicable to the system in which the data will be stored, if an item, collection, ot grouping of information will be ereated with the intent of retrieving an individual's information using a unique identifier:

N/A

\section{SYSTEM SECURITY INFORMATION}

If data will be stored, processed, maintained or used on DoD approved equipment, include the DoD approval information below (e.g., Authority to Operate, Interim Autbority to Operate, etc.).

Consult the technical representative responsible for maintaining the computing resources proposed for this data use if necessary.

a. Provide DoD Approval Information for each system on which DHA data will be used:

List Fach System or Network

Tynda? AFB
Indicate Type of Approval

ATO
Expiration Date

27 Apr 2017

b. List any organizations, that will store, proeess, maintain of use the data on equipment that is not DoD approved (e.g. contractor, academic institution equipment):

Non-PI data will be recorded on personal laptop, and password protected. A beck-up oogy will be stored on an encrypted DVD, which will be slocod in a secure location

If the data contain individual identifiers, a System Security Verifieation (SSV) template must be completed by each organization indicated above.

The SSV is available on the DSA termplates page of the Privacy Office web site.

\section{APPL.ICABLE SUPPORTING DOCLMENTATION}

Check all documents that will be submitted in support of this DSAA

Data Flow, Use and Management

$\square$ Data Request Templates

SSV Template

7) Other (briefly describe):

UVA IRB Approval; Prosocol

Submit DSAA and supporting doctumentation to DSA-Mail 
Privacy Orfoe Use DSAA $\#$ 16-1622

\section{CERTIFICATIONS}

The initials, provided by the Applicant and Government Sponsot, verify that the responses in this applicatica are truthful and aceurate. These representatives agree to promptly notify the Privacy Office of any project change(s) that may affect the data use reflected in this DSAA.

The parties acknowledge that after this application is approved, the Privacy Office will send the appropriate Data Sharing Agreement (DSA) to the Applicant (refereneed as the Recipient on the DSA) and the Government Sponsor for signature.

After receiving the Recipient/Sponsor-signed DSA, the Privacy Office will provide final signature and forward the executed DSA, which incorporates the approved DSAA, to the Recipient and Government Sponsor.

APPLICANT

By electronically initialing this application, I certify that this application is submitted with my consent

Initials: $\mathrm{KMH}$
Date: 27 Sept 2016

\section{GOVERNMENT SPONSOR}

By electronically initialing this application, 1 certify that this application is submitted with my consent

\section{PRIVACY NOTICE}

Data Sharing Agreements are project or contract-specific, not individual data user-speciffc. Only the names and peofessional contact information of the Applicant and Government Sponsor should be listed. The names and contact information for the listed individuals are msintrined so informstion and notices ean be sent to these individusis. It may be protected under the provisions of the Privacy Act of 1974 and only released as permitted by law.

PRIVACY OFFICE SIGNATURE DSAA APPROVAL

\section{DESHIELDS RITA SC Dightyly yoned by DESHIELDS.RITA.SOHINE.1229361795 \\ DN: $c=U 5,0=U S$, Government, ou=DoD, ous $=9 x$. HINE.1229361798}

Ms. Rita Deshicids

Data Sharing Compliance Manager

Defense Health Agency Privacy and Civil Liberties Office

7700 Arlington Boulevard, Suite 5101

Falls Church, VA 22042-5101

$703-275-6050$ 


\section{Defense Health Agency \\ APPENDIX A \\ RESPONSIBILITIES}

Data Sharing Agreement Application

\section{DSAA APPL.ICANT/DSA RECIPIFNT RESPONSIBILITIFS:}

- Provide and maintain accurate and complete DSAA responses

- Agree to and execute a DSA after the DSAA is approved by the Privacy Office

- Ensure the project abides by the submitted protocol and the stipulations as stated in the DSA

- Assume physical or contractual liability for preserving the data integrity

- Fulfill Business Associate Agreement (BAA) requirements, if applicable

- Submit a DSA modification request template to notify the Privacy Office of any data use, storage of disclosure changes

- Follow DHA breach notification and response procedures (in the event of potential or actual loss, theft, of compromise of data) as outlined on the Privacy Office website

- Notify the Privacy Office, no later than 30 days after the completion of the project or the DSA expiration (unless requesting renewal), by submitting a Certification of Data Disposition (CDD)

\section{GOVERNMENT SPONSOR RFSPONSIBILITIFS:}

- Examine the intended project to avoid both duplication and unnecessary generation of DHA data

- Verify that the data are used in compliance with applicable privacy and security standards

- Coefirm that publications, of any other release of data results/findings, adheres to DoD requirements

- Affirm scientific merit, feasibility and usefulness in relation to the MHS mission, goals, and objectives

- Assure that the project outcomes will benefit DoD

- Certify that aceurate and complete responses are reflected in the DSAA

- Agree to and execute a DSA once the DSAA is approved by the Privacy Office

- Provide Applicant/Recipient oversight for the duration of the project reflected in the DSA

- Ensure that the BAA requirements, if applieable, are fulfilled

- Assure that DHA breach notification and response procedures are followed (in the event of potential of actual loss, theft, or compromise of data) as outlined on the Brivacy Office website

- Serve as the Government (military or DHA civilian personnel) Point of Contact

- Maintain current contact information with the Privacy Office

- Sign a DSA modification request template to endorse any data use, storage or disclosure changes

- Endorse timely DSA renewal, if necessary

- Authorize the submission of a CDD no later than 30 days after DSA expiration 


\section{Defense Health AgenCy \\ Data Sharing Agreement Application}

Privacy Orfice tise

DSAA $16-1622$

\section{APPENDIX B}

DE-IDENTIFIED, AGGREGATE, SENSITIVE AND PROPRIETARY DATA

A. The HIPAA Privacy Rule provides two methods by which bealth information may be de-identified

1. Expert Determination Method:

- This expert must have knowledge of and experience with the statistieal and seientific procedures used to de-identify PHI and is competent in determining that the risk of identifying an individual from the de-identified data, when used alone or in combination with other information, is very small.

- This expert must document the methods and results of the analysis that justify such determination.

2. Safe Harbor Method:

- All 18 of the HIPAA direct individual identifier categories (including those of the individual or their relatives, employers, or household members) are removed.

B. Data Aggregation is included in the Final Rule's list of business associate services

1. Data aggregation involves grouping independent but similar information components of gathered data into summary form, generally for purposes such as statistical analysis (i.e., grouping summary information about specifie groups based on definite variables such as age, profession, or ineome).

2. Aggregate data is not automatically categorized as de-identified data. To ensure that aggregated health data is de-identified in compliance with HIPAA, the appropgriate methods must be used to determine that the data carnot be used alone or in coenbinstion with other information to identify an individual.

C. The potential use of or access to sensitive of proprietary business, technical, financial, and/or source selection information belonging to the Government or other contractors must be safeguarded so as not to cause adverse effects on organizational operations, organizational assets, or individuals.

1. Protection of proprietary information prevents the compromise of property rights of economic interest, reduees risk to a contractor's commercial position, and safeguards the Government's ability to obtain aceess to or use of the data.

2. Sensitive data includes eost comparisons and price quotes, Government spend plan data, contractor technieal proposal data, independent Government cost estimates, negotiation strategies and contractor data presented in negotiations, eontracting plans and statements of work.

D. When documenting the intended method of de-identificatica, keep the following questions in mind:

1. How will the 18 categories of HIPAA identifiers be removed? (explain eneryption/redaction processes)

2. How will small cell size be determined?

3. How will small cell sizes be eliminated? (i.e., redacted, rolled up, etc.)

4. How will the process for ensuring minimum risk of data re-identification be explainod?

5. How will the combination of fields be redueed to ensure minimum risk of re-identification?

(In other words, how will the requestar deal with the potential ability to triangulate data to come up with data that's small enotgh to identify an individual?)

- Examples of combination fields:

i. Cross tab of data sets

ii. Connecting data (i.e., users with aceess to areas where data may be combined with information obtained from another system, potentially deducing a person's identity) 
EXAMPLE DATA FLOW (AS INDICATED IN SECTION $5 \Lambda$ )

Data Flow Diagram - XYZ Company for DSAA \#XX-XXXX "Analysis for DHA Leadership"

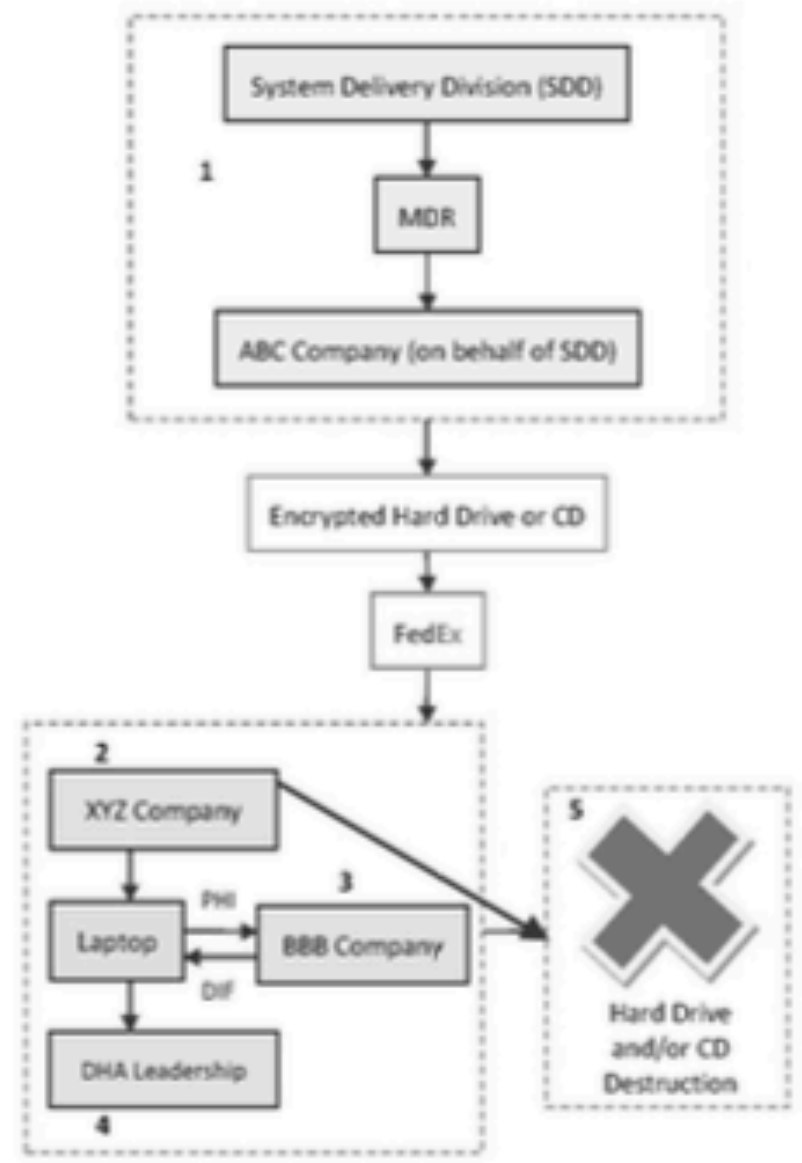

Duta flow:

1. ABC Company (on behalf of $\mathrm{SDO}$ ) will extract Pril from the MOR and send to the DSA Recipient (D) Companyl via encrypted (using Guardian fdge) $\mathrm{CD}$ or hard drive via fedfo.

2. Once recieived, $\times 2$ Company will load the data onto one (1) laptop. Access to the dats will be limited to $\mathrm{m} / \mathrm{Z}$ Company analyzts and ReR ubeontractors with need to know.

3. Subcontractor BBB will access the PUII on the XVR Company laptop for the sole purpose of de-identifying the data as per HiPAA guidelines. Identifiers will be deleted or encrypted.

4. Dina leadership will receive a copy of the summarised results only.

5. Upon completion of the proinct. the original $\mathrm{CD}$ on which the data was recelved will be destroyed by a shredder. $\mathrm{x}$. Company will delete the data from the luptop and perform a wipe of the laptop hard drive. 


\author{
Defense Health Agency \\ Data Sharing Agreement Application \\ APPENDIX D \\ HIPAA DEFINED BUSINESS ASSOCIATE FUNCTIONS AND SERVICES
}

DSAA 1 16-1E22

A. An individual or organization, that performs one or more of the following functions or services on behalf of a covered entity, may be a business associate, according to HIPAA:

1. Performs or assists in performanee of one of more of the following functions or activities, involving the use or disclosure protected bealth information (PHI), such as:

- Data analysis

- Claims processing or administration

- Utilization feview
- Quality assurance reviews

- Any other function or activity regulated by the HIPA.A Administrative Simplification Rules, including the Privacy Rule

2. Performs one or more of the following services to of fot a covered entity, involving the use or disclosure of $\mathrm{PHI}$, such as:

- Legal

- Actuarial

- Accounting
- Consulting

- Data aggregation

- Management
- Administrative

- Accreditation

- Financial

3. Provides data transmission services of PHI to a covered entity (e.g., Health Information Organization, E-prescribing gateway)

4. Aceesses PHI to peovide a personal health record on behalf of a covered entity

5. Works for a business associate that delegated a function of service to you that the business associate agreed to provide for a covered entity of for another business associate

B. An individual or organization that fits into one of the four exceptions listed below may not meet the definition of business associate:

1. Covered entity in an organized health care arrangement, performing a covered function/service to, for, oe oe behalf of the arrangement

2. Government agency that receives or collects $\mathrm{PHI}$ to determine eligibility ot enrollment in a Government health plan

3. Plan sponsors who only receive PHI from a group bealth plan that meets HIPAA requirements

4. Health eare providers who only receive PHI from a covered entity for purposes of treating individuals 


\author{
Defense Health Agency \\ Data Sharing Agreement Application
}

Paivacy Orfoe tise

DSAA $16-1622$

\title{
APPENDIX E
}

\section{A. Deranrnons}

Business Assosiate: A person or entity, who is not a member of the covered entity's workforee, that ereates, receives, maintains, of transmits PHI on behalf of the covered entity or in providing a HIPAA-allowed service to the covered entity that involves the use or disclosure of PHI.

Covered Entity: A health plan, a health care elearinghouse, or a bealth care provider that conducts one or more HIPAA-covered transactions in electronie form.

DSA Recipient: The individual who initials the DSAA as "Applicant," and functions in the role of Recipient upoen DSA execution.

DSAA Applicant: The individual who completes and submits a DSAA and serves as the primary point of contact during the Privacy Offiee approval process. This individual is generally employed by a non-DoD organization (i.e, contractor, grant recipient, research staff) that supports a Government project or research. Government personnel may meet the definition of Applicant if the data use involves only Government staff (no contractor participation).

Information System: For the purpose of this application, a set of information resources organized for the collection, stoeage, processing, maintenance, use, sharing, dissemination, disposition, display, or transmission of information. Includes automated information system applications, enclaves, outsourced information technology (IT)-based processes, and platform IT intereornections.

Limited Data Set: A limited set of identifiable patient information as defined in the Privacy Regulations issued under HIPAA.

Minimum Nesessary: A covered entity must make reasonable efforts to limit the use, disclosure, or request of PHI to the minimum necessary for accomplishing the described purpose. HIPAA's minimum necessary rule does not apply when disclosing PHI for treatment, to a medieal training program, when disclosed to the individual, pursuant to an authorization.

Personally Identifiable Information (PII): Information that can be used to distinguish or trace an individual's identity, such as his or her name, social security number, date and place of birth, mother's maiden name, biometric records, including any other personal information that is linked or linksble to a specified individual.

Brotected_Heallh_Information (PH): Individually identifiable bealth information that is transmitted or maintained by electronic or any other form or medium, except as otherwise contained in employment records held by DHA in its role as an employer.

B. FEDERAL LAW

Privacy Act of 1974, as amended (5 U.S.C. 552a)

HIPAA Privacy and Security Rules (45 C.F.R. $160 \& 164)$

C. Department of Defense (DoD) Regulatgons

DoDD 5400.11, DoD Privacy Program, May 8, 2007

DoD 5400.11-R, DoD Privacy Program, May 14, 2007

DoDl 6025.18, Privacy of Individually Identifiable Health Information in DoD Health Care Programs, Dee. 2, 2009

DoD 6025.18-R, DoD Health Information Privacy Regulation, January 24, 2003

DoDI 8500.2, Information Assuranee (IA) Implementation, February 6, 2003

DoD 8580.02-R, DoD Health Information Security Regulation, July 12, 2007 


\section{Approval from Air Force Human Research Protection Program}
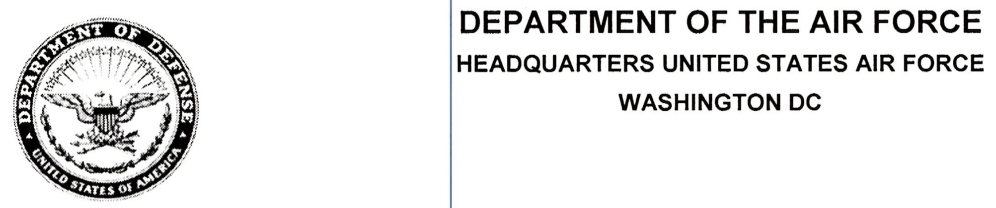

MEMORANDUM FOR UNIVERSITY OF VIRGINIA

FROM: AFMSA/SGE-C ATTN: KATHYRN REID, MSN, RN

AF Research Oversight \& Compliance Division

7700 Arlington Blvd. Ste. 5151

Falls Church, VA 22042-5151

SUBJECT: Air Force Human Research Protection Program Review of FSG20160050H

References: (a) 32 CFR 219, Protection of Human Subjects, Paragraph 102

(b) DoDI3216.02_AFI40-402, Protection of Human Subjects and Adherence to

Ethical Standards in Air Force Supported Research

In accordance with the References, the HRPO has reviewed and approved the following minimal risk protocol:

FSG20160050H: "Military Children with ADHD: Maximizing Guideline Adherence"

In accordance with Reference (b), Enclosure 3, Section 17, the HRPO also strongly recommends consulting with the Defense Health Agency (DHA) for other applicable requirements related to authorization and access of Protected Health Information (PHI) under DHA oversight.

Contact AFMSA/SGE-C at usaf.pentagon.af-sg.mbrx.afmsa-sge-c@mail.mil to discuss any substantive change to this activity prior to implementation and to ensure it does not impact the determination herein or compliance with the above references.

Please provide a copy of the approved DHA Data Sharing Agreement and all other applicable documents related to authorization and access of PHI to protect privacy of subjects and confidentiality of data. In addition, please refer to the Terms of Air Force HRPO Approval (attached) regarding reporting requirements and responsibilities of the Principal Investigator to the HRPO. Failure to comply could result in suspension of Air Force support for this research activity.

\section{Quncitiliots}

IMELDA M. CATALASAN, Lt Col, USAF, BSC

Director, AF Research Oversight \& Compliance Division 


\title{
Condensed Article for Journal Submission
}

\author{
Abstract \\ Introduction: This project evaluates provider adherence to the ADHD CPG in a military primary \\ care pediatric clinic 24 months after a targeted educational intervention. This project \\ incorporates a "Plan-Do-Study-Act" (PDSA) session to evaluate performance, identify barriers \\ that impede guideline adherence, and address areas for improvement. \\ Methods: A retrospective chart review is conducted using a convenience sample $(n=50)$ to \\ evaluate CPG adherence. A goal-oriented meeting with clinic providers and nurses is utilized to \\ disseminate findings and implement the PDSA model. \\ Results: Providers adhered to $2 / 6$ of the key guideline components with an overall mean \\ adherence rate of $28.6 \%(0-100 \%$, SD $33.8 \%)$. The PDSA model facilitated ongoing quality \\ improvement efforts. \\ Discussion: Military provider adherence to the ADHD CPG at the selected clinic is consistent \\ with findings of poor adherence in the civilian sector. The PDSA session led to development of a \\ standardized ADHD documentation template and clinical process improvement.
}


Military Children with Attention Deficit Hyperactivity Disorder (ADHD): Maximizing Adherence to Clinical Practice Guidelines

\section{Introduction}

Despite almost 2 decades of clear clinical practice guidelines (CPG) for the diagnosis and treatment of attention deficit hyperactivity disorder (ADHD), provider adherence to the guidelines continues to vary greatly. While variable adherence to the guidelines in non-military settings is widely reported in the literature, published evaluations of adherence in military settings is lacking. Action was taken by an experienced Pediatric Nurse Practitioner (PNP) from 2013-2015 to improve provider adherence to the CPG in a selected pediatric primary care military clinic, including a series of "Lunch and Learn" sessions as well as in-clinic coaching and support. This project, in keeping with the quality improvement framework of "Plan-Do-StudyAct" (PDSA), has the following objectives:

1. Evaluate the current status of provider adherence to the ADHD CPG in the selected military setting following the targeted educational intervention previously carried out, hereinafter referred to as "CPG evaluation," and

2. Demonstrate Doctorate of Nursing Practice (DNP) level leadership to improve quality care delivery using the PDSA model, hereinafter referred to as "PDSA session." The PDSA session will be conducted to empower providers, nurses, and clinical staff to evaluate performance, identify existing barriers that impede guideline adherence, and address areas for improvement through the use of evidence-based interventions.

\section{Background and Significance of the Problem}

ADHD is a common pediatric neurodevelopmental disorder affecting between 7 and 11\% of children in the United States (Akinbmai, Liu, Pastor, \& Reuben, 2011). The Centers for 
Disease Control and Prevention (CDC) report a 5\% annual increase in ADHD prevalence over the last decade (Akinbmai, Liu, Pastor, \& Reuben, 2011). The core symptoms of ADHD include hyperactivity, inattention, and/or impulsivity, and cause impairment in multiple settings (e.g. school and home) (American Psychiatric Association [APA], 2013). Youth with ADHD also often have comorbid mental health disorders, substance abuse, learning difficulties, peer relationship difficulties, and difficulty with completion of activities of daily living (Wolraich, Brown, \& Brown, 2011). Advances in neuroimaging and neuropsychological testing in children with ADHD identify difficulties with forward planning, abstract reasoning, mental flexibility, working memory, and response inhibition (Barkley, 1999; Pennington \& Ozonoff, 1996). Individuals with ADHD have a higher incidence of injuries, motor vehicular accidents, drinking and driving, and traffic violations, and the estimated U.S. economic burden of this disorder is between $\$ 36$ and \$52 billion annually (Akinbmai, Liu, Pastor, \& Reuben, 2011).

Risk factors related to ADHD are largely unknown, however there is a strong genetic component (CDC, 2017). Other possible risk factors include brain injury, exposure to environmental toxins (e.g., lead) during pregnancy or at a young age, alcohol and tobacco use during pregnancy, premature delivery, and low birth weight (CDC, 2017). Children with a genetic predisposition for developing ADHD may be more vulnerable to exhibiting core symptoms if their psychosocial environment is one with high levels of stress and/or contains parents who are unable or unwilling to model coping techniques and self-regulation (Lange et al., 2005).

It has been well established that ADHD is a chronic condition that is often present, and impairing, into adulthood (Friedman, Blaschke, Klam, \& Stein, 2006). Treatment with stimulants and/or behavior therapy has shown to be effective; however, long-term medication compliance is 
a significant issue for this population (American Academy of Pediatrics [AAP], 2011). Primary care providers are responsible for caring for children with ADHD under the medical home model (World Health Organization [WHO], 2015) and should not routinely refer children to a mental health professional. Standardized psychological tests are costly and time consuming, and are not as reliable as clinical interview in diagnosing ADHD (AAP, 2011). Despite this recommendation, provision of comprehensive care in the primary care setting can be quite challenging, particularly when addressing mental health disorders in children (Foy et al., 2010), and significant disparities among populations persist (Akinbmai, Liu, Pastor, \& Reuben, 2011).

Military Considerations. Approximately 2 million dependent children live in activeduty, reserve, or guard families, and since the attack on 9/11, over 2 million children have had a parent deploy (The National Military Family Association (NMFA), 2017). This population is vulnerable to experiencing significant trauma related to the increased wartime demands over the last decade (Clever \& Segal, 2013), necessitating frequent relocations, geographic separation from family members due to deployment or military training, and the potential for a parent sustaining combat-related injuries or death (Meadows, et al., 2015). While protective factors such as stable income, community support, and consistent accessibility to healthcare are noted among military families, studies also demonstrate an increase in anxiety, drug use, risk taking behaviors, and suicide rates among children and adolescents who undergo frequent relocations (Millegan, McLay, \& Engel, 2014). It is estimated that military children have almost twice as many ADHD-related outpatient visits per year than their civilian counterparts, making up 30\% of all mental health visits (Hisel-Gorman, Eide, Coll, \& Gorman, 2014), yet prevalence and management of the disorder is poorly studied in this population. 
Finally, in addition to frequent relocations among the patient population, military providers are typically reassigned to a different military treatment facility (MTF) every 2-4 years. The transient atmosphere in the clinic creates challenges when working to establish professional relationships with the community members who are needed to assist in providing support to children with ADHD. These unique factors may make the military population particularly vulnerable to fragmented care, poor treatment compliance, and loss of follow up. Provision of comprehensive, high quality care to military dependents is essential for maintaining an effective, resilient military force, especially during times when the demands on service members are high.

\section{Overview of the ADHD CPG}

In an effort to reduce variability among providers, decrease cost, minimize harm, and produce optimal health outcomes (AAP, 2004), the AAP endorses the used of evidence-based guidelines for the diagnosis and treatment of ADHD (AAP, 2011). The CPG recommends that ADHD be treated as a chronic condition by the medical home, and have individualized treatment goals with ongoing follow-up care (AAP, 2011). The most recent updated guidelines include an expanded age range, expanded scope, and a process-of-care algorithm for diagnosis and treatment (AAP, 2011). Standardization of care and quality are promoted with the use of validated assessment tools and evidence-based interventions including assessment for comorbid conditions, medication management, behavior therapy, and recommendations for timing and focus of follow-up visits (AAP, 2011).

\section{Review of the Literature}

A review of the literature is undertaken to further explore the status of ADHD CPG adherence and to further explore the prevalence of ADHD among the general population and in 
children with parental military affiliation. Key search terms include "attention deficit," "attention deficit hyperactivity disorder," "hyperactivity," "hyperkinesis," "guideline," "ADHD” or "attention deficit," "military," and "prevalence." The search is limited to human subjects with ADHD under 19 years of age, studies written in the English language, and published after 2000. Ovid Medline, CINAHL (EBSCOhost), PubMed, and Psych Info search retrieves 378 studies; of the articles reviewed, 24 are retained for inclusion. Findings are divided into 4 categories: 1) evaluation of adherence to the AAP CPG; 2) ADHD prevalence and treatment patterns among military treatment facilities; 3) barriers to guideline adherence; and 4) interventions designed to improve adherence to AAP CPG.

Despite the AAP's attempts to widely disseminate guidelines for diagnosis and treatment of ADHD, studies show that primary care management of ADHD continues to lack standardization (Chan, Hopkins, Perrin, Herrerias, \& Homer, 2005; Dreyer, O’Laughlin, Moore, \& Milam, 2010; Epstein et al., 2014; Gordon et al., 2016; McElligott et al., 2014; Rushton, Rant, \& Clark, 2004; Visser et al., 2014; Visser et al., 2015). Variability among providers' diagnosis and management of ADHD can lead to delayed or incorrect diagnosis, under-identification of comorbid conditions, and subjection of the patient to unnecessary testing procedures (McElligott et al., 2014). A survey of 1,374 pediatricians reveals that $78 \%$ report using ADHD guidelines, $55 \%$ report using DSM criteria, and $80 \%$ report routine collection of parent and teacher rating scales (Rushton, Rant, Clark, 2004); however, additional studies involving multiple chart reviews are inconsistent with pediatricians' self reports, thereby invalidating provider surveys as a tool to measure guideline adherence (Epstein et al., 2014). Chart reviews performed on 311 patients (including 84 pediatricians from 19 different practices) reveal that only $38 \%$ of children have documentation of meeting DSM criteria for a diagnosis of ADHD (Epstein et al., 2008). 
Follow up rating scales are rarely collected to monitor treatment response after diagnosis (9\%), and fewer than half of children have a follow-up visit documented within the first month (Epstein et al., 2008).

There are no studies evaluating ADHD treatment or CPG adherence in the military sector. A retrospective cohort study of 413,665 military children ages 4-8 years evaluates mental health visits and medication changes during parental deployment, and provides limited insight on ADHD treatment (Hisel-Gormon, Eide, Coll, \& Gorman, 2014). The study identifies an ADHD prevalence rate of $8 \%$, and only $55.9 \%$ of children in the study are prescribed ADHD medications (Hisel-Gormon, Eide, Coll, \& Gorman, 2014). Children with ADHD and a deployed parent have a $13 \%$ increase in mental health visits and a decrease in medication changes (HiselGormon, Eide, Coll, \& Gorman, 2014).

Although the current guidelines have a strong evidence base, many barriers to addressing pediatric mental health concerns remain (AAP, 2011; Foy et al., 2010; Leslie, Weckerly, Plemmons, Landsverk, \& Eastman, 2004). Common barriers that are identified by civilian pediatric providers include lack of time and/or expertise, limited access to pediatric mental health specialists, stigma, and reimbursement for services (AAP, 2011; Foy et al., 2010). Providers also report having limited knowledge of different ADHD rating scales and management of coexisting conditions and poor access to community resources for patient and family support, therapy, and education (Leslie, Weckerly, Plemmons, Landsverk, \& Eastman, 2004).

A variety of interventions are effective in improving ADHD guideline adherence including education protocols, decision support tools, web portals, telehealth, and patient registry programs (Baum, Epstein, \& Kelleher, 2013; Geltman et al., 2015; Myers, Vander Stoep, Zhou, McCarty, \& Katon, 2015; Nelson, Duncan, Peacock, \& Bui, 2012; Polaha, Cooper, Meadows, \& 
Kratochivil, 2005). The most promising of the existing interventions for improving provider ADHD CPG adherence is a quality improvement program implemented by Epstein, Langberg, Lichtenstein, Kolb, \& Stark (2010). The program consists of didactic training sessions focusing on evidence-based guidelines, as well as office-based process-improvement interventions that empower the staff to efficiently incorporate guideline-based care into their daily operations through use of the PDSA model. Immediate improvements in guideline adherence with this quality improvement model are noted and are sustained 2 years after training (Epstein, Langberg, Lichtenstein, Kolb, \& Stark, 2010).

\section{Theoretical Framework}

The primary theoretical framework chosen for this project is the PDSA model. Plan-dostudy-act is a 4-step cyclical process that is ideal for testing change in a busy practice setting (Holly, 2014). Step 1 (Plan) involves identifying the problem and formulating a solution with stated objectives. The implementation phase (Do), step 2, activates the plan while collecting data for later evaluation. The third step (Study) analyzes data that have been collected, and compares outcomes with the stated objective. Finally, step 4 (Act) identifies successes and failures and refines the plan as needed for further improvement and/or sustainability of the changed process (Holly, 2014).

\section{Methodology}

From 2013-2015, a master's prepared pediatric nurse practitioner (PNP) exerted clinical leadership to facilitate implementation of the AAP ADHD CPG in an Air Force pediatric clinic. A more thorough evaluation of current adherence to the ADHD CPG among the military pediatric providers is now needed to ensure that military dependents with ADHD are receiving quality, evidence-based care within the medical home. 


\section{Description of the Sample}

A convenience sample ( $\mathrm{n}=50,62$ total encounters) is selected from a medium-sized Air Force military treatment facility (MTF) pediatric clinic in the Southeastern United States. Patients are dependents of military members or retirees, and are covered by TRICARE. Patients attend local civilian schools based on zoning and/or parental choice, and live both on and off of the military installation. A convenience sampling approach was utilized to select patient encounters with a chief complaint of "ADHD", "school concerns", "learning problems", "behavior concerns", "behavior problems", "hyperactivity”, “inattention", “impulsivity", "problems focusing", or "medication follow-up." Encounters were evaluated using the following inclusion criteria: ages $0-18$ years, assigned to a providers in the selected clinic, ADHD is managed by the PCM. Patients $>18$ years of age, and/or not assigned to the pediatric clinic are excluded. Meeting participants for the PDSA session are affiliated with the same clinic as described above, and include 3 active duty pediatricians and 1 active duty pediatric nurse practitioner (PNP).

\section{Setting}

The pediatric clinic empanels approximately 3,500 patients from birth to 18 years of age with a broad range of pediatric conditions. Services are offered to military dependents, and include well child visits, sick and acute care, and primary care management of other pediatric conditions, including chronic care. The local community hospital offers basic emergency and inpatient care for pediatric patients, however patients with more complex conditions or surgical needs must travel approximately 80 miles to reach a children's hospital for inpatient or outpatient pediatric subspecialty care.

\section{Protection of Human Subjects}


Study IRB provided by: University of Virginia Institutional Review Board for Health Sciences Research HIPAA Privacy Board, IRB-HSR \# 19169. Approval also received from Air Force Human Research Protection Program Review (HRPO), \# FSG20160050H and the Data Sharing Agreement for Protected Health Information, DSA \# 16-1622, approved by the Defense Health Agency. Verbal consent for PDSA session participation has been obtained, and the participants are aware that attendance is voluntary and this project is not affiliated with the DoD or any military branch.

\section{Project Design}

Evaluation of guideline adherence was conducted using a retrospective, chart review of a convenience sample $(n=50)$ of patients empaneled to the selected military pediatric clinic from January through December 2016. Among the 50 patients included in the sample, 62 encounters were reviewed to include initial visits (19/62), follow-up visits (43/62), and telephone encounters $(5 / 62)$ that addressed the patients ADHD. Patients were assigned a participant identification number, and no personally identifiable information was retained after the completion of data collection. Demographic data were recorded and reported as descriptive statistics to characterize the sample. Each variable received an entry for "addressed" =1, "not addressed" =0, or "N/A" = 3. SPSS v24 was used for analysis, and data reported as frequency distributions and percentages of adherence to the specific guideline key components. Additional anecdotal notes were recorded to explain any deviation from the guideline so this could be accounted for in the final analysis.

A single, 2-hour PDSA session was held in the clinic. The meeting was structured as follows: review of AAP CGP, review of chart review findings, discussion of identified barriers to guideline adherence using the questionnaire as a guide, and discussion of PDSA model and evidence based-interventions to improve adherence to ADHD guidelines. 


\section{Variables and Measures}

An adapted 1-page chart abstraction tool was used to systematically perform chart reviews. The tool was shown to have strong inter-rater reliability when used to evaluate compliance with ADHD guidelines (Vreeman, Madsen, Vreeman, Carroll, \& Downs, 2006). Permission has been granted from the author of a validated chart abstraction tool for replication and adaptation as needed (R.C. Vreeman, personal communication, July 6, 2016). A survey based on the key components of the ADHD guideline was designed for use in a study published by Epstein et al. (2008). More recent literature indicates that provider report is an invalid measure of guideline adherence; therefore, questions were adapted to inquire about barriers rather than adherence (with permission by Epstein, personal communication, July 9, 2016). The adapted survey tool's strength lies in the organization of these key components, and adds to the utility. The questionnaire was not formally collected for the quality improvement project, but used to guide discussion.

\section{Results}

\section{Sample Demographics}

Patients included in the sample are between the ages of 5-18 years (mean 12 years, SD 3). Mean age at diagnosis is 8 years (range $4-13$ years, SD 2.4). Females represent $38 \%(n=19)$ of the sample, males $62 \%(n=31)$. Race is largely undocumented in the records $(32 / 50(64 \%)$ participants). Air Force, Army, Navy, and Coast Guard are represented in the sample, with the most frequent ranks being Staff Sergeant (SSgt, E-5) (n=13, 26\%), Technical Sergeant (TSgt, E6) $(n=11,22 \%)$, and Master Sergeant (MSgt, E-7) $(n=8,16 \%)$. Air Force dependents comprise $88 \%$ of the sample.

\section{CPG Adherence}


Compliance with the AAP CPG is evaluated by calculating the number of variables in each encounter that address the specific key component. Variables are determent to have "Met" the standard if they are addressed in $>/=80 \%$ of the encounters. The variable is determined to have "Not Met" the standard if addressed in less than $80 \%$ of the encounters. Evaluation of overall provider adherence to the AAP CPG for ADHD in the selected military pediatric clinic reveals that $2 / 6$ key components are consistently "met." Of the 62 encounters reviewed, zero met all 6 key components of the guideline; 3 encounters address at least one variable from each key component. Of 85 total variables, the providers have an overall mean adherence rate of $28.6 \%$ (0-100\%, SD 33.8\%). The clinic currently has access to an ADHD specific documentation template that includes some of the variables measured in this study. Rates of adherence among the variables that are included in the documentation template are much higher than those not included. Of the 32 variables included on the ADHD template, the mean adherence rate is $63.5 \%$ $(0-100 \%$, SD $31.5 \%)$. Of the 55 variables not included on the template, the mean adherence rate is $7.2 \%(0-27 \%, \mathrm{SD} 7 \%)$.

The following section describes chart review findings based on the key guideline components for initial and follow up visits.

Key component 1. The PCM initiates the evaluation for ADHD in 4/19 encounters $(21.1 \%)$. Most patients at the selected clinic receive the initial evaluation from a psychologist in the community $(14 / 19,73.3 \%)$, and $1 / 19(5.3 \%)$ by the child's school psychologist. During initial evaluations, providers routinely document patient history $(19 / 19,100 \%)$, physical exam $(18 / 19,94.7 \%)$, and cardiac history assessment $(17 / 19,89.5 \%)$. Neurological examinations $(12 / 19,63.2 \%)$, weights $(9 / 19,47.4 \%)$, hearing screenings $(1 / 19,5.3 . \%)$, and vision screenings $(5 / 19,26.3)$ are documented less frequently. 
Key component 2. Of the 4 evaluations conducted by the PCM, all 4 document presence of symptoms before age 12 and evidence of impairment in multiple settings, while only $3 / 4$ (75\%) document use of a validated instrument and 1/4 (25\%) note that symptoms have been present for longer than 6 months.

Key component 3. The providers that utilize the Vanderbilt scale during initial evaluations $(3 / 4,75 \%)$ address comorbidities as part of the tool. Of the initial evaluations conducted outside of the medical home, comorbidity assessment is not documented consistently enough to meet the standard: psychoeducational evaluation to rule out learning disorders (13/19, $68.4 \%)$, developmental delay or intellectual disability $(9 / 19,47.4 \%)$, conduct disorder or oppositional defiant disorder (3/19, 15.8\%), depression or anxiety $(7 / 19,36.9 \%)$, sleep disorders $(12 / 19,63.6 \%)$, and tics $(8 / 19,42.1 \%)$.

Key component 4. Strengths include school performance (initial 17/19, 89.5\%; follow-up 42/43, 97.7\%), EFMP status (initial 19/19, 100\%; follow-up 39/43, 90.7\%), and history of counseling (initial 15/19, 80\%; follow-up 35/43, 81.3\%). None of the encounters document a team coordination plan or evidence of collaboration with the school. No target goals are documented, however there is assessment of impact on peer and family relationships (initial 8/19, 42.1\%; follow-up 34/43, 79.1\%) and disruptive behavior (initial 9/19, 47.4\%; follow-up $34 / 43,79.1 \%)$. Impact on functioning is addressed less consistently related to areas of independence (initial 3/19, 15.8\%; follow-up 9/43, 20.9\%), self-esteem (initial 2/19, 10.5\%; follow-up 0/43, 0\%), and safety (initial 3/19, 15.8\%; follow-up 7/43, 16.3\%). Additional factors pertinent to chronic care management that are unique to the military population include assessment of recent or pending relocation (initial 2/19, 10.5\%; follow-up 6/43, 14\%) and parental deployment status $(0 / 62,0 \%)$. 
Key component 5. Stimulant therapy is initiated in 17/19 (89.5\%) of newly diagnosed patients. Both the medication formulation and dose are consistent with the recommendations for stimulant initiation $(17 / 19,89.5 \%)$. The records do not include documentation related to behavior therapy education or parent training provided by PCM; however, assessment for history of counseling is conducted in most encounters $(15 / 19,80 \%)$. Treatment based on age groups is as follows: preschool $(\mathrm{n}=1,2 \%)$ no stimulant prescribed and patient referred to a mental health professional; elementary school-age ( $\mathrm{n}=1734 \%)$ stimulants prescribed $(16 / 17,94.1 \%)$ and no behavior therapy is documented, but 76\% assess counseling history; and adolescents $(34 \%, 17 / 50)$ stimulants prescribed $(17 / 17,100 \%)$ and no documentation of behavior therapy is present, but counseling history assessed (17/17, 100\%).

Key component 6. Titration of stimulant medications based on effect (93\%), while monitoring side effects $(90.7 \%)$, is consistent among providers; however, validated follow-up scales are not utilized in any encounters $(0 / 42,0 \%)$. See figure for adherence to follow-up recommendations.

\section{PDSA Session}

During the PDSA session, providers identify protective factors unique to the population: free mental health counseling, free prescription medications, most children have at least one parent with a stable income and overall emphasis on health, and access to Military Family Life Consultants and EFMP school liaisons to help identify local resources. Common themes related to barriers to guideline adherence include timely receipt of completed assessment forms, patient self-referrals for ADHD testing by a community psychologist without the PCM's knowledge, limited access in the pediatric clinic, and insufficient time during the appointments. 
Identified barriers and plans for improvement. The 6 key guideline components are used to outline findings from the PDSA session.

Key component 1. Providers report that patients frequently come to the appointment already having received a psychoeducational evaluation by a community psychologist without PCM approval; patients have either self-referred for testing, or have been instructed to obtain testing by the clinic nurse. An additional barrier identified by the clinic staff includes limited access within the pediatric clinic, which are exacerbated by the additional demands of the military. Recommendations for improvement identified by the providers include talking with the referral specialist about requiring a PCM referral for psychoeducational testing, providing education to the schools regarding the preferred process for ADHD evaluations, and re-educating clinic staff regarding the importance of conducting ADHD evaluations in the medical home rather than referring to a specialist in the community.

Key component 2. Providers report that obtaining evaluation forms from 2 different settings is challenging; this process can be exceptionally difficult when parents are also stressed by a deployment or relocation. One provider suggests that a system be put in place where teachers and parents can access the forms online, and can either print them out for completion, or complete electronically and email them to the healthcare team. Suggestions for putting the links to the forms on the medical group Facebook page are discussed, however the clinic staff explain that the process for obtaining approval to add to the site is laborious, and the page is not perceived to be a resource that families use as routinely as they do the spouse support page. Finally, providers recommend adding the DSM criteria to the existing ADHD documentation template to improve adherence. 
Key component 3. During the discussion related to comorbid disorder assessment, the providers feel that they are screening for these disorders routinely, however this assessment is not being captured in their documentation. They agree that revising the documentation template to include assessment for comorbidities will improve adherence to this key component.

Key component 4. Military relocation and deployment requirements are identified as barriers to provision of care under the CCM. Providers feel that they do not have the time or consistent clinical support staff to dedicate to facilitating ongoing communication with the school systems, and community partnerships are lacking.

Key component 5. All of the providers are familiar with the existing Vanderbilt follow-up scale, but report not realizing that use for assessment of response and side effects is recommended in the guideline. Implementation of use of the Vanderbilt follow-up scales is identified as an acceptable practice change to improve adherence to this guideline. Providers also discuss revising the existing nurse telephone questionnaire for ADHD to address the key guideline components.

Key component 6. Providers plan to add a 1-month follow-up visit after stimulant initiation to comply with guideline recommendations, and consider creating a protocol for a nurse-led visit if the former is not feasible due to clinic access limitations.

\section{Discussion}

This project, including the process and findings, addresses a critical gap in the diagnosis and treatment of military children with ADHD. This pediatric population is particularly vulnerable due to transiency of care associated with frequent family relocations and parental deployments. Facilitating adherence to CPG will foster improved behavioral, academic, and physiological 
outcomes for these children and their families. Finally, this project highlights the important role of the DNP-prepared APRN in fostering evidence-based practice and outcomes improvement.

Findings from the retrospective chart review indicate that efforts to implement the CPG in the selected military pediatric clinic were not fully sustained 24 months post-intervention. Sustaining change in clinical practice requires ongoing performance evaluation with associated revision of the implementation plan if needed. The cyclical PDSA process supports this proactive approach to quality improvement by ensuring that goals have been established, data is being collected during the implementation phase, and the process is re-evaluated and adapted based on outcomes. The group is receptive to utilizing the PDSA model to guide ongoing quality improvements, and agree that the process is logical and user-friendly. Interventions that are identified by the team to address areas for improvement included revision of the provider ADHD documentation template, utilizing the Vanderbilt follow-up ADHD scales to assess treatment response and presence of side effects, providing education to clinic nurses, referral specialists, and patients regarding the PCM's role in ADHD diagnosis and management.

This study has several strengths; this is the first study evaluating provider adherence to the AAP CPG within the military health system. Evaluation of current performance and discussion of perceived barriers will facilitate development of a plan to standardize ADHD care among all DoD pediatric clinics. This study is limited by a small sample size, within one pediatric clinic, in a military treatment facility; therefore findings cannot be generalized to other settings. Another limitation of the current project is the small number of initial visits identified that were conducted within the medical home. The difficulty in obtaining approval for the project by the military is also presents significant limitations, requiring a change in the sampling design from randomized to convenience sampling. Convenience sampling methods have the potential for 
bias; therefore care was taken to select subjects systematically. The length of time required to obtain approval and the complexity of the application process have the potential to discourage researchers from choosing this as a population to study, and may be a contributing factor to the current scarcity of published work. Turnover of the clinical staff could be seen as a limitation; however, being that frequent relocation is one of the factors unique to this population, it illustrates the potential for practice variation and importance of an established quality improvement process.

\section{Nursing Practice Implications}

APRNs with a doctor of nursing practice (DNP) are in an ideal position to guide evidence-based practice, improve chronic disease management (Fiandt, 2006), and to improve overall provider adherence to guidelines. Process improvement methodology such as the PDSA model provides an effective framework by which the DNP can empower staff to continue evaluating, improving, and sustaining quality care at the organizational level.

\section{Recommendations for Future Research}

Further studies are needed to determine if there is a relationship between ADHD and parental military affiliation; supporting the addition of demographic questions assessing family members past and current military status to existing national surveys is a critical first step.

The effects of deployment on military children certainly need to be understood to improve the quality of care to the population; however, the effects of frequent relocations have yet to be studied. The extent of the ramifications that frequent relocations place on the child with ADHD, the family unit, and the military healthcare system must be identified to guide quality improvement measures.

\section{Conclusion}


Retrospective chart reviews suggest that military provider adherence to the ADHD CPG is consistent with findings of poor adherence in the civilian sector. Since previous quality improvement efforts to implement the CPG in the selected clinic are not sustainable throughout periods of provider turnover, the PDSA model's cyclical process is used to design evaluation methods alongside intervention development. Development of a standardized documentation template to address each of the guideline components is a product of this project in response to findings and provider preferences. The validated chart abstraction tool adapted for this study is an efficient method to conduct future follow-up evaluations to CPG adherence. Further studies are needed to compare the selected clinic with other military medical homes providing care to children with ADHD. 